Aus der Abteilung Gastroenterologie und Endokrinologie

(Komm. Leiter: Prof. Dr. Tilman Sauerbruch)

im Zentrum Innere Medizin

der Medizinischen Fakultät der Universität Göttingen

\title{
Charakterisierung von Ratten-Myofibroblasten des Gastrointestinaltrakts und der Leber unter Berücksichtigung mikroskopischer und molekularbiologischer Aspekte
}

\author{
INAUGURAL-DISSERTATION \\ zur Erlangung des Doktorgrades \\ der Medizinischen Fakultät \\ der Georg-August-Universität zu Göttingen
}

vorgelegt von

Fabian Lührs

aus Cuxhaven

Göttingen 2012 
Dekan: Prof. Dr. rer. nat. H. K. Kroemer

I. Berichterstatter: Prof. Dr. rer. nat. J. Wilting

II. Berichterstatter/in: Prof. Dr. med. Zeisberg

III. Berichterstatter/in: Prof. Dr. med. Oppermann

Tag der mündlichen Prüfung: 30.04.2013 


\section{Inhaltsverzeichnis}

1. Einleitung

1.1. Überblick

1

1.2. Myofibroblasten 1

1.2.1. Definition eines Myofibroblasten 1

1.2.2. Vorkommen und Funktion 2

1.2.3. Ursprung und Aktivierung 3

1.3. Intestinale Stromazellen 4

1.4. Magen-MF / Ösophagus-MF

1.5. Leber-MF 8

1.6. Pankreas-MF 9

1.7. Marker der Fluoreszenzfärbungen $\quad 10$

1.8. Zusätzliche PCR-Marker 11

1.9. Zielsetzung 13

2. Material und Methoden

2.1. Materialen 14

2.2. Methoden 18

2.2.1. Zellkultur 18

2.2.2. Färbungen 21

2.2.3. Transmissionselektronenmikroskopie 22

2.2.4. Proteinnachweis 23

2.2.5. Expressionsuntersuchung 25

3. Ergebnisse

3.1. Ergebnisse Zellkulturen 31

3.2. Ergebnisse Fluoreszenzmikroskopie 36

3.3. In-vivo-Darstellung 41

3.4. Ergebnisse Elektronenmikroskopie 48

3.5. Ergebnisse Western-Blot 53

3.6. Ergebnisse der Expressionsuntersuchung 54 
4. Diskussion 78

4.1.Zellkultur $\quad 79$

4.2. Immunfluoreszenz $\quad 79$

4.3. Transmissionselektronenmikroskopie 81

4.4. Western-Blot 81

4.5.PCR 82

4.6. Zusammenfassung und Ausblick 84

5. Zusammenfassung 86

6. Literaturverzeichnis $\quad 88$ 


\section{Abbildungsverzeichnis}

Abb. $01 \quad$ Darm-MF, Zellkulturen, lichtmikroskopisch 32

Abb. 02 Ösophagus-MF, Zellkulturen, lichtmikroskopisch 33

Abb. 03 Magen-MF, Zellkulturen, lichtmikroskopisch 34

Abb. $04 \quad$ Pankreas-MF, Zellkulturen, lichtmikroskopisch 35

Abb. 05 Leber-MF, Zellkulturen, lichtmikroskopisch 36

Abb. $06 \quad$ Darm-MF, Zellkulturen, fluoreszenzmikroskopisch 37

Abb. 07 Ösophagus-MF, Zellkulturen, fluoreszenzmikroskopisch 38

Abb. $08 \quad M a g e n-M F$, Zellkulturen, fluoreszenzmikroskopisch 39

Abb. 09 Pankreas-MF, Zellkulturen, fluoreszenzmikroskopisch 40

Abb. 10 Leber-MF, Zellkulturen, fluoreszenzmikroskopisch 41

Abb. 11 Darm-Präparate, licht-/fluoreszenzmikroskopisch 42

Abb. 12 Ösophagus-Präparate, licht-/fluoreszenzmikroskopisch 43

Abb. 13 Magen-Präparate, licht-/fluoreszenzmikroskopisch 44

Abb. 14 Pankreas- Präparate, licht-ffluoreszenzmikroskopisch 45

Abb. 15 Leber- Präparate, licht-/fluoreszenzmikroskopisch 46

Abb. $16 \quad E M$-Darstellung Darm-MF, Zellkulturen 48

Abb. 17 EM-Darstellung Ösophagus-MF, Zellkulturen 49

Abb. 18 EM-Darstellung Magen-MF, Zellkulturen 50

Abb. 19 EM-Darstellung Pankreas-MF, Zellkulturen 51

Abb. $20 \quad E M$-Darstellung Leber-MF, Zellkulturen 52

Abb. $21 \quad$ Western-Blot, B-Aktin, $\alpha$-SMA 53

Abb. 22 Western-Blot, Desmin, Thy-1 54

Abb. 23 Darm-MF, Genexpression nach der $\Delta$ CT-Methode 56

Abb. 24 Ösophagus-MF, Genexpression nach der $\Delta$ CT-Methode 58

Abb. $25 \quad$ Magen-MF, Genexpression nach der $\triangle$ CT-Methode $\quad 59$

Abb. 26 Pankreas-MF, Genexpression nach der $\triangle$ CT-Methode 61

Abb. $27 \quad$ Leber-MF, Genexpression nach der $\triangle \mathrm{CT}$-Methode 63

Abb. 28 Vergleich der a-SMA-Genexpression der MF der unterschiedlichen Organe 64

Abb. 29 Vergleich der Thy-1-Genexpression der MF der unterschiedlichen Organe 
unterschiedlichen Organe

Abb. $31 \quad$ Vergleich der Fibrillin-2-Genexpression der MF der unterschiedlichen Organe

Abb. 32 Vergleich der Kollagen-1-Genexpression der MF der unterschiedlichen Organe

Abb. 33 Vergleich der Kollagen-4-Genexpression der MF der unterschiedlichen Organe

Abb. $34 \quad$ Vergleich der Fibulin-1-Genexpression der MF der unterschiedlichen Organe

Abb. $35 \quad$ Vergleich der Fibulin-2-Genexpression der MF der unterschiedlichen Organe

Abb. $36 \quad$ Vergleich der IL-6-Genexpression der MF der unterschiedlichen Organe

Abb. $37 \quad$ Vergleich der MCP-1-Genexpression der MF der unterschiedlichen Organe

Abb. $38 \quad$ Vergleich der MIP-1-Genexpression der MF der unterschiedlichen Organe

Abb. 39 Vergleich der MIP-3-Genexpression der MF der unterschiedlichen Organe

\section{$\underline{\text { Tabellenverzeichnis }}$}

Tbl. 1 Mittelwerte der gemessenen Genexpression für die unterschiedlichen Zellpopulationen

Tbl. 2 Genexpression (objektiv) der unterschiedlichen Zellpopulationen

Tbl.3 Genexpression (deskriptiv) der unterschiedlichen 


\section{Abkürzungsverzeichnis}

APS

bp

BSA

$\mathrm{CCL}$

CD

DAPI

DMEM

DNA

DTT

ECL

ED-A

EDTA

EZM

FCS

HBSS

HGF

HSC

ICC

IL-1

IL-6

$\mathrm{kDa}$

LARC

MCP-1

MF

MIP-1

MIP-3

MLV-RT

mRNA

PBS

PCR

PDGF
Ammoniumperoxodisulfat

Basenpaar

bovine serum albumin

Chemokin-ligand

cluster of differentiation

4',6-Diamidino-2-Phenylindol

Dulbecco's Modified Eagle's Medium

Desoxyribonukleinsäure

Dithiotreitol

enhanced chemiluminescence

extra domain $A$

Ethylendiamintetraessigsäure

Extrazelluläre Matrix

Fetales Kälber Serum

Hank's Balanced Salt Solution

hematopoetic growth factor

hepatische Sternzellen

interstitielle Cajalzellen

Interleukin 1

Interleukin 6

Kilodalton

liver- and activation regulated chemokin

Monozyten-chemotaktisches Protein 1

Myofibroblasten

Makrophagen-inflammatorisches Protein 1

Makrophagen-inflammatorisches Protein 3

moloney murine leukaemia virus reverse transcriptase

messenger-Ribonukleinsäure

Phosphate Buffered Saline

polymerase chain reaction

platelet derived growth factor 
PSC

rER

RPMI

SCF

SDS

a-SMA

TBE

TEM

TEMED

TGF- $\beta$

Thy -1

TNF- $\alpha$ pankreatische Sternzellen

raues endoplasmatisches Retikulum

Roswell Park Memorial Institute

stem cell factor

Natriumdodecylsulfat

alpha smooth muscle actin

Tris-Borat-EDTA

Transmissionselektronenmikroskopie

Tetramethylethylendiamin

transforming growth factor beta

thymocyte differentiation antigen 1

Tumornekrosefaktor-alpha 


\section{Einleitung}

\section{1 Überblick}

Myofibroblasten (MF) gehören zu einer Gruppe ubiquitär vorkommender Bindegewebszellen mit Charakteristika von Fibroblasten und glatten Muskelzellen. Erstmalig wurden MF elektronenmikroskopisch in Granulationsgewebe bei der Wundheilung beobachtet (Gabbiani et al. 1971). In den vergangenen Jahren konnten jedoch in nahezu allen Organen diese speziellen Zellen nachgewiesen werden. Obwohl MF in jedem Organ spezifische Aufgaben haben, zeigen sie eine ähnliche Morphologie und Funktion auf, unabhängig von ihrer Lokalisation (Powell et al. 1999b). Im Unterschied zu normalen Fibroblasten exprimieren diese Zellen als typischen Marker alpha smooth muscle actin ( $\alpha$-SMA), welches für die kontraktilen Eigenschaften von Bedeutung ist, und die Ähnlichkeit von MF und glatten Muskelzellen erklärt (Gabbiani 1996). Als parakrine Zellen sezernieren MF sowohl Zytokine, Chemokine und Wachstumfaktoren als auch Bestandteile der Extrazellulären Matrix (EZM) und spielen so eine wichtige Rolle bei physiologischen wie auch pathophysiologischen Vorgängen. Obwohl die Erkenntnisse über MF in den letzten Jahren stetig zugenommen haben, sind noch viele Fragen ungeklärt.

\section{$1.2 \quad$ Myofibroblasten}

\subsubsection{Definition eines Myofibroblasten}

Am einfachsten lassen sich MF als a-SMA-positive Bindegewebszellen bezeichnen. In der Vergangenheit gingen einige Autoren davon aus, dass Fibroblasten sich zu MF differenzieren können, und damit eine spezielle Fibroblasten-Subpopulation darstellen (Desmoulière et al. 1993, Hinz et al. 2007, Zhang K et al. 1994). Andere Forschungsgruppen bezeichnen MF als aktivierte Muskelzellen oder "glatteMuskulatur-ähnliche" Zellen (Moore et al. 1989). An den fetalen Gefäßen in Plazentarzotten konnten verschiedene Differenzierungsgrade der Stromazellen nachgewiesen werden (Kohnen et al. 1996). In enger räumlicher Beziehung konnten sowohl Fibroblasten und glatte Muskelzellen als auch Zellen mit Expressionsmustern von MF identifiziert werden. Somit könnten MF auch eine Zwischenform von Fibroblasten und glatten Muskelzellen darstellen (Powell et al. 1999a). 
MF zeichnen sich durch eine charakteristische, spindelförmige Morphologie sowie durch die Expression bestimmter Zytoskelettanteile aus, welche immunhistochemisch oder mittels Immunfluoreszenz nachgewiesen werden können. Elektronenmikroskopisch weisen MF zytoplasmatische Aktin-Mikrofilamente, so genannte „stress-fibers“, auf. Daneben zeigen sie als Korrelat für die Produktion von EZM-Bestandteilen, Zytokinen, Chemokinen u.a. reichlich raues endoplasmatisches Retikulum, Golgi-Apparat sowie viele Mitochondrien (Valentich et al. 1997). Außerdem weisen MF Fibronexus auf, die der Kommunikation zwischen einzelnen Zellen dienen und eine Verbindung zur EZM darstellen (Eyden 2005). Dem Nachweis dieser Strukturen kommt eine wichtige Bedeutung bei der Identifizierung von MF zu.

Der typische immunhistologische Marker für MF ist das alpha smooth muscle actin (a-SMA). Zusätzlich können als Marker für die Intermediärfilamente Vimentin und Desmin verwendet werden (Mermall et al. 1998). Die Expression dieser Zytoskelettanteile variert jedoch abhängig von der Spezies, dem Organ und Umwelteinflüssen (Powell et al. 1999b). Mit Hilfe dieser drei Marker kann eine Klassifizierung der MF vorgenommen werden (Kohnen et al. 1996, Schmitt-Graff et al. 1994). Dabei werden MF, die nur Vimentin exprimieren, als V-Typ bezeichnet, MF mit Expression von Vimentin und Desmin als VD-Typ, solche mit Expression aller 3 Marker als VAD-Typ oder bei fehlender Desmin-Expression als VA-Typ.

In unserer Arbeitsgruppe konnten wir zeigen, dass MF der Leber durch das Adhäsionsmolekül Thy-1 (CD 90), das EZM-Protein Fibulin-2 und das Zytokin Interleukin-6 von anderen „MF-ähnlichen“ Zellen unterschieden werden können (Dudas et al. 2009, Dudas et al. 2007, Piscaglia et al. 2009).

\subsubsection{Vorkommen und Funktion}

Obwohl MF zuerst nur in Granulationsgewebe beobachtet wurden, scheint es sich doch um eine ubiquitär vorkommende Zellart zu handeln. So konnten MF bzw. Bindegewebszellen mit den typischen Charakteristika, in vielen Geweben nachgewiesen werden. Hierzu zählen u.a. die Leber, der Gastrointestinaltrakt, Herz, Lunge, Niere, Pankreas, Mamma, und Prostata (Ahmed 1990, Bostrom et al. 1996, Desmoulière et al. 1995, Joyce et al. 1987, Kassen et al. 1996, Peehl and Sellers 1997, Tang WW et al. 1996, Weber et al. 1997). Während sich die spezifischen 
Funktionen der MF in den Organen unterscheiden, gibt es allgemeine Aufgaben die MF unabhängig von ihrer Lokalisation erfüllen (Powell et al. 1999b). Durch ihre kontraktilen Eigenschaften und durch die Sekretion von Entzündungsmediatoren, Chemokinen, Zytokinen, Wachstumsfaktoren sowie Bestandteilen der EZM und der Basalmembran spielen sie eine wichtige Rolle bei der Wundheilung (Desmoulière et al. 2004), Wachstum und Differenzierung des Gewebes (Furuya and Furuya 2007, Kedinger et al. 1988, Simon-Assmann et al. 1995) und bei der Modulation der Immunantwort (Crowston et al. 1997, Saada et al. 2004).

Ihrer physiologischen Bedeutung stehen die Erkrankungen gegenüber, die auf eine übermäßige Aktivierung/Proliferation oder eine Schädigung oder das Fehlen von MF zurückzuführen sind. Hierzu gehören insbesondere die fibrosierenden Erkrankungen der meisten Organe (Lungenfibrose, Pankreasfibrose, Keloidbildung, DupuytrenKontraktur, u.a.). Ein Zusammenhang von Multisystemerkankungen wie z.B Sklerodermie und dem vermehrten Auftreten von MF wird ebenfalls vermutet (Beon et al. 2004, Manetti et al. 2007). Neben den neoplastischen Erkrankungen, die von MF ausgehen, wie z.B. das myofibroblastische Sarkom, sind auch die Aufgaben der MF bei der Tumorgenese und Ausbreitung von Malignomen Gegenstand der aktuellen Forschung (Adegboyega et al. 2004, Mahida et al. 1997a).

\subsubsection{Ursprung und Aktivierung}

Der genaue Ursprung der MF ist trotz intensiver Forschung noch nicht gänzlich geklärt. Es wird jedoch angenommen, dass es, abhängig vom Organ und der physiologischen oder pathologischen Situation, verschiedene Quellen für die MFPopulationen gibt (Hinz et al. 2007). Nach Gewebsschädigung bzw. als Reaktion auf einen Entzündungsreiz finden sich vermehrt MF im Gewebe. Einige Arbeitsgruppen gehen davon aus, dass sich lokale Fibroblasten sowie glatte Muskelzellen zu MF differenzieren zu können ( Desmoulière et al. 1993, Hao et al. 2006, Zhang K et al. 1994). Andere Beobachtungen hingegen legen eine vermehrte Einwanderung von MF nahe (Powell et al. 1999a). Neben anderen Zytokinen (z.B. IL-1, TNF- $\alpha$, PDGF) scheint TGF- $\beta$ den stärksten Einfluss auf die Aktivierung und die konsekutive Expression von $\alpha$-SMA zu haben (Border and Noble 1994, Hautmann et al. 1997, Muchaneta-Kubara and el Nahas 1997). Bei der Wundheilung ist die Aktivierung von Fibroblasten eng verknüpft mit dem Auftreten von Proto-MF. Unter dem Einfluss von 
TGF- $\beta$ und ED-A Fibronektin differenzieren sich diese Zellen zu MF und exprimieren $\alpha$-SMA (Desmoulière et al. 2004, Tomasek et al. 2002).

Des Weiteren konnten bei fibrotischen Prozessen in Niere und Lunge Epithelien als Vorläufer der MF nachgewiesen werden, ein Vorgang, der als EpithelialMesenchymale-Transition (EMT) bezeichnet wird (Kim et al. 2006, Zeisberg and Kalluri 2004). Eine weitere mögliche Quelle für MF sind die Stammzellen des Knochenmarks. Stammzellen von männlichen Mäusen wurden weiblichen Tieren transplantiert und mit Hilfe des Y-Chromosoms detektiert. Nach 6 Wochen entstammte ein Großteil der intestinalen MF dem Spender (Brittan and Wright 2004), bei Tieren mit experimentell induzierter Kolitis erhöhte sich dieser Anteil signifikant. Bei ähnlichen Versuchen konnten markierte Stammzellen in Hepatozyten, Lungenepitihelien, Tubuluszellen der Niere und MF von Magen und Ösophagus nachgewiesen werden (Anjos-Afonso et al. 2004, Direkze et al. 2003). Es ist daher anzunehmen, dass bei erhöhtem Zellumsatz wie z.B. nach Verletzungen der Bedarf an Zellen aus mehreren Quellen gedeckt werden kann.

Gegenstand dieser Arbeit waren die intestinalen MF, die MF des Ösophagus, des Magens, des Pankreas und der Leber, die im Folgenden genauer beschrieben werden.

\subsection{Intestinale Stromazellen}

Es existieren zwei unterschiedliche Populationen a-SMA-positiver Stromazellen im Gastrointestinaltrakt. Die interstitiellen Cajalzellen (ICC) und die subepithelialen intestinalen MF.

ICC

Die ICC liegen in der Tunica muscularis zwischen der zirkulären und longitudinalen Muskelschicht in Magen, Dünndarm und Kolon im Plexus myentericus. Daneben kommen sie auch intramuskulär in Ösophagus, Magen, Kolon und lumenseitig auf der Ringmuskulatur des Kolons vor (Sanders 1996, Torihashi et al. 1994). Sie sind sternförmig und bilden ein Synzytium, das über Gap-Junctions miteinander verbunden ist (Komuro 1989). Sie sind positiv für Vimentin und exprimieren darüber 
hinaus das C-Kit Protoonkogen (Wester et al. 1999). C-Kit ist eine TransmembranProtein-Kinase, die durch ihren Liganden, den Stammzellfaktor (SCF), aktiviert werden kann. SCF spielt eine wichtige Rolle bei Wachstum und Entwicklung verschiedener Zellreihen (Smith et al. 2001). Im Gastointestinaltrakt sind neben den ICC nur Mastzellen c-Kit-positiv, weshalb sich c-Kit als zuverlässiger Marker für ICC etabliert hat.

ICC triggern lokale Kontraktionen der Darmwandmuskulatur und kontrollieren die durch das vegetative Nervensystem gesteuerte Darmaktivität. Aufgrund dieser Wirkungen spielen sie eine wichtige Rolle bei der Regulation der Darmmotilität und der Peristaltik (Streutker et al. 2007). Bei mit c-Kit-Antikörpern behandelten Mäusen können keine ICC nachgewiesen werden und die Muskelaktivität ist gestört (Streutker et al. 2007). Mutanten mit gestörter c-Kit-Expression zeigen ebenso eine verminderte Darmmotilität (Isozaki et al. 1995).

ICC sind von Bedeutung bei verschiedenen Krankheiten, die mit einer gestörten Motilität einhergehen. Bei Patienten mit Morbus Hirschsprung, einer polygen vererbten Erkrankung, die zu einer Aganglionose des Kolon führt, fehlen die ICCs oder ihre Anzahl ist vermindert (Piotrowska et al. 2003). Ähnliche Beobachtungen gibt es bei Achalasie-Patienten (Gockel et al. 2008) und bei Patienten mit infantiler hypertropher Pylorusstenose (Vanderwinden et al. 1996). Daneben sind die ICC als Ursprungszellen der gastrointestinalen Stromatumoren (GIST) identifiziert worden (Hirota et al. 1998).

Intestinale subepitheliale MF

Die intestinalen MF bilden ein dreidimensionales Netzwerk unter der Basalmembran des Darms, das sich bis in die Lamina propria erstreckt. Hier haben die MF über Gap-junctions und Tight-junctions Kontakt zu Fibroblasten und Perizyten der Kapillaren (Komuro 1989). Im Bereich der Dünndarm-Krypten sind sie oval oder keilförmig. In den Mikrovilli und nahe dem Lumen in den Dickdarmkrypten werden sie sternförmig (Joyce et al. 1987). In der Basallamina finden sich zahlreiche Fenestrierungen, durch die Zellausläufer der MF reichen (Komuro and Hashimoto 1990, Mahida et al. 1997b). Eine zweite Barriere wird von einer Lage retikulärer Fasern gebildet, in denen die MF liegen (Toyoda et al. 1997). Auch diese Schicht enthält Foramina und Fenestrierungen. Die subepithelialen MF sind mit Antikörpern 
gegen a-SMA und Vimentin darstellbar. Im Unterschied zu glatten Muskelzellen exprimieren sie kein Smoothelin, Caldesmon und in gesundem Gewebe kein oder wenig Desmin (Powell et al. 2005).

Es konnte gezeigt werden, dass MF die Morphogenese, Organogenese und durch ihre Lokalisation unterhalb der Basalmembran die Differenzierung von Epithelzellen durch Sekretion löslicher Entzündungsfaktoren fördern (Haffen et al. 1987, Kedinger et al. 1988). So scheint z.B. die Differenzierung des intestinalen Epithels durch TGF$\beta 1$ vermittelt zu sein (Halttunen et al. 1996, Simo et al. 1992, Stallmach et al. 1989). Interessanterweise sezernieren MF aus Jejunum, lleum und Kolon unterschiedliche Mengen von HGF, TGF- $\beta 1$ und Epimorphin. Es scheint daher regional unterschiedliche Einflüsse der MF auf die Differrenzierung des Epithels zu geben (Plateroti et al. 1998). Des Weiteren konnte belegt werden, dass intestinale Ratten-MF das Wachstum fetaler Rattenendodermzellen stimulieren (Fritsch et al. 1997). Es wird zudem vermutet, dass MF, analog zu den Epithelien von den Krypten in die Mikrovilli wandern. Dabei scheinen sich die Reifung und Differenzierung der beiden Zellreihen gegenseitig zu beeinflussen (Hall et al. 1994, Powell et al. 1999b). Ein Effekt der MF auf die Sekretion von Epithelzellen ist ebenfalls bekannt. So konnte in Ussing-Kammer-Experimenten die Chloridsekretion von T-84-Zellen nach Stimulation mit Bradykinin, Serotonin und Histamin in Gegenwart intestinaler MF gesteigert werden (Berschneider and Powell 1992). Bemerkenswert ist, dass MF auch an Regenerationsprozessen beteiligt zu sein scheinen. So konnte dokumentiert werden, das MF, bedingt durch ihre kontraktilen Eigenschaften, in der Lage sind, die Oberfläche von Wunddefekten zu verkleinern (Moore et al. 1989, Racine-Samson et al. 1997, Tomasek et al. 2002). Zudem können nach Schädigung der Mukosa vermehrt MF nachgewiesen werden (Brittan and Wright 2004). Da MF ein breites Spektrum an Zytokinen, Chemokinen und Entzündungsmediatoren produzieren (Pang et al. 1994, Simon-Assmann et al. 1995, Sprenger et al. 1997, Youngman et al. 1993), scheinen sie darüber hinaus eine entscheidende Rolle bei Entzündungsprozessen zu spielen. Durch Anlagerung von Lymphozyten, Mastzellen und neutrophilen Granulozyten an MF sind diese auch an immunologischen Prozessen beteiligt (Crowston et al. 1997, Fiocchi 1997, Roberts et al. 1997). Wie neuere Forschungen zeigen, exprimieren intestinale MF zudem auch MHC-IIMoleküle und können so die Proliferation von CD4+-T-Zellen stimulieren (Saada et al. 2006). Zudem konnte gezeigt werden, dass MF durch ihre Synthese von 
Prostaglandinen sowie durch konstitutive Cyclooxygenase-1- und induzierbare Cyclooxygenase-2-Expression mit in den Arachidonsäurezyklus eingreifen (Berschneider and Powell 1992, Forstermann et al. 1998, Hinterleitner et al. 1996, Mahida et al. 1997b). Die Erkenntnisse über die Rolle der MF bei der Pathogenese von fibrotischen Veränderungen im Darm wie z.B. bei chronisch entzündlichen Darmerkrankungen sind noch nicht umfassend. Bei in-vitro-Kulturen von MF aus gesundem Darm, von Patienten mit Morbus Crohn und Colitis ulcerosa konnten Unterschiede in der Expression von TGF- $\beta$ Isoformen festgestellt werden (McKaig et al. 2002). In der Submukosa von Morbus-Crohn-Patienten konnten zudem Inseln von a-SMA-positiven Zellen nachgewiesen werden, die für die pathologische Zusammensetzung der EZM verantwortlich zu sein scheinen (Regan et al. 2000). Dabei ist jedoch unklar ob es sich hierbei um Fibroblasten, MF oder glatte Muskelzellen handelt. Auch bei der Entstehung der kollagenen Kolitis gibt es Hinweise auf eine Mitbeteiligung der MF (Aigner et al. 1997, Zeroogian and Chopra 1994). Ein weiterer interessanter Aspekt der MF ist ihre Rolle bei der Tumorentstehung und -ausbreitung. Ein großer Teil der Zellmasse von Neoplasien des Kolons wird von Stromazellen gebildet (Powell et al. 2005). Deshalb sind die Interaktionen von Stroma- und Tumorzellen Gegenstand intensiver Forschung (Bhowmick et al. 2004, Desmoulière et al. 2004, Elenbaas and Weinberg 2001). Hinlänglich bekannt sind die chemoprotektiven Effekte von Aspirin und anderen NSAID bei der Entstehung von Polypen bei familärer adenomatöser Polyposis und dem kolorektalen Karzinom (Giardiello et al. 1993, Giovannucci et al. 1995). Der genaue Mechanismus ist jedoch noch nicht geklärt. Experimentelle und klinische Daten weisen auf eine Schlüsselrolle der Cyclooxygenase-2 (Cox-2) in der Genese von kolorekalen Adenomen und Karzinomen hin (Dubois 2001, Ota et al. 2002). Bemerkenswert ist hierbei, dass nicht nur ein Teil der Tumorzellen die induzierbare Cox-2 exprimiert, sondern auch in MF Cox-2 nachgewiesen werden kann (Mahida et al. 1997a).

\subsection{Magen-MF / Ösophagus-MF}

Die MF des Magens und des Ösophagus (nicht ICC), liegen ebenso wie die intestinalen MF unterhalb der Basallamina in der Lamina propria. Sie zeigen die typischen Charakteristika von MF, wie zytoplasmatische Mirkofilamente und die 
Expression von a-SMA und Vimentin (Wu et al. 1999). Über die Funktion der Magen- sowie Ösophagus-MF ist wenig bekannt. Es konnte jedoch gezeigt werden, dass MF aus normaler Magenschleimhaut über die Expression von Cox-1 und Cox-2 in den Arachidonsäurezyklus eingreifen (Wu et al. 1999). In Granulationsgewebe von Magenulzera konnten zudem vermehrt MF nachgewiesen werden (Nakamura et al. 1995). Dass MF eine wichtige Funktion bei der Wundheilung zukommt, konnte auch tierexperimentell am Ösophagus gezeigt werden (Chai et al. 2007). Interessanterweise konnten auch bei Patienten mit Sklerodermie MF in der fibrotisch veränderten Magenwand nachgewiesen werden (Beon et al. 2004, Manetti et al. 2007). Daneben zeigen Untersuchungen bei Magenkarzinomen von intestinalem und diffusem Typ unterschiedliche Verteilungen von a-SMA-positiven Stromazellen (Nakayama et al. 2002).

\subsection{Leber-MF}

In der Leber sind mehrere mesenchymale Zellpopulationen beschrieben worden (Johnson et al. 1992). Zu innen zählen unter anderen die Hepatischen Sternzellen (HSC), früher auch als Itozellen bezeichnet, sowie die Leber-MF. Die HSC liegen perisinuidal und bilden zusammen mit den Endothelzellen eine lockere Barriere um die Lebersinusoide. Die MF sind hingegen in den Periportalfeldern um die Zentralvenen sowie in der Leberkapsel lokalisiert (Dudas et al. 2009). Nach Leberverletzungen können HSCs aktiviert werden und eine MF-ähnliche Morphologie annehmen (Verlust der Vitamin-A-Speicher, Expression von SMA) (Cassiman et al. 2002). Die Unterscheidung von aktivierten HSCs und MF ist daher schwierig und wird kontrovers diskutiert. Allerdings konnte gezeigt werden, dass MF im Gegensatz zu aktivierten HSCs Thy-1 (CD90) exprimieren und somit sowohl in vivo als auch in vitro identifiziert werden können (Dudas et al. 2009, Dudas et al. 2007). Andere Forschungen belegen zudem, dass auch Fibulin-2 und Gremlin als spezifische Leber-MF-Marker in vitro verwendet werden können (Ogawa et al. 2007).

Neben den HSCs scheinen auch die MF eine wichtige Rolle bei fibrotischen Prozessen in der Leber zu spielen. So konnten im Tiermodell MF in den fibrotischen Septen nach chronischer Leberschädigung nachgewiesen werden (Beaussier et al. 2007, Dudas et al. 2009, Knittel et al. 1999). Ähnliche Ergebnisse zeigten die immunhistochemischen Untersuchungen von Proben von Zirrhose-Patienten (Dudas 
et al. 2009). Von Bedeutung scheinen außerdem die unterschiedlichen Effekte von TNF- $\alpha$ und TGF- $\beta$ auf Leber-MF bei akuter und chronischer Leberschädigung zu sein (Knittel et al. 2000, Saile et al. 2002). Zudem konnte die konsekutive Expression eines IGF-Rezeptor-Subtyps über mehrere Passagen bei Leber-MF beobachtet werden, was darauf hindeutet, dass diese längere Zeit sensibel für die mitogenen Effekte von IGF bleiben (Novosyadlyy et al. 2004).

\subsection{Pankreas-MF}

Analog zu den Erkenntnissen der Leberzellen werden auch verschiedene pankreatische Stromazellpopulationen beschrieben. Ein Großteil der aktuellen Forschung beschäftigt sich hierbei mit pankreatischen Sternzellen (PSC), welche nach Stimulation durch inflammatorische Zytokine eine MF-ähnliche Morphologie annehmen (Omary et al. 2007, Won et al. 2011). Während diese Zellen vor Aktivierung durch die Speicherung von Fetten und Vitamin A gekennzeichnet sind, weisen die aktivierten PSC eine a-SMA-Expression auf und produzieren vermehrt Bestandteile der EZM (Bachem et al. 1998, Watari et al. 1982). Darüber hinaus sind lokale, periazinäre und periduktale MF untersucht worden. Diese Zellen konnten neben ihrem typischen Expressionsmuster ( $\alpha-S M A$, Vimentin, Desmin) durch elektronenmikroskopische Untersuchungen und den Nachweis von Fibronexus charakterisiert werden (Izumi et al. 2001, Saotome et al. 1997). Ob es sich hierbei, wie in unserer Arbeitsgruppe bei den HSC und Leber-MF beschrieben, um unterschiedliche Zellpopulationen handelt ist nicht abschließend geklärt. Unabhängig davon spielen diese Stromazellen eine wichtige Rolle bei akuten und chronischen Entzündungen sowie dem Wachstum und den Ausbreitungen von Tumoren (Direkze et al. 2004, Inatomi et al. 2007, Kuroda et al. 2004, Mews et al. 2002, Nishida et al. 2008). 


\subsection{Marker der Fluoreszenzfärbungen}

Thy-1 (CD90)

Thy-1 oder CD90 ist ein hochgradig glykolysiertes, Membranprotein mit einem GPIAnker (Glykophosphatidylinositol) und einer Molekülmasse von 25-35kDa. Es besitzt eine einzelne Immunglobulin-Domäne und gehört zu der ImmunglobulinSuperfamilie. Erstmals nachgewiesen wurde das Protein auf Thymozyten. Daneben konnte es auf Neuronen, Stammzellen, Endothelien, MF und bei einzelnen Leukämie- Zelllinien nachgewiesen werden. Funktionell bindet Thy-1 an $\beta 2-$ und $\beta 3-$ Integrin und nimmt so Einfluss auf Wachstum und Proliferation von hämotopoetischen Stammzellen (Bradley et al. 2009).

a-SMA

Das $\alpha$-SMA ist eine Isoform des zytoplasmatischen Aktins mit einer Molekülmasse von $42 \mathrm{kDa}$. Daneben gibt es fünf weitere Aktin-Isoformen, die in Alpha-, Beta- und Gamma-Isoformen unterteilt werden. Für die verschiedenen Muskelgewebe (glatte Muskulatur, Skelettmuskel, Herzmuskel) sind jeweils spezifische Alpha-AktinIsoformen bekannt. Die Alpha-Aktin-Filamente sind neben weiteren Proteinen für die kontraktilen Eigenschaften der Zellen verantwortlich (Junqueira et al. 2001). BetaAktin ist ein ubiquitär vorkommendes Protein des Zytoskeletts ohne kontraktile Eigenschaften. Es wird häufig für Kontrolluntersuchungen im Rahmen von WesternBlots und PCRs verwendet (siehe 2.2.5, S. 27).

Vimentin

Vimentin ist ein Intermediärfilament mit einem Molekulargewicht von $57-60 \mathrm{kDa}$. Es ist neben den aktinischen Mikrofilamenten und Mikrotubuli am Aufbau des Zytoskeletts beteiligt. Es wird hauptsächlich von mesenchymalen Zellen exprimiert und hat diagnostische Relevanz als Markerprotein von Sarkomen und undifferenzierten Neoplasmen (Minin and Moldaver 2008). 
Desmin

Desmin gehört ebenfalls zu den Intermediärfilamenten. Die relative Molekülmasse beträgt $52 \mathrm{kDa}$. Es ist von Bedeutung für die Zellarchitektur und den Aufbau des kontraktilen Apparats. Desmin ist ein typischer Marker für Muskelgewebe und kann bereits früh in der embryonalen Entwicklung von Myozyten nachgewiesen werden. Mutationen im Desmin-Gen verhindern die Ausbildung von Desminpolymeren und führen zu den sogenannten Desminopathien (Paramio 2006).

\subsection{Zusätzliche PCR-Marker}

Fibrillin-2

Fibrillin-2 ist ein Glykoprotein der Fibrillin-Familie, welches von Fibroblasten exprimiert und sezerniert wird. Es ist am Aufbau der Extrazellulärmatrix beteiligt bzw. an der Bildung von Mikrofibrillen. Während Mikrofibrillen in elastischen und nicht elastischen Fasern vorkommen, ist Fibrillin-2 insbesondere an der Bildung von elastischen Fasern beteiligt. Der Arachnodaktylie liegt ein Defekt im Fibrillin-2-Gen zugrunde (Zhang $\mathrm{H}$ et al. 1994).

Interleukin-6

Interleukin-6 (IL-6) ist ein Glykoprotein, das zu den Akute-Phase-Proteinen gehört und von vielen verschiedenen Zellen gebildet wird, wie zum Beispiel Monozyten, Makrophagen, Endothelzellen und Fibroblasten. Besonders hohe IL-6-Werte konnten bislang in Gewebe, das sich in einer akuten Entzündungsreaktion befindet, detektiert werden. Aktiviert von bakteriellen Lipopolysacchariden und proinflammatorischen Zytokinen, wie IL-1 und TNF- $\alpha$, induziert IL-6 die Proliferation von hämatopoetischen Stammzellen. Differenzierung und Antikörperproduktion von B-Zellen und eine T-Zellvermittelte Immunantwort werden verstärkt (Donnelly et al. 1993). 
Fibulin-1, Fibulin-2

Fibuline sind Glykoproteine der EZM, die durch einen ähnlichen ultrastrukturellen Aufbau gekennzeichnet sind. Bislang sind 8 verschiedene Fibuline identifiziert worden. Fibulin-1 und Fibulin-2 findet man in Fibronectin-Fasern, Elastin-Fasern und in der Basalmembran (Sasaki et al. 1996). Fibulin-1 hat daneben durch die Bindung von Fibrinogen Einfluss auf die Thrombozytenaggregation. Fibulin-2 scheint maßgeblich am Aufbau von elastischen Strukturen beteiligt zu sein (Mecham 2010). Es konnte gezeigt werden, dass Fibroblasten eine beträchtliche Menge Fibulin-2 bilden und es als feines Netzwerk ablagern, und diese zusätzlich Fibronektin enthalten (Pan et al. 1999, Sasaki et al. 1996)

MCP-1

Monozyten-chemotaktisches Protein (MCP-1) oder Chemokin-Ligand 2 (CCL2) ist ein Zytokin der CC-Chemokin-Familie, das u. a. von Monozyten, Mastzellen, TZellen, Fibroblasten und glatten Muskelzellen sezerniert wird. Erhöhte Konzentrationen von MCP-1 werden nach Trauma, Infektionen und Entzündungen beobachtet. MCP-1 hat nicht nur chemotaktische und aktivierende Wirkung auf Monozyten, da ebenfalls Natürliche Killerzellen (NK-Zellen), T-Zellen, Granulozyten und hepatische Sternzellen durch MCP-1 rekrutiert werden (Deshmane et al. 2009).

MIP-1

Das menschliche Makrophagen-inflammatorische Protein 1 (MIP-1) existiert in einer Alpha- und Beta-Form und wird auch als Chemokin-Ligand 3 (CCL3/MIP-1 $\alpha$ ) bzw. 4 (CCL4/MIP-1 $\beta$ ) bezeichnet. Diese Chemokine der CC-Familie werden besonders von Makrophagen, dendritischen Zellen und Lymphozyten im Rahmen von Entzündungsreaktionen sezerniert und haben starke chemotaktische Wirkung auf Granulozyten. Darüber hinaus wird auch die Synthese von weiteren proinflammatorischen Zytokinen wie IL-1, IL-6 und TNF- $\alpha$ durch MIP-1 induziert (Menten et al. 2002). 
MIP-3

Das menschliche Makrophagen-inflammatorische Protein 3 (MIP-3), Chemokin Ligand 20 (CCL-20) oder liver- and activation regulated chemokin (LARC) ist ebenfalls der CC Familie zuzuordnen. Die Expression von MIP-3 wird durch Lipopolysaccharide getriggert und führt zu einer Rekrutierung von Lymphozyten und dendritischen Zellen (Baba et al. 1997).

Kollagen-1, Kollagen-4

Kollagenfasern machen den Großteil der Bindegewebsfasern des menschlichen Körpers aus. Die Fasern bestehen aus Kollagenfibrillen, welche ihrerseits von Mikrofibrillen gebildet werden. Die Mikrofibrillen weisen eine Tripelhelixstruktur auf die von jeweils drei Tropokollagenfibrillen gebildet werden. Kollagen-1 zeichnet sich durch eine hohe Zugfestigkeit aus und wird besonders von Fibroblasten, Chondroblasten und Osteoblasten gebildet. Kollagen-4 ist ein Bestandteil der Basalmembran und hat somit eine Barrierefunktion (Junqueira et al. 2001).

\subsection{Zielsetzung}

MFs des Gastrointestinaltrakts spielen für die Differenzierung von Epithelzellen, bei intestinalen Entzündungsprozessen, sowie bei der Regeneration eine Rolle. Ziel dieser Arbeit war zunächst die Isolation, Kultivierung und Charakterisierung intestinaler MF. Schließlich sollten die für intestinale MFs gefundenen charakteristischen Marker bezüglich Strukturproteinen, Matrixproteinen und Mediatoren mit denjenigen für Ösophagus, Magen, Pankreas und Leber verglichen werden.

Anhand der gewonnenen Daten sollen Aussagen über Gemeinsamkeiten und Unterschiede im Hinblick auf Vorkommen, Wachstum und Expressionsmuster getroffen werden. 


\section{Material und Methoden}

\subsection{Materialien}

Zellkulturreagenzien

Dithiotreitol (DTT)

Sigma, München

Ethylendinitrilotetraessigsäure (EDTA) Sigma, München

Fetales Kälber Serum (FCS) PAA, Colbe

Hank's Balanced Salt Solution (HBSS)

Life Technologies, Karlsruhe

DMEM, low Glucose without Glutamine

PAA, Colbe

RPMI 1640

PAA, Colbe

Non Essential Amino Acids (NEAA)

PAA, Colbe

Phosphate Buffered Saline (PBS)

Life Technologies, Karlsruhe

Penicillin/Streptomycin-Lösung

Life Technologies, Karlsruhe

Trypsin-Lösung

Life Technologies, Karlsruhe

L-Glutamin

Invitrogen, Karlsruhe

Chemikalien

Aceton

Merck, Darmstadt

Agarose

Life Technologies, Karlsruhe

Ampuwa $^{\mathrm{TM}}$

Fresenius, Bad Homburg

APS

Invitrogen, Karlsruhe

BCA Protein Assay

Invitrogen, Karlsruhe

Benzil

Merck, Darmstadt

Bromphenolblau

Merck, Darmstadt

Chloroform

Sigma, München

DePex

Serva, Heidelberg

DNA-Ladder

Invitrogen, Karlsruhe

dNTP-Mix

Roche, Mannheim

$\mathrm{dT}_{15}$ (q-PCR-Primer)

Roche, Mannheim

Eosin

Sigma, München

Ethanol

Merck, Darmstadt

Ethidiumbromid

Sigma, München

Fluoromount G

Southern Biotech, Birmingham, USA 
Gentamycin

GG-free

Glutaraldehyd

Glycerol

Hämatoxylin

Isopropanol

Kollagenase IV

LR-Gold

Mercaptophenol

M-MLV

$\mathrm{NaCl} 0,9 \%$

Neomycin

Nitrocellulose-Membran

Nystatin

Osmiumtetroxid $\left(\mathrm{OsO}_{4}\right)$

Paraformaldehyd

PCR-Buffer

Phenobarbital 16\% (Narcoren)

RNAtidy G

SDS

Sörensen Puffer

SYBR® Green

Taq Polymerase

TEMED

Tris- $\mathrm{HCl}$

Triton X-100

Trizol

Tween $^{\mathrm{TM}}$

Xylol
Ratiopharm, Darmstadt

Invitrogen, Karlsruhe

Sigma, München

Invitrogen, Karlsruhe

Sigma, München

Merck, Darmstadt

Sigma, München

Sigma, München

Sigma, München

Invitrogen, Karlsruhe

Braun, Melsungen

AppliChem, Darmstadt

Serva, Heidelberg

AppliChem, Darmstadt

AppliChem, Darmstadt

Sigma, München

Life Technologies, Karlsruhe

Merial, Halbergstadt

AppliChem, Darmstadt

AppliChem, Darmstadt

Merck, Darmstadt

Life Technologies, Karlsruhe

Life Technologies, Karlsruhe

Invitrogen, Karlsruhe

Sigma, München

Sigma, München

Invitrogen, Karlsruhe

Sigma, München

Merck, Darmstadt

Antikörper für Fluoreszenzfärbung

Primärantikörper

Anti-Ratte Thy1

Anti-Ratte a-SMA

\section{Spezies}

monoklonal, Maus

monoklonal, Maus

\section{Hersteller}

Pharmingen, Heidelberg

Sigma, München 
Anti-Ratte Desmin

Anti-Ratte Vimentin

\section{Sekundärantikörper}

(FITC)

Anti-Maus IgG

polyklonal, Ziege

\section{Kernfärbung}

Dapi-Kernfärbung

Antikörper für Proteinanalyse

\section{Primärantikörper}

Anti-Ratte Desmin

Anti-Ratte Thy-1

Anti-Ratte B-Aktin

Anti-Ratte $\alpha$-SMA

\section{Sekundärantikörper(HRP)}

Anti-Kaninchen IgG

Anti-Maus IgG monoklonal, Maus

monoklonal, Maus
Pharmingen, Heidelberg

Sigma, München
Invitrogen, Karlsruhe

Invitrogen, Karlsruhe

\section{Spezies}

Polyklonal, Kaninchen

Monoklonal, Maus

Monoklonal, Maus

Monoklonal, Maus

\section{Hersteller}

Acris, Herford

Novus Biological, Littleton, USA

Sigma, München

EMD, Billerica, USA
Dako, Glostrup, Dänemark

Dako, Glostrup, Dänemark

PCR-Primer

\begin{tabular}{|c|c|c|}
\hline B-Actin & $\begin{array}{l}\text { Forward 5' ACC ACC ATG TAC CCA GGC ATT 3' } \\
\text { Reverse 5' CCA CAC AGA GTA CTT GCG CTC A 3, }\end{array}$ & $\begin{array}{l}\text { Invitrogen, } \\
\text { Karlsruhe }\end{array}$ \\
\hline Thy-1 & $\begin{array}{l}\text { Forward 5' TGA ACC CAG TCA TCA GCA TCA 3' } \\
\text { Reverse 5' CAG TCG AAG GTT CTG GTT CAC 3' }\end{array}$ & $\begin{array}{l}\text { Invitrogen, } \\
\text { Karlsruhe }\end{array}$ \\
\hline$\alpha-S M A$ & $\begin{array}{l}\text { Forward 5' GGC TCC ATC CTG GCT TCT CTA 3' } \\
\text { Reverse 5' GGC GTG ACT TAG AAG CAT TTG 3' }\end{array}$ & $\begin{array}{l}\text { Invitrogen, } \\
\text { Karlsruhe }\end{array}$ \\
\hline Desmin & $\begin{array}{l}\text { Forward 5' CAG GTA GGA GAT GGA CAT GTC 3' } \\
\text { Reverse 5' TTC CGG TAG GTG GCA ATC TC 3' }\end{array}$ & $\begin{array}{l}\text { Invitrogen, } \\
\text { Karlsruhe }\end{array}$ \\
\hline Kollagen-1 & $\begin{array}{l}\text { Forward 5' CCT GGT AAA GAT GGT GCC 3' } \\
\text { Reverse 5' CAC CAG GTT CAC CTT TCG CAC C 3' }\end{array}$ & $\begin{array}{l}\text { Invitrogen, } \\
\text { Karlsruhe }\end{array}$ \\
\hline
\end{tabular}




\begin{tabular}{|c|c|c|}
\hline IL-6 & $\begin{array}{l}\text { Forward 5' GTC AAC TCC ATC TGC CCT TCA G 3' } \\
\text { Reverse 5' GGC AGT GGC TGT CAA CAA CAT 3' }\end{array}$ & $\begin{array}{l}\text { Invitrogen, } \\
\text { Karlsruhe }\end{array}$ \\
\hline Kollagen-4 & $\begin{array}{l}\text { Forward 5' GTC AAG ACT TGG GTA CGG CTG 3' } \\
\text { Reverse 5' GCA TGG TAC TGA AGC GAC GAA 3' }\end{array}$ & $\begin{array}{l}\text { Invitrogen, } \\
\text { Karlsruhe }\end{array}$ \\
\hline Fibulin-1 & $\begin{array}{l}\text { Forward 5' TTC CTG AGG AGG AGG AAC AA 3', } \\
\text { Reverse 5' CCA CTG TGT TGA TGC AGG AT 3' }\end{array}$ & $\begin{array}{l}\text { Invitrogen, } \\
\text { Karlsruhe }\end{array}$ \\
\hline Fibulin-2 & $\begin{array}{l}\text { Forward 5' TGT CAC GCG CAG ACT CAA CG 3' } \\
\text { Reverse 5' CTT GGC CTG TAC TCA GTG CC 3' }\end{array}$ & $\begin{array}{l}\text { Invitrogen, } \\
\text { Karlsruhe }\end{array}$ \\
\hline Fibrillin-2 & $\begin{array}{l}\text { Forward 5' CAA CAC CGT GGG AAG CTA TT 3' } \\
\text { Reverse 5' AGC ACT GAG CTT TTG CCA TT 3' }\end{array}$ & $\begin{array}{l}\text { Invitrogen, } \\
\text { Karlsruhe }\end{array}$ \\
\hline MCP-1 & $\begin{array}{l}\text { Forward 5' AGG CAG ATG CAG TTA ATG CCC 3' } \\
\text { Reverse 5' ACA CCT GCT GCT GGT GAT TCT C 3' }\end{array}$ & $\begin{array}{l}\text { Invitrogen, } \\
\text { Karlsruhe }\end{array}$ \\
\hline MIP-1 $1 \alpha$ & $\begin{array}{l}\text { Forward 5' GAC GGC AAA TTC CAC GAA AA 3' } \\
\text { Reverse 5' AGA TCT GCC GGT TTC TCT TGG 3' }\end{array}$ & $\begin{array}{l}\text { Invitrogen, } \\
\text { Karlsruhe }\end{array}$ \\
\hline MIP-3a & $\begin{array}{l}\text { Forward 5' CAA CTT TGA CTG CTG CCT CA 3', } \\
\text { Reverse 5, TTC CAT CCC AGA AAA GCA TC 3' }\end{array}$ & $\begin{array}{l}\text { Invitrogen, } \\
\text { Karlsruhe }\end{array}$ \\
\hline TNF- $\alpha$ & $\begin{array}{l}\text { Forward 5' ACA AGG CTG CCC CGA CTA T 3' } \\
\text { Reverse 5' CTC CTG GTA TGA AGT GGC AAA TC 3' }\end{array}$ & $\begin{array}{l}\text { Invitrogen, } \\
\text { Karlsruhe }\end{array}$ \\
\hline
\end{tabular}

Sonstige Materialien

3mm Filterpapier

Cellscraper 25mm

Dako Pen ${ }^{\mathrm{TM}}$

ECL-Detektions Kit

Eppendorf cups 500 $\mathrm{\mu l}, 1500 \mu \mathrm{l}$

Falcon Tube 15ml

Falcon Tube 50ml

Falcon Zellkulturschale $35 \times 10 \mathrm{~mm}$

Filmkassette mit Verstärkerfolie

Labtek $^{\mathrm{TM}}$ Chamber Slide 8 Well,

Pernanox

Mini-PROTEAN II Cell-System

Pipetten 5,10,25 ml

Pipettenspitzen ep TIPS 100 $\mu \mathrm{l}, 1000 \mu \mathrm{l}$

Quarzküvetten
Whatman, Göttingen

Sarstedt, Nümbrecht

Dako, Glostrup, Dänemark

Amersham, Freiburg

Eppendorf, Hamburg

BD Biosciences, San Jose, USA

BD Biosciences, San Jose, USA

BD Biosciences, San Jose, USA

Amersham, Freiburg

Thermo Fisher Scientific (Nunc GmbH \& Co. KG ), Langenselbold

BioRad, München

Sarstedt, Nümbrecht

Eppendorf, Hamburg

Helma, Mannheim 
Steritop ${ }^{\mathrm{TM}}$ Filter

Technocut ${ }^{\mathrm{TM}}$ Skalpell

Zellkulturflasche $75 \mathrm{~cm}^{2}$

Zellkulturplatten mit 6 Vertiefungen

(6-well-plates)

Zellkulturplatten mit 96 Vertiefungen

( 96-well-plates)

Whatman-Papier

Geräte

Vortex Vibrofix VF1

Pipettus-Akku

Wasserbad

Zentrifuge Universal 16R

Begasungsschrank

Sterilbank

Absaugpumpe Aeromat

Lichtmikroskop ID03

Fluoreszenzmikroskop AxioVision

Feinwaage BP 1105

Blot BioRad 300

Canon EOS 60D

Schwenkgerät WT12

TaqMan-Detektor ${ }^{\text {TM }}$ Abi 7000

Heizblock
EMD, Billerica, USA

Transatlantic, Wehrheim

Sarstedt, Nümbrecht

Thermo Fisher Scientific (Nunc GmbH \& Co. KG ), Langenselbold

Thermo Fisher Scientific (Nunc GmbH \& Co. KG ), Langenselbold

Whatman international Ltd., Maidstone, England

IKA Labortechnik, Staufen

Hirschmann, Eberstadt

GFL, Burgwedel

Hettich, Tuttlingen

Heraeus, Hanau

Clean Air, Woerden, Niederlande

KNF Neunberger, Freiburg

Zeiss, Jena

Zeiss, Jena

Sartorius, Göttingen

BioRad, München

Canon, Japan

Biometra, Göttingen

Perkin Elmer, Weiterstadt

Eppendorf, Hamburg

\subsection{Methoden}

\subsubsection{Zellkultur}

Proben

Alle Proben sowie die isolierten Zelllinien wurden aus gesunden Wistarratten entnommen. Die Versuchstiere erhielten keine spezielle Diät, hatten ungehinderten Zugang zu Nahrung und Wasser und wurden in einem 24-stündigen Hell-DunkelZyklus gehalten. Die Versuche wurden in einem Tötungsantrag genehmigt. 
Isolation der Darm-MF

Für die Isolation wird ein modifiziertes Protokoll von Mahida et al. verwandt (Mahida et al. 1997a).

Die Ratten werden mit Phenobarbital anästhesiert. Nach 10-minütiger Wartezeit und Kontrolle der Betäubung Desinfektion des Abdomens und Bauchschnitt. Nach Durchtrennung des Peritoneums wird das Kolon freipräpariert und nahe dem Zäkum und Rektum abgesetzt. Das Kolon wird nun in einen proximalen und distalen Teil getrennt und separat dem gleichen Protokoll folgend weiterbehandelt. Die Teile werden ausgiebig mit Waschlösung $1(0,9 \% \mathrm{NaCl}$ Lösung, 1\% Nystatin, $1 \%$ Neomycin) gewaschen und von innen mit einer 1-ml-Spritze gespült. Bei allen Waschschritten wird der Überstand abgesaugt und verworfen. Hiernach werden die Teile in Längsrichtung aufgeschnitten und erneut gewaschen. Anschließend folgt die Zerteilung in ca. $0,5 \mathrm{~cm}^{*} 0,5 \mathrm{~cm}$ große Stücke und ein erneuter Waschschritt. Dann werden die Teile in HBSS gewaschen und in Waschlösung 2 (HBSS, 1\% DDT) überführt. Die Kolonteile werden nun für 15 Minuten bei Raumtemperatur auf einem Schwenkgerät bewegt. Die Lösung wird nun für 1 min mit einer Tischzentrifuge mit $1000 \mathrm{Upm}$ bei $20^{\circ} \mathrm{C}$ zentrifugiert. Der Überstand wird abgesaugt und die Kolonteile in ein neues Falcontube gegeben. Hierauf folgt ein dreimaliges Waschen mit HBSS. Danach werden die Kolonteile in Waschlösung 3 (HBSS, 1\% EDTA) gegeben und für 30 Minuten in einem Ofen bei $37^{\circ} \mathrm{C}$ bewegt. Die Lösung wird nun erneut für $1 \mathrm{~min}$ zentrifugiert (1000Upm) und der Überstand verworfen. Der dreimalige Waschvorgang mit HBSS, die Inkubation mit Waschlösung 3 sowie das Zentrifugieren werden noch zweimal wiederholt. Hiernach werden die Kolonteile in eine Zellkulturschale mit Nährmedium1 (RPMI, 10\% FCS, 1\% Glutamin, 1\% Nystatin, 1\% Gentamicin, 1\% Penicillin/Streptomycin) überführt. Die Inkubation erfolgt im Brutschrank bei $37^{\circ} \mathrm{C}$ $4 \% \mathrm{CO}_{2}$. Nach 24 Stunden werden die Kolonteile entfernt, das Nährmedium abgenommen und die Schalen mit 5ml Nährmedium 2 (DMEM, 15\% FCS, $1 \%$ Glutamin, 1\% NEAA, 1\% Gentamicin, 1\% Nystatin, 1\% Penicillin/Streptomycin) befüllt. Das Medium wird alle 48-96 Stunden gewechselt. Die Kultivierung der proximalen Kolonabschnitte blieb wiederholt ohne Ergebnis. Die Färbungen sowie die RNA-Isolation für die PCR und der Proteinnachweis erfolgten aus den Primärkulturen der distalen Kolonabschnitte. 
Isolation der Ösophagus-/Pankreas-/Magen-MF

Im Rahmen der Entnahme des Kolons wurden den Ratten Magen, Pankreas sowie der distale Abschnitt des Ösophagus entnommen. Die Isolation erfolgte nach einem modifizierten Protokoll von Müller et al.(Mueller et al. 2007).

Hierzu werden die Gewebeteile zerkleinert, mit Waschlösung 4 (Kollagenase IV $0,25 \%$, DMEM) versetzt und anschließend für 40 Minuten im Wasserbad bei $37^{\circ} \mathrm{C}$ inkubiert. Danach werden die Zellen filtriert und die Proben für 10 Minuten bei 2500U/min zentrifugiert. Der Überstand wird nachfolgend auf mehrere Kulturschalen verteilt und mit Nährmedium 2 versetzt. Die Inkubation erfolgt im Brutschrank bei $37^{\circ} \mathrm{C} 4 \% \mathrm{CO}_{2}$. Das Medium wird alle 48-96 Stunden gewechselt. Die Zellen wachsen bis zur Konfluenz und können danach passagiert werden.

\section{Leber-MF}

Die Isolation von Leber-MF erfolgte analog dem Isolationsverfahren von Dudas et. al. (Dudas et al. 2009). Bei der hier gut etablierten Methode, werden zunächst die nichtparenchymalen Zellen mittels einer Nycodenz-Dichte-Zentrifugation entfernt. Um die unterschiedlichen parenchymalen Zellen (HSC, Kupferzellen, Endothelien und MF) zu trennen, erfolgt eine Gegenstromzentrifugation, bei der die gesuchte Zellfraktion mit einer Flussrate von $23 \mathrm{ml} / \mathrm{min}$ bei $2500 \mathrm{U} / \mathrm{min}$ isoliert werden kann. Die Zellfraktion kann nun in Nährmedium 3 (DMEM, 10\% FCS, $1 \%$ Glutamin, 1\% Penicillin/Streptomycin) kultiviert werden. Nach 1-2 Wochen wachsen die Zellen bis zur Konfluenz und können passagiert werden

Gewebeproben für Lichtmikroskopie und Fluoreszenzmikroskopie

Bei der Organentnahme für die Isolation der MF werden außerdem Proben aller 4 Gewebe genommen. Diese Proben werden für die Darstellung der MF in situ genutzt. Für die Fluoreszenzmikroskopie werden diese in flüssigem Stickstoff eingefroren und bei $-80^{\circ} \mathrm{C}$ gelagert bzw. weiter verarbeitet. Hierzu werden die Gewebeproben am Kryostatmikrotom bei $-20^{\circ} \mathrm{C}$ in $6-7 \mu \mathrm{m}$ dicke Schnitte zerteilt, auf Objektträger gebracht und getrocknet. Anschließend erfolgt die Fixation mit Aceton über 10 Minuten. Zur Anfertigung der lichtmikroskopischen Präparate wurden die Proben in Paraffin-Blöcke eingefasst. Am Mikrotom können so dünne Paraffinschnitte 
angefertigt und auf Objektträger gebracht werden. Zur Entparaffinierung werden diese zweimalig für 15 Minuten in Xylol gelagert. Anschließend werden die Präparate für jeweils $2 \times 2$ Minuten in einer absteigenden Ethanolreihe (100\%, 95\%, 80\%, 75\%, $30 \%$ ) hydrolisiert. Die Präparate können nun direkt gefärbt werden (siehe 2.2.2).

\section{Anfertigen der Labteks}

Für die Färbungen der Zellkulturen wurden die Zellen auf Labteks gebracht. Das Medium wird aus den Kulturschalen abgesaugt und verworfen. Die Zellkulturen werden anschließend zweimal mit PBS gewaschen, um etwaige Rückstände des Medium, die die Wirkung des Trypsin beeinträchtigen könnten, zu entfernen. Nun werden sie mit $1 \mathrm{ml}$ Trypsin versetzt und 5 Minuten im Brutschrank inkubiert. Hiernach wird die Ablösung der Zellen lichtmikroskopisch kontrolliert. Wenn sich der Großteil der Zellen gelöst hat, werden die Kulturschalen mehrmals mit Nährmedium gespült und die Zellsuspension anschließend auf Labteks gebracht. Nach 1 bis 2 Tagen sind die Zellen auf den Objektträgern angewachsen und können fixiert werden. Hierzu wird das restliche Nährmedium verworfen und die Objektträger für 5 Minuten in einer Küvette mit PBS gewaschen. Danach werden die Zellen für 10 Minuten mit Aceton fixiert. Die getrockneten Objektträger können nun gefärbt werden.

\subsubsection{Färbungen}

Immunfluoreszenz Färbung

Die Objektträger der Zellkulturen sowie die der Gewebeproben werden nach dem gleichen Verfahren gefärbt. Zunächst werden die zu färbenden Bereiche mit einem Dako Pen umkreist. Um eine unspezifische Bindung des 1. Antikörpers an den Präparaten zu verhindern, werden sie 30 min mit FCS blockiert. Danach werden die Objektträger wiederholt über $10 \mathrm{~min}$ mit PBS gewaschen. Nun werden die Objektträger in einer feuchten Kammer für 45 min bei Raumtemperatur mit einer individuellen Konzentration des 1. Antikörper inkubiert. Anti-a-SMA und Anti-Vimentin werden in einer Verdünnung von 1:250, Anti-Thy-1 und Anti-Desmin in einer Verdünnung von 1:100 verwendet. Die Objektträger werden nun für 15 min mit PBS gewaschen. Vor dem Aufbringen des 2. Antikörpers muss auch hier eine Blockierung 
unspezifischer Bindungsstellen erfolgen. Hierzu werden 25 $\mu$ Antikörper mit Serum $60 \mathrm{~min}$ bei $37^{\circ} \mathrm{C}$ inkubiert und anschließend $5 \mathrm{~min}$ bei $1000 \mathrm{U}$ zentrifugiert. $25 \mu \mathrm{l}$ Überstand werden entnommen und es werden $175 \mu$ PBS und $300 \mu$ l GG-free hinzugegeben. Danach erfolgt in der feuchten Kammer die 45-minütige Inkubation bei Raumtemperatur mit dem 2. Antikörper. Nachdem die Objektträger erneut mit PBS gewaschen wurden, werden sie zur Färbung der Zellkerne noch einmal für 5 min in der feuchten Kammer mit DAPI (4',6-Diamidino-2-Phenylindol)-Farbstoff inkubiert. Die Objektträger werden 15min in PBS gewaschen, an der Luft getrocknet und zuletzt mit Fluoromount eingedeckt.

\section{HE-Färbung}

Zur Färbung der lichtmikroskopischen Präparate werden die Proben für 3 Minuten mit Mayer's Hämatoxylin versetzt. Anschließend werden die Präparate für etwa 10 Minuten mit Leitungswasser gewaschen, bis ein $\mathrm{pH}$-Umschlag messbar wird. Es folgt eine Gegenfärbung mit Eosin für 30-60 Sekunden. Nach einem erneuten Waschvorgang mit Leitungswasser, erfolgt der Wasserentzug mit einer aufsteigenden Ethanolreihe (95\%, 100\%) für jeweils 30 Sekunden bzw. mit XylolBehandlung für insgesamt 10 Minuten. Abschließend werden die Präparate mit DePex eingedeckt.

\subsubsection{Transmissionselektronenmikroskopie (TEM)}

Die TEM erlaubt eine ultrastrukturelle Darstellung von Objekten durch die Anwendung von Elektronenstrahlung. Die Elektronen werden hierbei in einem Spannungsfeld beschleunigt und mittels elektromagnetischer Linsen gebündelt bzw. fokussiert. Die hochenergetischen Elektronen werden bei Auftreffen auf das zu untersuchende Objekt z. T. gestreut bzw. durchdringen das Objekt ohne Ablenkung. Diese Elektronenstrahlung wird nach Vergrößerung auf einem Leuchtschirm sichtbar gemacht. Die Auflösung ist hierbei abhängig von der Beschleunigungsspannung, der Ordnungszahl der Atome, aus denen das Objekt besteht sowie der Probendicke.

Fixierung und Einbettung der Zellen für die Elektronenmikroskopie

Das Medium wird von den Zellkulturen abgenommen. Anschließend werden die Kulturen zweimal mit PBS gewaschen. Nach Trypsinisierung werden die Zellen in 
Nährmedium gelöst und auf 96-Well-Plates gebracht. Die Fixierung und Einbettung erfolgt nach 24 Stunden.

Hierzu wird das Nährmedium abgesaugt und die Zellen werden für 1 Stunde mit Fixans (3\% Paraformaldehyd, $3 \%$ Glutaraldehyd in 0,15 M Sörensen-Puffer) versetzt und bei $4^{\circ} \mathrm{C}$ gelagert. Hiernach werden die Zellen für 10 min bei $4^{\circ} \mathrm{C}$ mit $0,15 \mathrm{M}$ Sörensen gewaschen. Anschließend wird die Färbelösung ( $2 \%$ wässriges $\mathrm{Os}_{4}, 0,3$ M Sörensen ) auf die Kulturplatten gegeben. An die 90-minütige Lagerung bei $4^{\circ} \mathrm{C}$ schließt sich ein erneuter Waschvorgang mit Sörensen-Puffer an. Zur Entwässerung werden die Zellen nun für jeweils 10 Minuten mit 30\%-, 50\%- und 70\%-Ethanol versetzt. In $70 \%$-Ethanol können die fixierten Zellen bei $4^{\circ} \mathrm{C}$ bis zum nächsten Tag aufbewahrt werden.

Zur Einbettung der entwässerten Zellen wurde der hydrophile Kunststoff LR-Gold verwendet. Dies erfolgte mit LR-Gold für 1 Stunde bei $4^{\circ} \mathrm{C}$ und für 16 Stunden mit LR-Gold mit $0,8 \%$ Benzil bei $-20^{\circ} \mathrm{C}$. Am nächsten Tag wurden die Zellen mit neuem LR-Gold $+0,8 \%$ Benzil versetzt und die Kulturplatten werden luftdicht zugeklebt. Durch Belichtung mit einer UV-Lampe über einen Zeitraum von 24 Stunden erfolgte die Polymerisation des Kunststoffes bei $-20^{\circ} \mathrm{C}$. Die Kulturplatten können nun in Xylol aufgelöst werden und die so erhaltenen Kunststoffblöcke am Ultramikrotom geschnitten werden.

\subsubsection{Proteinanalyse}

Vorbereitung der Proben für die Proteinanalyse

Das Medium wird von den Zellkulturen abgenommen. Anschließend werden die Kulturen zweimal mit PBS gewaschen. Danach wird 0,5ml Lyse-Puffer (50mM Tris$\mathrm{HCl}, 150 \mathrm{mM} \mathrm{NaCl}, 1 \%$ Triton X-100) auf die Kulturen gegeben. Die Zellen werden mit einem Zellschaber abgelöst. Der Überstand wird abpipettiert, homogenisiert und in ein 1-ml-Eppendorfgefäß gegeben. Um Verunreinigungen zu vermeiden, werden die Proben kurz zentrifugiert und der klare Überstand für die weitere Analyse verwendet.

Die Bestimmung der Konzentration der Proteine wurde mit dem BCA ${ }^{\text {TM}}$-Protein-

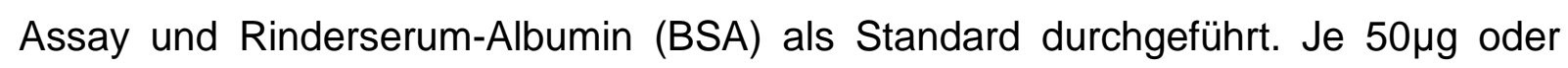
$100 \mu$ Protein wurden in Proben-Puffer (20\% Mercaptophenol, 4\% SDS, 20\% 
Glycerol, $0,5 \%$ Bromphenolblau) gelöst und anschließend bei $-80^{\circ} \mathrm{C}$ bis zur weiteren Verwendung gelagert.

Polyacrylamid-Gelelektrophorese

Entsprechend ihrem Molekulargewicht können Proteine im Polyacrylamidgel aufgetrennt werden. Durch die Zugabe von SDS in hoher Konzentration erhalten alle Proteine eine negative Ladung und wandern hiernach entsprechend ihrer Größe im Spannungsfeld in den Polyacrylamidgelen in Richtung der positiv geladenen Katode. Beim anschließenden Western-Blot können die so aufgetrennten Proteine mithilfe von Antikörperreaktionen nachgewiesen werden.

Für die Proteingelelektrophorese wurde das Mini-PROTEAN-II-Cell-System verwendet. Die Proben werden auf ein 5\%iges Sammelgel (5\% Acrylamid, 125 $\mathrm{mMTris}-\mathrm{HCl}, \mathrm{pH} 6,8,0,1 \%$ APS, 0,1\% TEMED) aufgetragen und einer konstanten Spannung von 80V in Laufpuffer (25 mM Tris, 0,192 M Glycin, 0,1\% SDS, pH 8,8) ausgesetzt. Zur Größenbestimmung wird ein Größenmarker parallel aufgetragen. Sobald der Bromphenolblau-Farbstoff das Trenngel (10\% Acrylamid, $375 \mathrm{mM}$ Tris $\cdot \mathrm{Cl}$, pH 8,8, 0,1\% APS, 0,1\% TEMED) erreicht, wird die Feldstärke auf $100 \mathrm{~V}$ erhöht. Die Proteinelektrophorese wird beendet, sobald der Bromphenolblau-Farbstoff den unteren Rand des Gels erreicht hat. Das Molekulargewicht der Proteine wird mit Hilfe der bekannten Molekulargewichte des parallel aufgetrennten Proteinstandards bestimmt.

\section{Western-Blot}

Zur weiteren Analyse wurden die gelelektrophoretisch aufgetrennten Proteine aus dem Polyacrylamidgel auf eine Nitrocellulose-Membran $(0,45 \mu \mathrm{m})$ übertragen. Dafür wurde das Mini Trans-Blot Transfer Cell-System verwendet. Die NitrocelluloseMembran und $4 \times 3$ MM Whatman-Papier wurden auf Gelgröße zugeschnitten und 15 min in Transferpuffer (25 mM Tris-HCl, pH 8,2; $192 \mathrm{mM}$ Glycin; 20\% (v/v) Methanol; $0,1 \%$ (w/v) SDS) äquilibriert. Der Western-Blot wurde gemäß dem Protokoll der Firma Bio-Rad durchgeführt. Die Proteine wurden $1 \mathrm{~h}$ bei $130 \mathrm{~V}$ (für 2 Gele) aus dem Proteingel auf die Nitrocellulose-Membran unter Kühlung transferiert. Ziel ist der möglichst vollständige Transfer der Proteine auf die Nitrozellulose-Membran. Diese 
kann mit Ponceau-S-Farblösung (0,5 g Ponceau S gelöst in $1 \mathrm{ml}$ Essigsäure, Zugabe

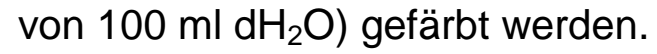

Der Nachweis der Proteine erfolgte mit spezifischen Antikörpern. Die Bindung der primären Antikörper an ihre Antigene erfolgt mit Hilfe sekundärer Antikörper, die mit Peroxidase markiert sind. Die sekundären Antikörper wurden durch Chemilumineszenz nachgewiesen. Die Nitrocellulose-Membran wurde nach dem Proteintransfer für 1 Stunde in Tris-gepufferter Salzlösung + Tween (TBS-T: $10 \mathrm{mM}$ Tris- $\mathrm{HCl}, \mathrm{pH}$ 7,3; $500 \mathrm{mM} \mathrm{NaCl} ; 0,2 \%$ Tween $20+5 \%$ Milchpulver) zur Blockierung unspezifischer Proteinbindungen inkubiert. Nach Spülung der Membran mit TBS-TPuffer (dreimal 5 min auf Schüttler) wurde die Membran mit den jeweiligen primären Antikörpern in einer Verdünnung von TBS-T-Puffer $+2,5 \%$ Milchpulver $+0,02 \%$ $\mathrm{NaN}_{3}$ über Nacht inkubiert (B-Aktin 1.1000, Desmin 1:400, Thy-1 1:100, a-SMA 1:1000). Anschließend wurde die Membran 4 mal 5 Minuten mit TBS-T-Puffer gewaschen und mit dem jeweiligen artspezifischen sekundären Antikörper (siehe 2.1) für 1 Stunde in einer Verdünnung von 1:10000 inkubiert. Nach erneutem

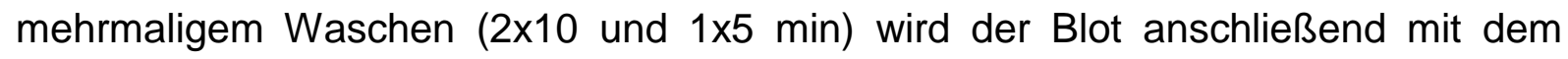
Substratansatz des ECL-Detektions-Kits gemäß den Angaben des Herstellers entwickelt. Zur internen Standardisierung wurde eine Positivkontrolle (B-Aktin) verwendet. Der Nachweis der sekundären Antikörper mit Markierung durch Peroxidase erfolgte durch Chemilumineszenz. Bei Zugabe geeigneter Substrate wird Licht emittiert, das fotografisch nachgewiesen werden kann. Die Membran wurde zur Inkubation in Frischhaltefolie verpackt und in der Dunkelkammer mit Hyperfilm ECL in einer Röntgenfilm-Kassette belichtet.

\subsubsection{Expressionsuntersuchung}

Polymerasekettenreaktion

Die PCR (polymerase chain reaction) ist ein Verfahren zur selektiven Vervielfältigung der DNA. Diese Methode wurde von Kary B. Mullis entwickelt (Saiki et al. 1985), dem für diese Leistung im Oktober 1993 der Nobelpreis verliehen worden ist. Dabei hybridisieren Oligonukleotide, auch Primer genannt, spezifisch an ihre komplementären Sequenzen des gesuchten Gens. 
Die PCR-Reaktion basiert auf drei Einzelschritten, die sich in Länge und Temperatur unterscheiden:

Denaturierung: Die DNA-Doppelstränge werden bei ca. $95^{\circ} \mathrm{C}$ aufgeschmolzen.

Annealing: Hier findet die Hybridisierung $\left(55-65^{\circ} \mathrm{C}\right)$ der Oligonukleotide an komplementäre DNA-Sequenzen statt.

Elongation: In dieser Phase findet die eigentliche Polymerisation (bei $72^{\circ} \mathrm{C}$ ) des DNA-Stranges statt.

Dieser Vorgang umfasst einen Zyklus. In jedem Zyklus verdoppelt sich die Menge der gebildeten Moleküle, so dass eine exponentielle Vermehrung der spezifischen Sequenz stattfindet. Bei dieser exponentiellen Vermehrung sollte die Plateauphase nicht erreicht werden, die zu einer Verfälschung der PCR-Ergebnisse führen könnte.

Die Zyklenzahlen werden abhängig von der Intensität des zu erwartenden Expressionssignals bestimmt und liegen in der Regel zwischen 23-37 Zyklen. Die PCR-Bedingungen werden durch Programmieren des Thermocyclers festgelegt.

Quantitative Polymerasekettenreaktion/ Real-time-PCR (q-PCR)

Die q-PCR zeichnet sich dadurch aus, dass die Amplifikation und der Nachweis des PCR-Produkts in einem Reaktionsgefäß ermöglicht wird. Dadurch wird ein zusätzlicher Arbeitsschritt zwischen den Zyklen vermieden, was sich in einem geringeren Reagenzienverbrauch äußert und die Gefahr einer Kontamination verringert. Zur Detektion wird eine fluorogene Sonde verwendet, so dass mit Hilfe des ABI-PRISMTM-Sequenz-Detektors die Veränderung der Fluoreszenzen im geschlossenen Reaktiongefäß zwischen den Zyklen erfasst werden kann. Das Signal ist direkt proportional mit der Menge an gebildetem PCR-Produkt. SYBR® Green ist ein DNA-spezifischer, interkalierender Farbstoff, der bei Anregung durch energiereiches UV-Licht, Licht im sichtbaren energieärmeren Wellenlängenbereich (Fluoreszenz) emittiert. Mit zunehmender Menge an PCR-Produkt nimmt die beobachtete Fluoreszenz zu. Die Interkalierung des Farbstoffs in die dsDNA macht eine extrem verstärkte Lichtemission möglich. Die in der q-PCR gemessenen, emittierten Fluoreszenzen dieses Farbstoffs dienen als Basis für die Auswertung. Emittierte Fluoreszenz und entstehendes Amplifikat sind linear proportional, so dass die Verhältnismäßigkeit über die Messung der Fluoreszenz auf die entstehende Menge an Produkt geschlossen werden kann. Bei einer positiven Reaktion kommt es 
zur Amplifikation des Produkts und damit zum Anstieg der Fluoreszenz im Laufe der Reaktion. Der Punkt, ab dem eine gemessene Fluoreszenz einer Probe klar von der Hintergrundfluoreszenz zu unterscheiden ist und als positiv zu werten ist, wird als Schwellenwert bezeichnet (Threshold). Der Schnittpunkt zwischen der Fluoreszenz und dem Schwellenwert projiziert auf die Abszisse wird als Cycle-threshold (CT) bezeichnet und stellt den niedrigsten messbaren positiven Wert einer quantitativen qPCR dar und gibt also eine Zyklenanzahl an. Er steht in direkter Beziehung zur Ausgangsmenge der eingesetzten DNA. Je höher der CT-Wert ist, desto kleiner ist die Ausgangsmenge an DNA und umgekehrt. Der CT-Wert ermöglicht somit die Quantifizierung einer Reaktion. Als Housekeeping-Gen wird B-Aktin verwendet. Die Quantifizierung erfolgt über eine $\Delta$ CT-Methode.

\section{Housekeeping-Gen}

Unter dem Begriff Housekeeping-Gen versteht man Gene, deren Expression konstitutiv und unabhängig von intra- oder extrazellulären Vorgängen erfolgt. Es wird somit angenommen, dass die Genexpression eines Housekeeping-Gens immer konstant bleibt und somit als internes Referenzgen gilt. Seine Transkription wird in jeder Probe bestimmt und dient durch den Abgleich der Daten dazu, Unterschiede, die nicht eine tatsächliche Regulation der mRNA-Expression widerspiegeln, sondern methodisch bedingt sind, zu eliminieren.

\section{RNA-Isolation für q-PCR}

Das Medium wird von den Zellkulturen abgenommen. Anschließend werden die Kulturen zweimal mit PBS gewaschen. Danach wird $1 \mathrm{ml}$ Trizol auf die Kulturen gegeben. Die Zellen werden mit einem Zellschaber abgelöst. Der Überstand wird abpipettiert, homogenisiert und in ein 1-ml-Eppendorfgefäß gegeben. Hiernach können die Proben bei $-20^{\circ} \mathrm{C}$ gefroren oder direkt dem nächsten Arbeitsschritt zugefügt werden.

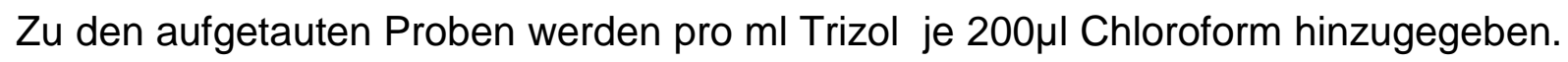
Die Ansätze werden geschwenkt, 5 Minuten bei Raumtemperatur inkubiert und anschließend einmalig gevortext. Hiernach werden die Proben für 15 Minuten bei $14000 \mathrm{U}$ und $4^{\circ} \mathrm{C}$ zentrifugiert. Die Zentrifugation bewirkt eine Auftrennung der 
Proben in drei Phasen, wobei die oberste klare Phase der RNA, die mittlere weiße Phase der Interphase und die untere Phase dem Trizol entsprechen. Die RNA-Phase

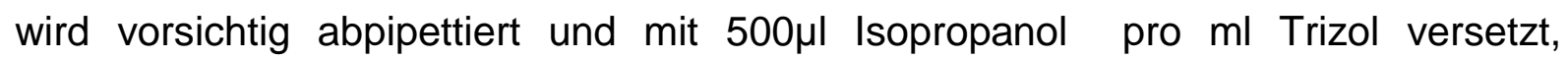
geschwenkt und 10 Minuten bei Raumtemperatur inkubiert. Hierauf erfolgt eine erneute 30-minütige Zentrifugation bei $14000 \mathrm{U}$ und $4^{\circ} \mathrm{C}$. Die RNA sollte jetzt als weißes Pellet im Eppendorfgefäß sichtbar sein. Der Überstand wird vorsichtig abgekippt und die Probe mit $1 \mathrm{ml}$ Ethanol $75 \%$ je $\mathrm{ml}$ Trizol resuspendiert und anschließend in ein sauberes Eppendorfgefäß überführt. Die Proben werden für 5 Minuten mit $13000 \mathrm{U}$ bei $60^{\circ} \mathrm{C}$ zentrifugiert, der Überstand verworfen und wenige

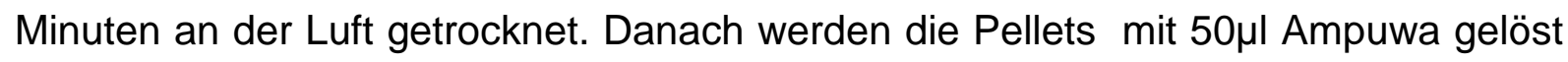
und 5 Minuten bei Raumtemperatur stehengelassen. Sollten sich die Pellets nicht lösen, können die Proben ggf. für 5 Minuten im Heizblock bei $60^{\circ} \mathrm{C}$ erwärmt werden. Anschließend kann die RNA-Konzentration photometrisch bestimmt werden und die RNA bei $-80^{\circ} \mathrm{C}$ tief gefroren oder in C-DNA umgeschrieben werden.

Photometrische Bestimmung der RNA

Die Konzentrationsbestimmung erfolgt UV-spektrophotometrisch bei einer Wellenlänge von $260 \mathrm{~nm}$. Zur Bestimmung des Reinheitsgrades der isolierten Nukleinsäuren wurde zusätzlich die optische Dichte (OD) bei einer Wellenlänge von $280 \mathrm{~nm}$ bestimmt. Der Quotient (Ratio) aus OD $260 \mathrm{~nm} /$ OD $280 \mathrm{~nm}$ sollte zwischen 1,8 und 2,0 liegen.

Umschreiben der RNA in cDNA für q-PCR

Zur weiteren Untersuchung der mRNA-Genexpression muß die mRNA in komplementäre cDNA umgeschrieben werden. Das Verfahren beruht auf der Fähigkeit eines viralen Enzyms (reverse Transkriptase:RT), sich an ein Oligonukleotid (OligodT) anzulagern, an das polyA-Ende der mRNA zu binden und DNA-Stränge zu synthetisieren. Die reverse Transkription wurde mittels eines $\mathrm{M}$ MLV-RT-(moloney murine leukaemia virus reverse transcriptase)-KITs durchgeführt.

Den Proben wird entsprechend ihrer Konzentration $1 \mu \mathrm{g}$ RNA entnommen (z.B. 4,69 $\mu \mathrm{l}$ Probe bei einer Konzentration von $0,213 \mu \mathrm{g} / \mu \mathrm{l})$, in ein 1 -ml-Eppendorfgefä $\beta$ 
überführt und mit Ampuwa bis zu einer Gesamtmenge von $9 \mu$ l aufgefüllt. Dem Gemisch wird $1 \mu \mathrm{l}$ RNase-Inhibitor hinzugegeben, der Ansatz wird anzentrifugiert und anschließend 10 Minuten bei $65^{\circ} \mathrm{C}$ inkubiert. Jeder Probe werden danach $30 \mu$ leiner Reaktionslösung $\left(8 \mu \mathrm{l} 5 \mathrm{xFS}\right.$ Buffer, $8 \mu \mathrm{l} \mathrm{dT_{15 }}$ Primer [entsprechend 2,5 $\mathrm{mM}$ Oligo- $\mathrm{dT}_{15}$ Endkonzentration], $8 \mu \mathrm{l} \quad$ dNTP-Mix $\quad$ [entsprechend $2,0 \quad \mathrm{mM}$ dNTP-Mix Endkonzentration], $4 \mu \mathrm{IDTT}, 2 \mu \mathrm{l}$ M-MLV) hinzugegeben, erneut anzentrifugiert und 1 Stunde bei $38^{\circ} \mathrm{C}$ inkubiert. Darauf folgt eine 10 minütige Inkubation bei $72^{\circ} \mathrm{C}$. Die Proben werden nun mit jeweils $120 \mu \mathrm{l}$ Ampuwa verdünnt und bei $-80^{\circ} \mathrm{C}$ gelagert oder weiter verwendet.

\section{Real-Time-PCR}

Für die nun folgende PCR werden $2 \mu \mathrm{l}$ der Proben mit $23 \mu \mathrm{l}$ Mastermix $(12,5 \mu \mathrm{l}$

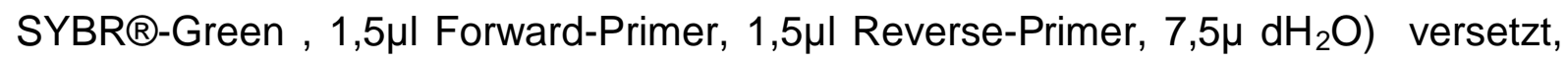
so dass $25 \mu \mathrm{l}$ Gesamtvolumen pro Versuchsatz erreicht werden. Die Platte wird anschließend abzentrifugiert und zur Messung in das ABI Prism® 7000 Sequence Detection System gelegt. Die Amplifikation und Detektion erfolgen nach diesem Profil:

$50{ }^{\circ} \mathrm{C} 2 \mathrm{~min}$

$95^{\circ} \mathrm{C} 2 \mathrm{~min}$

$95^{\circ} \mathrm{C} 15 \mathrm{~s}$

$60^{\circ} \mathrm{C} 30 \mathrm{~s} \backslash 45$ Zyklen

$95{ }^{\circ} \mathrm{C} 15 \mathrm{~s} \mathrm{/}$

$60{ }^{\circ} \mathrm{C} 30 \mathrm{~s}$

$95^{\circ} \mathrm{C} 15 \mathrm{~s}$.

Jede Probe wurde als Duplikat aufgetragen und analysiert. Mit Hilfe des Programms ABI Prism ${ }^{\circledR} 7000$ SDS Software wurden die so erhaltenen Daten ausgewertet. Um eine methodisch bedingte Änderung in der mRNA Expression zu eliminieren, werden ausschließlich Proben mit signifikanter B-Actin-Expression verwendet. Des Weiteren wird der Mittelwert der doppelt aufgetragenen und bestimmten Proben für die Berechnung verwendet. CT-Werte über 30 werden in die Berechnung nicht mit einbezogen. 
Als Formel für die Genexpression gilt hierbei

$$
\begin{gathered}
\text { Genexpression }_{\mathrm{x}}=2^{\Delta \mathrm{CT}} \\
\text { mit } \Delta C T=C T_{\text {Housekeeping-Gen }}-\mathrm{CT}_{\mathrm{x}}
\end{gathered}
$$

Die errechneten Expressionswerte erlauben somit eine graphische Darstellung der Genprodukte der verschiedenen MF-Kulturen.

Nachweis der PCR-Produkte

Der Nachweis von Reaktionsprodukten erfolgt durch elektrophoretische Auftrennung in 1,5\%-Agarosegelen. Hierzu wird 1,87 g Agarose in $125 \mathrm{ml} 1$ xTBE-Puffer für $3 \mathrm{~min}$. in einem Mikrowellengerät erhitzt. Anschließend werden $5 \mu \mathrm{l}$ Ethidiumbromid hinzugegeben, Abkühlung bis zu etwa $60^{\circ} \mathrm{C}$ und dann luftblasenfrei in eine Horizontalflachbettkammer mit senkrecht eingestecktem Kamm gegossen. Nach Erstarren des Gels wird der Kamm entfernt und das Gel in eine Horizontalelektrophoresekammer gelegt. Die Kammer wurde mit 1xTBE-Puffer als Laufpuffer so weit gefüllt, daß das Gel vollständig mit Flüssigkeit bedeckt ist. Die zu

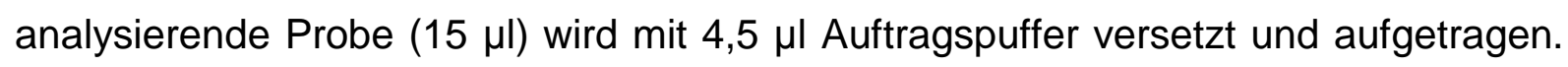
Zur Größenbestimmung der Fragmente wird ein 100bp-DNA-Größenmarker eingesetzt. Die Auftrennung erfolgte bei 75-85 V, bis die Bromphenolblaubande des Auftragspuffers eine Wanderungsstrecke von etwa $5 \mathrm{~cm}$ im Gel zurückgelegt hat. Die Visualisierung der DNA erfolgt unter UV-Anregung des interkalierenden Ethidiumbromids in einem UV-Leuchtkasten.

\section{Statistische Auswertung}

Für die Darstellung der PCR-Produkte der einzelnen Organpopulationen erfolgte keine statistische Auswertung, da diese lediglich deskriptiv ist und keine Basiswerte oder Vergleichsdaten vorliegen.

Beim Vergleich der PCR-Produkte untereinander wurde zunächst mittels des D'Agostino-Pearson-omnibus-Tests geprüft, ob die Messwerte normalverteilt sind. Dies erfolgte bei normalverteilten Werten durch den ANOVA-Test und bei nicht normalverteilten Werten durch den Kruskal-Wallis-Test. Zur besseren Visualisierung 
wurden bei weniger als 5 Messwerten die Werte doppelt verrechnet, wobei Mittelwerte und Standardabweichung gleich blieben, die Fallzahl sich jedoch verdoppelte. Diese Daten wurden wie nicht normalverteilte Werte behandelt. Anschließend wurde eine Varianzanalyse der Mittelwerte durchgeführt. Ließen sich somit signifikante Unterschiede nachweisen $(p<0,05)$, wurden die einzelnen PCRProdukte untereinander verglichen. Dunn's nichtparametrischer post-hoc-Test wurde für den Vergleich von nicht normalverteilten Daten und der Bonferroni -Test für normalverteilte Daten angewandt. Signifikante Unterschiede $(p<0,05)$ wurden bei der graphischen Darstellung mit * gekennzeichnet.

\section{Ergebnisse}

Die nachfolgenden Experimente wurden mit Zellen aus den verschiedenen Isolationsversuchen durchgeführt. Für die Immunfluoreszenz, die Genexpressionsanalysen sowie den Proteinnachweis wurden mit Ausnahme der intestinalen subepithelialen MF mehrfach passagierte Zellen verwendet. Die Untersuchungen der Darm-MF erfolgten an Primärkulturen. Die folgenden Abbildungen zeigen die Zellkulturen in unterschiedlichen Vergrößerungen.

\subsection{Ergebnisse Zellkulturen}

Die ersten Zellen mit einer für MF typischen Morphologie konnten nach 3-4 Tagen (Ösophagus, Magen) beobachtet werden. Bei den Pankreas- und Darm-Kulturen konnten diese Zellen jedoch erst nach bis zu 2 Wochen beobachtet werden. Die Dauer bis sich ein konfluenter Monolayer in den Schalen gebildet hatte, unterschied sich ebenso deutlich; so konnten die isolierten Zellen von Ösophagus, Magen und Leber bereits nach 10-14 Tagen passagiert werden, während die Passage der Zellen des Pankreas erst nach 3-4 Wochen möglich war. Die isolierten Zellen aus den Darmabschnitten proliferierten hingegen erst nach 3 Wochen und erreichten keine Konfluenz. 


\section{Darm-MF}

Lichtmikroskopische Darstellung der primären Darm-MF-Kulturen 2 bzw. 3 Wochen nach Isolation. Die MF weisen typische Merkmale von mesenchymalen Zellen auf. Neben den großen Zellausläufern sind bei hoher Vergrößerung auch filamentäre Strukturen im Zytoplasma sichtbar. Das Wachstum der Zellen geht von Zusammenlagerungen mehrerer Zellen aus, die zu einem Monolayer zusammenwachsen. Es kommen sowohl einkernige als auch mehrkernige Zellen vor.

A)

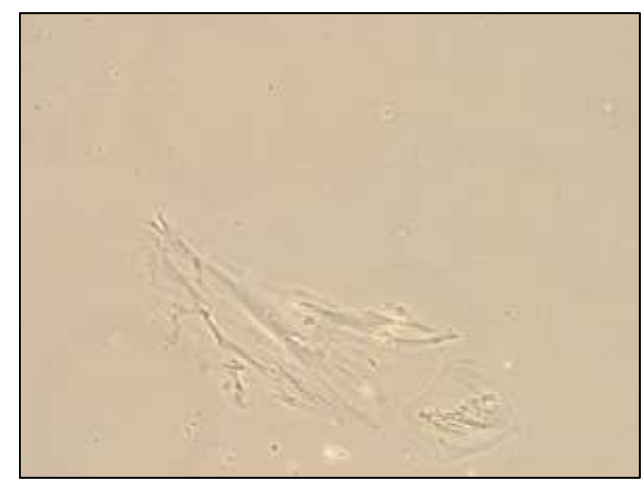

C)

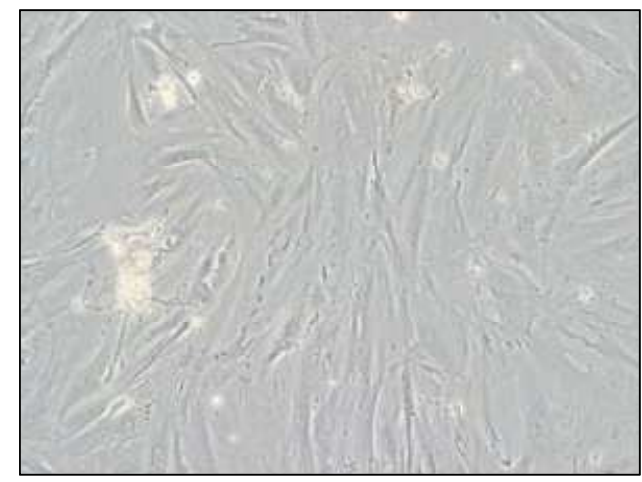

B)

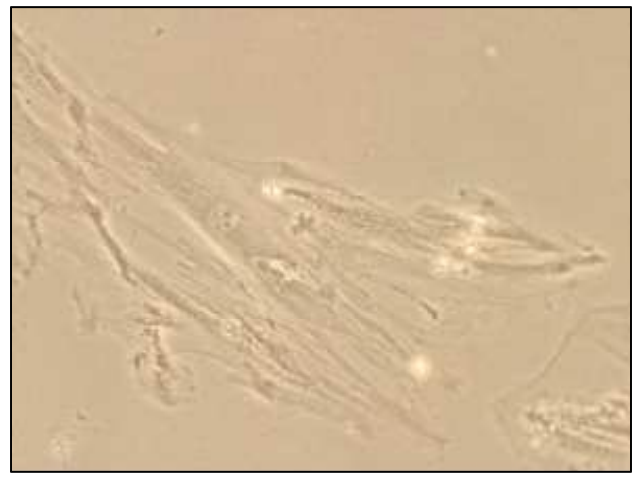

D)

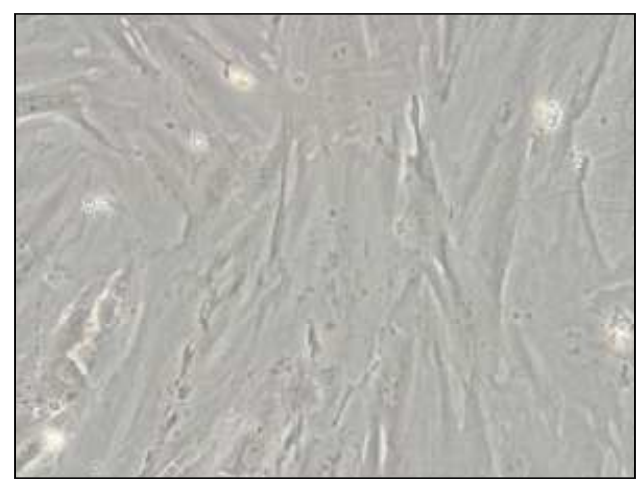

Abb. 01: Darm-MF, 2 Wochen nach Isolation, Vergrößerung: 100-fach (A) und 200fach (B); 3 Wochen nach Isolation, Vergrößerung: 100-fach (C), 200-fach (D) 


\section{Ösophagus-MF}

Lichtmikroskopische Darstellung der Ösophagus-MF-Kulturen nach Passagierung. Die Zellen imponieren spindelförmig und wachsen zügig bis zur Konfluenz. Die Zellausläufer sind weniger ausgeprägt und die Zellkörper insgesamt kleiner.

A)

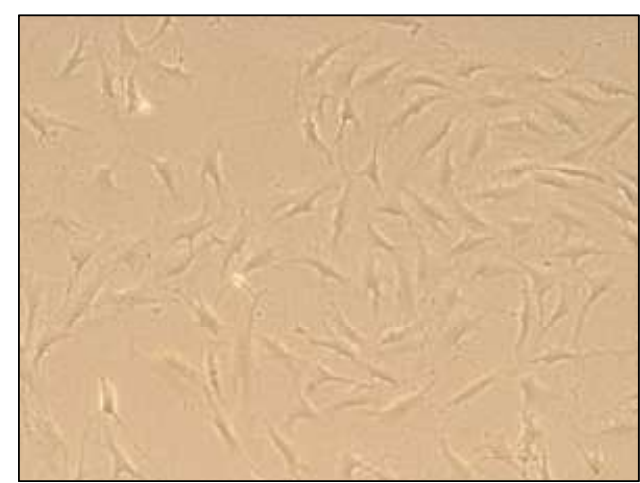

C)

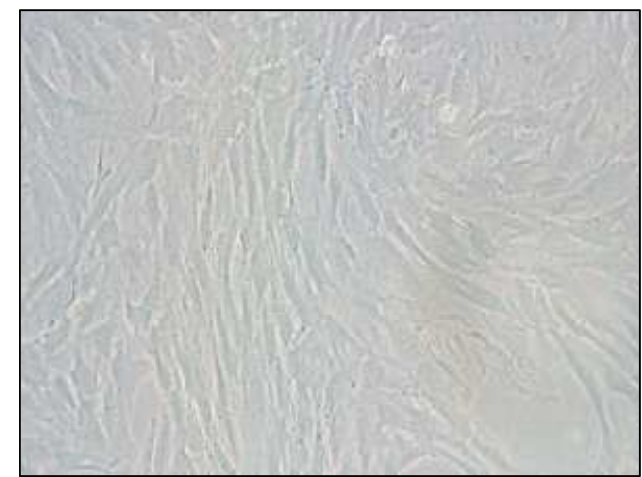

B)

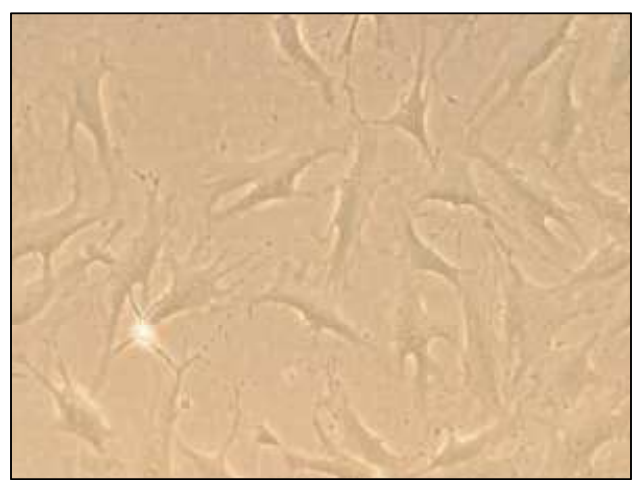

D)

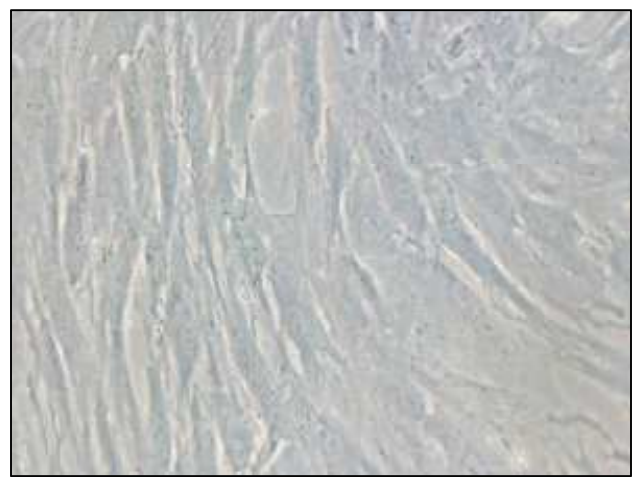

Abb. 02: Ösophagus-MF, nach Passage 1, Vergrößerung: 100-fach (A), 200-fach (B); nach Passage 2, Vergrößerung: 100-fach (C), 200-fach (D)

Magen-MF

Lichtmikroskopische Darstellung der Magen-MF-Kulturen nach Passagierung. Die spindelförmigen Zellen lagern sich auch hier zu Gruppen zusammen, von denen das 
Wachstum ausgeht. Die Kern-Plasma-Relation ist zugunsten des Zellkerns verschoben.

A)

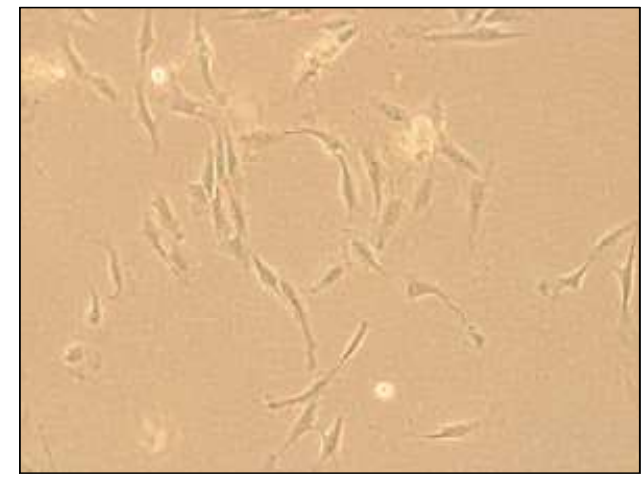

C)

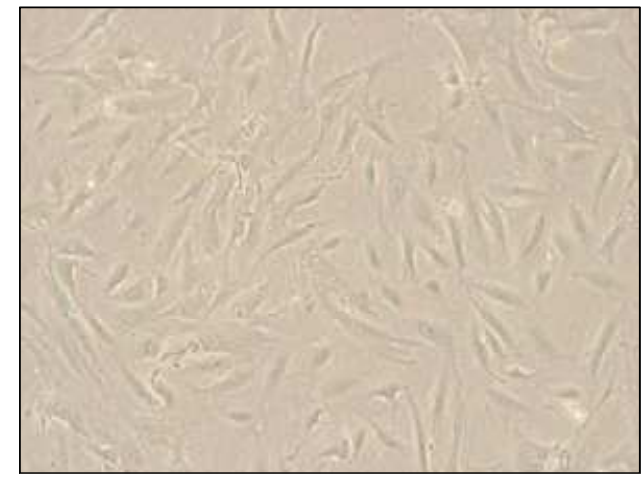

B)

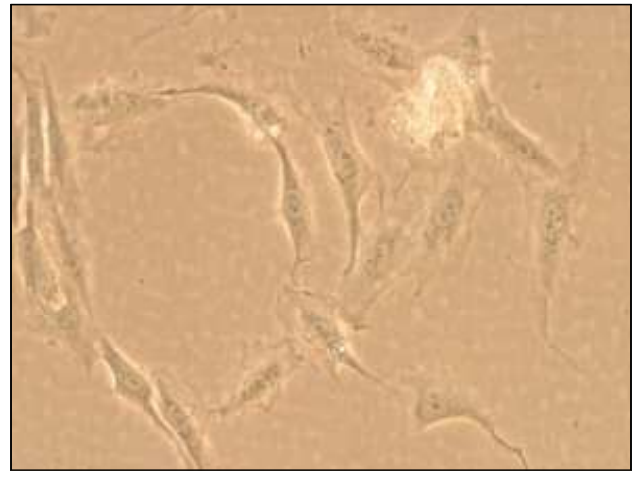

D)

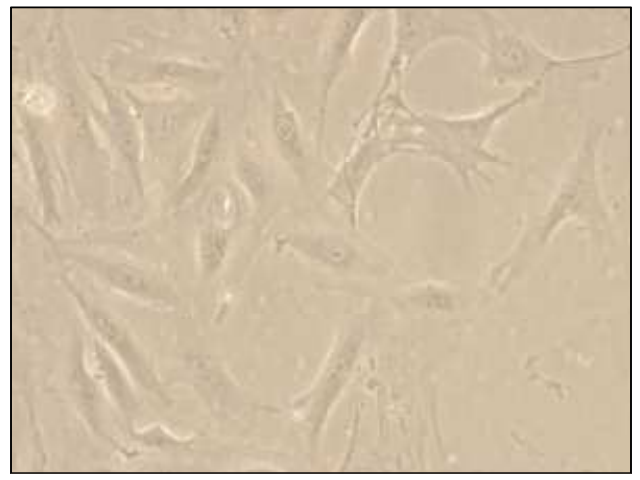

Abb. 03: Magen-MF, nach Passage 1, Vergrößerung: 100-fach (A), 200-fach (B); nach Passage 2, Vergrößerung: 100-fach (C), 200-fach (D)

Pankreas-MF

Lichtmikroskopische Darstellung der Pankreas-MF-Kulturen nach Passagierung. Im Vergleich zu den Kulturen aus Ösophagus, Magen und Leber weisen die Kulturen ein wesentlich langsameres Wachstum auf. Morphologisch ähneln sie den Zellen aus den Magen- und Ösophagus-Kulturen. 
A)

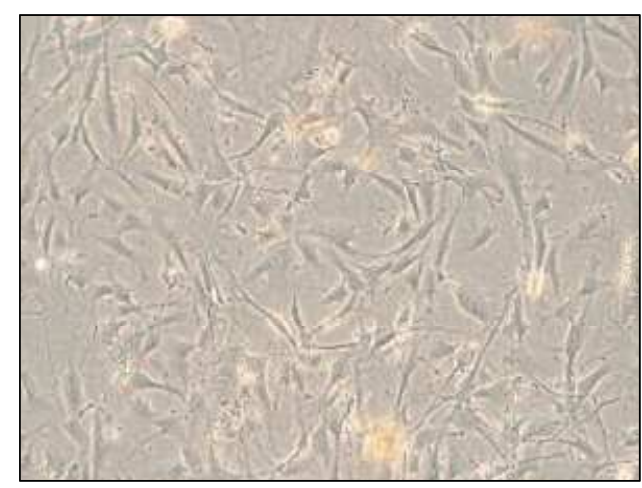

C)

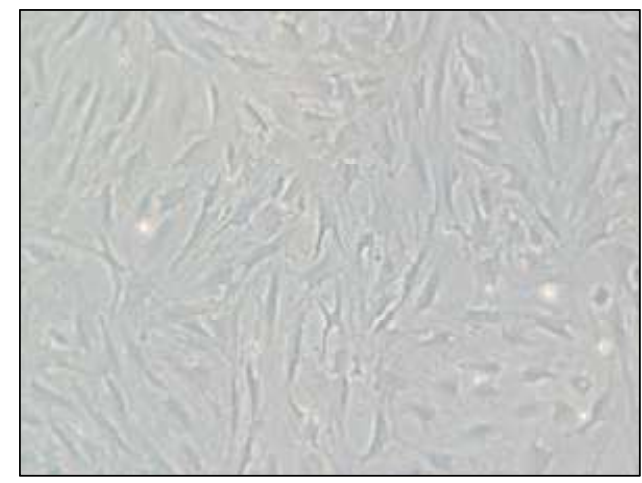

B)

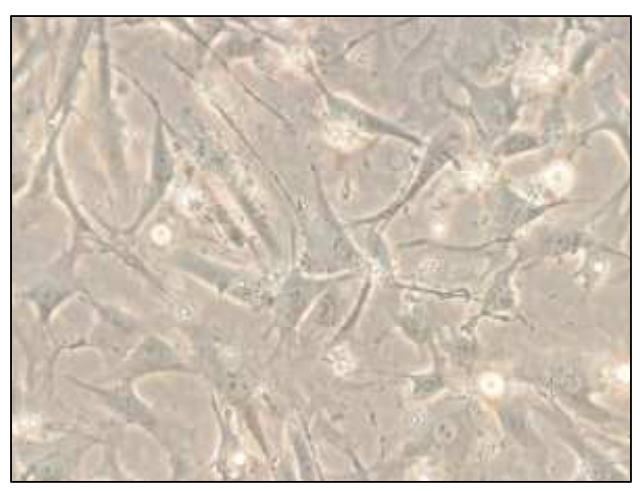

D)

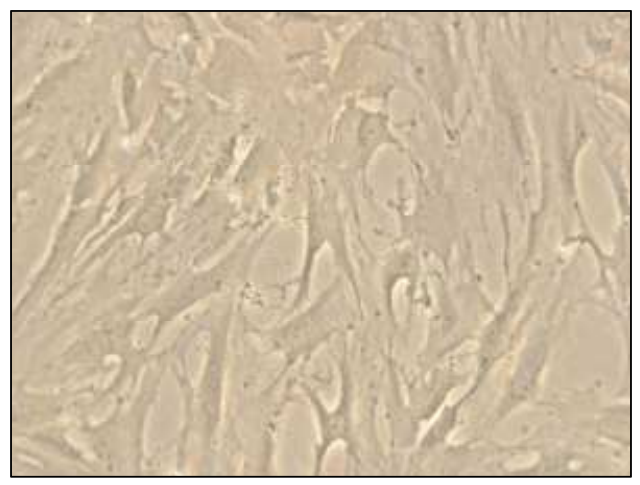

Abb. 04: Pankreas-MF, nach Passage 1, Vergrößerung: 100-fach (A), 200-fach (B); nach Passage 2, Vergrößerung: 100-fach (C), 200-fach (D)

Leber-MF

Lichtmikroskopische Darstellung der Leber-MF-Kulturen nach Passagierung. Die Zellen lagern sich im Monolayer zu dichten Gruppen zusammen. Ein großer Teil des charakteristischen Zellkörpers wird vom Kern eingenommen. 
A)

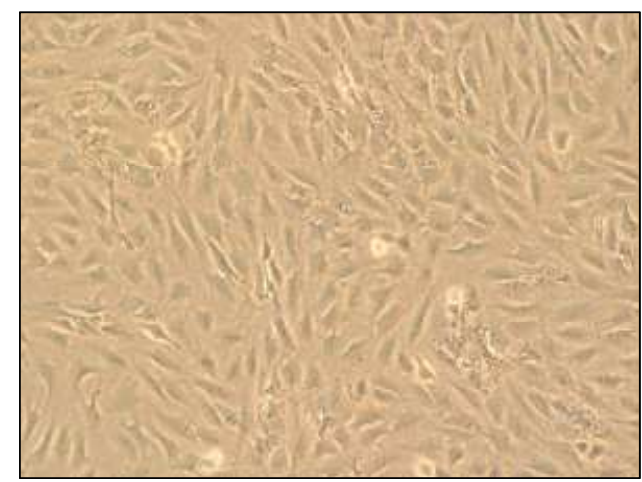

B)

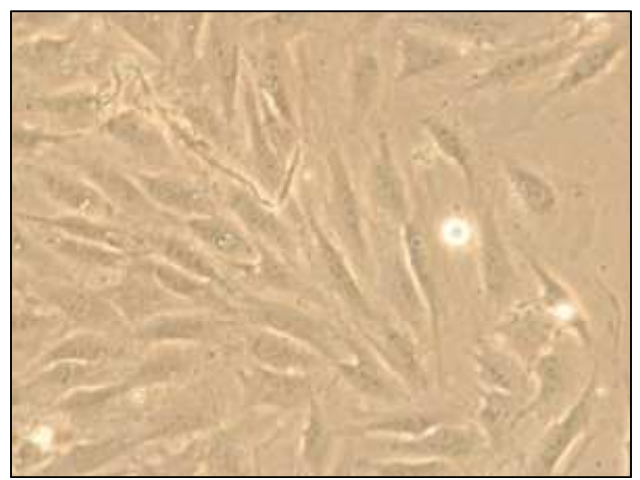

Abb. 05: Leber-MF, nach Passage 5, Vergrößerung: 100-fach (A), 200-fach (B)

Färbungen

\subsection{Ergebnisse Fluoreszenzmikroskopie}

Zur Charakterisierung der isolierten Zellen wurden diese immunhistochemisch auf spezifische Zell-Marker untersucht. Hierbei wurden die isolierten Zellen auf die Expression des mesenchymalen Markers Vimentin und des MF-typischen Markers $\alpha$ Smooth-Muscle Actin untersucht. Desweiteren wurde eine Thy-1 Färbung gewählt, da neuere Forschungen an Leber-MF belegen, dass Thy-1 (CD90) ebenfalls als Marker zur Identifizierung von MF geeignet ist (Dudas et al. 2007). Um eine Unterscheidung von glatten Muskelzellen vornehmen zu können, wurde daneben eine Desmin-Färbung durchgeführt. Während Desmin ein typischer Marker für glatte Muskelzellen ist (Paramio 2006), weisen MF in Abhängigkeit von Organ und Spezies unterschiedlich viele Desminfilamente auf (Beaussier et al. 2007, Mermall et al. 1998, Powell et al. 1999b).

\section{Darm-MF}

Fluoreszenzmikroskopische Darstellung der Darm-MF-Kulturen nach Passage auf Labteks.

Die a-SMA-Färbung zeigt in allen Zellen Aktinfilamente als Teil des Zytoskeletts. Vimentinfilamente sind ebenfalls in nahezu allen Zellen sichtbar. Zum größten Teil sind die Zellen auch Thy-1 positiv. Da es sich um ein Protein der Zelloberfläche 
handelt resultiert jedoch ein anderes Färbemuster. Demgegenüber sind die Desminfilamente nur vereinzelt in wenigen Zellen sichtbar.

A)

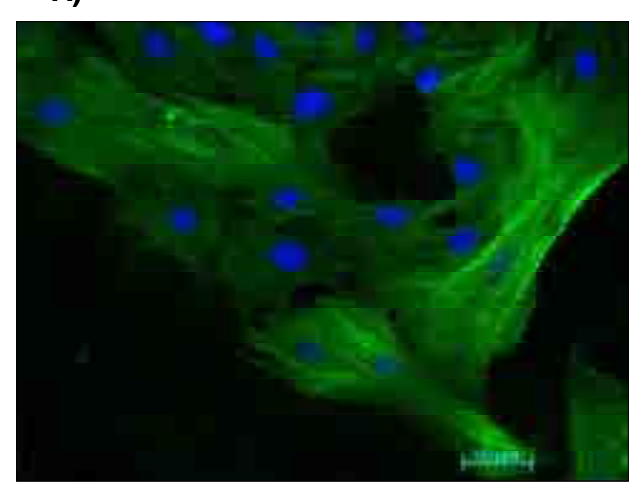

C)

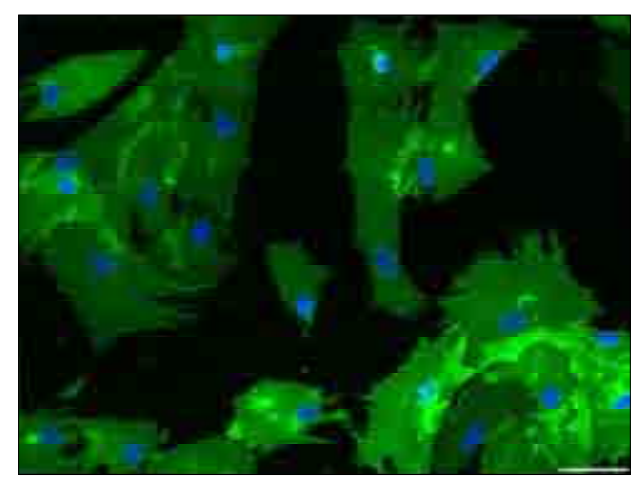

B)

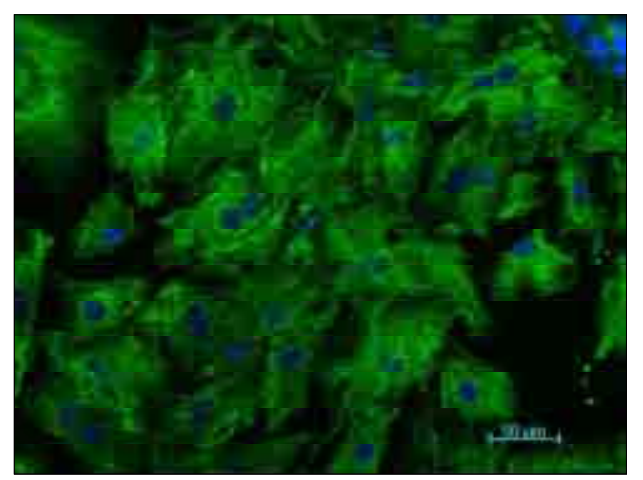

D)

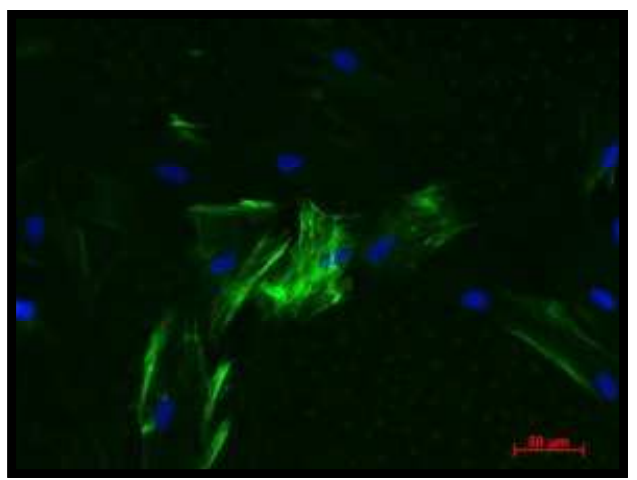

Abb. 06: Darm-MF, fluoreszenzmikroskopische Darstellung einer repräsentativen Färbung der auf Labtex kultivierten Zellen. Vergrößerung: 200-fach (A) aSMA, (B) Vimentin, (C) Thy-1(CD90), (D) Desmin.

Der jeweilige Antikörper ist in Grün dargestellt. Gegenfärbung der Zellkerne mit DAPI (blau).

Ösophagus-MF

Fluoreszenzmikroskopische Darstellung der Ösophagus-MF-Kulturen nach Passage auf Labteks. 
Erwartungsgemäß zeigen die Färbungen des a-SMA sowie Vimentin auch hier in allen Zellen die Filamentstrukturen. Thy- 1 ist in unterschiedlicher Ausprägung sichtbar, während die Desminfilamente nur in wenigen Zellen nachweisbar sind

A)

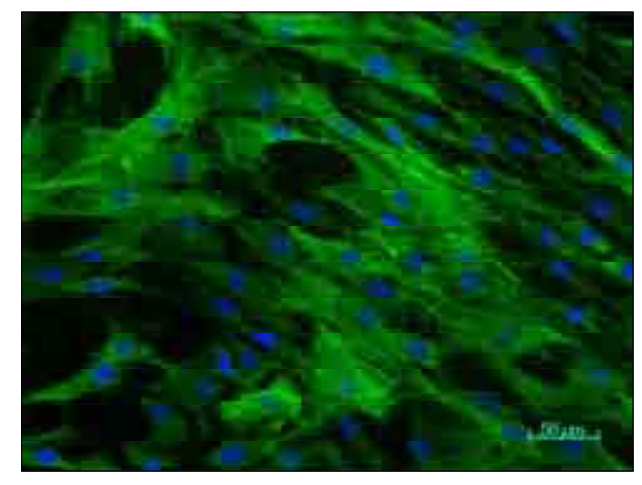

C)

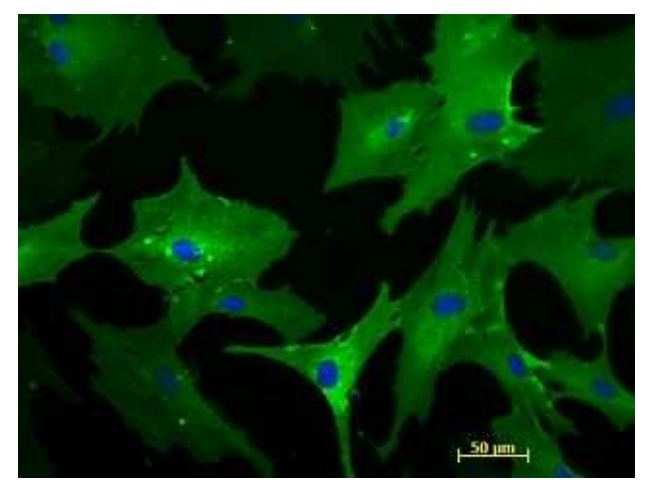

B)

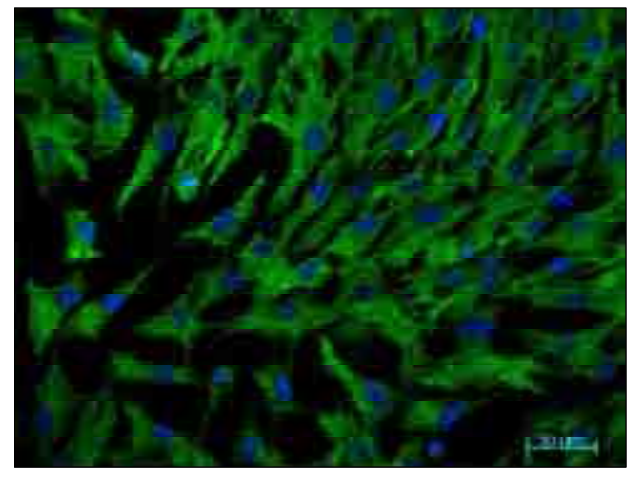

D)

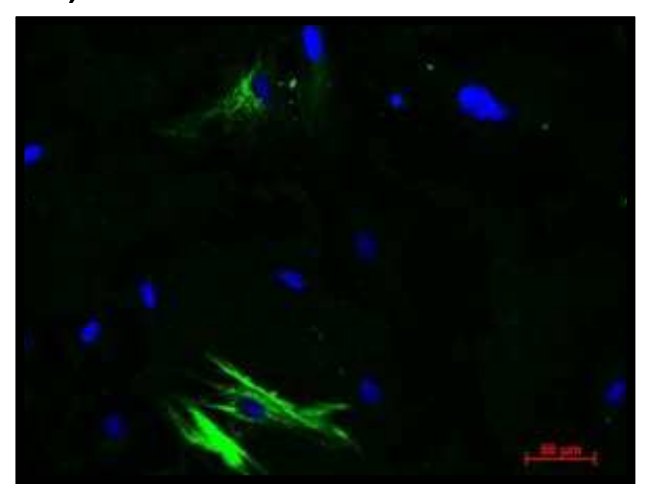

Abb. 07: Ösophagus-MF, fluoreszenzmikroskopische Darstellung einer repräsentativen Färbung der auf Labtex kultivierten Zellen. Vergrößerung: 200-fach (A) a-SMA, (B) Vimentin, (C) Thy-1(CD90), (D) Desmin. Der jeweilige Antikörper ist in Grün dargestellt. Gegenfärbung der Zellkerne mit DAPI (blau).

Magen

Fluoreszenzmikroskopische Darstellung der Magen-MF-Kulturen nach Passage auf Labteks.

Man erkennt sehr gut die Aktinfilamente, die den gesamten Zellkörper zu durchspannen scheinen. Gut sichtbar sind auch die Vimentinfilamente in der gesamten Zellkultur. Die Thy-1-Darstellung zeigt wiederum ein inhomogenes 
Färbeverhalten, wobei viele Zellen positiv reagieren. In der Desmin-Färbung sind nur vereinzelt Fluoreszenzsignale zu sehen.

A)

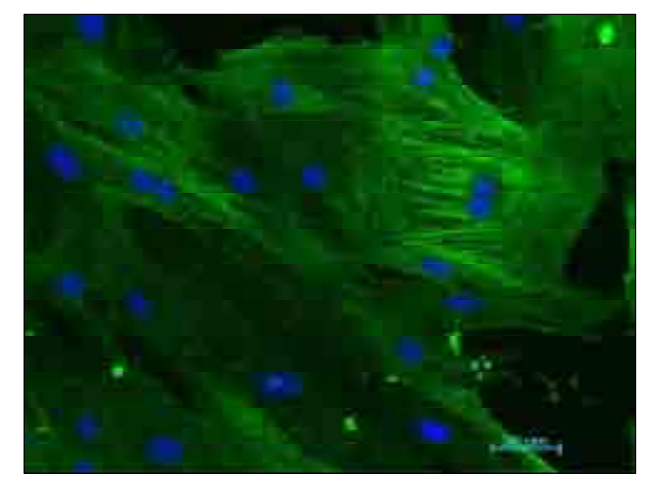

C)

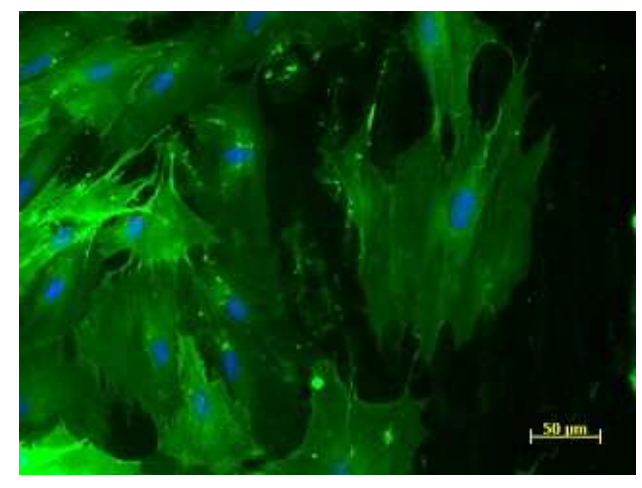

B)

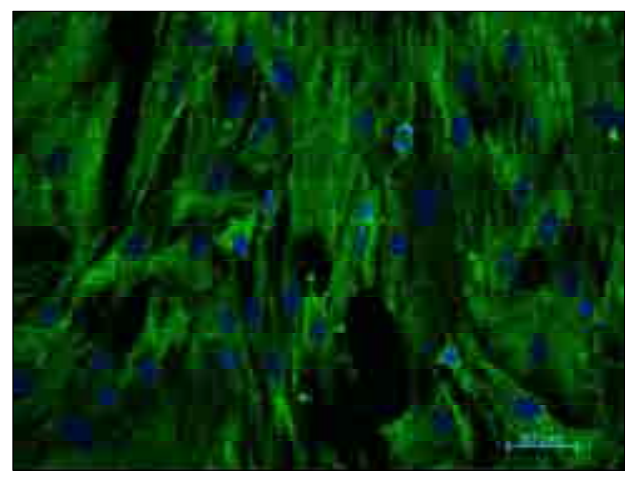

D)

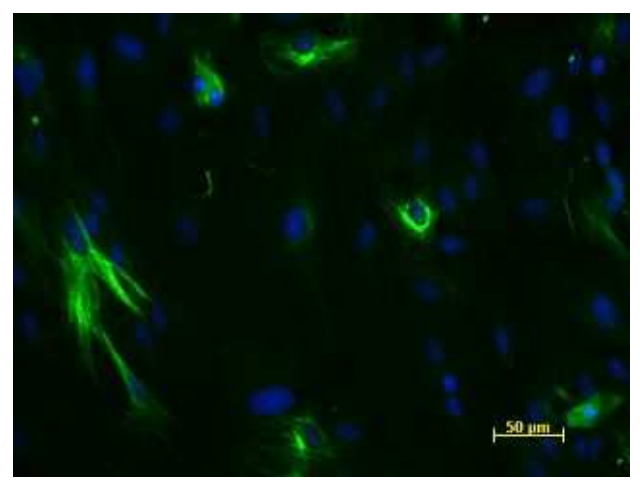

Abb. 08: Magen-MF, fluoreszenzmikroskopische Darstellung einer repräsentativen Färbung der auf Labtex kultivierten Zellen. Vergrößerung: 200-fach (A) aSMA, (B) Vimentin, (C) Thy-1(CD90), (D) Desmin.

Der jeweilige Antikörper ist in Grün dargestellt. Gegenfärbung der Zellkerne mit DAPI (blau).

Pankreas

Fluoreszenzmikroskopische Darstellung der Pankreas-MF-Kulturen nach Passage auf Labteks.

Auch hier können die typischen Anteile des Zytoskeletts der MF nachgewiesen werden. Sowohl Aktin- als auch Vimentinfilamente kommen in allen Zellen vor. 
A)

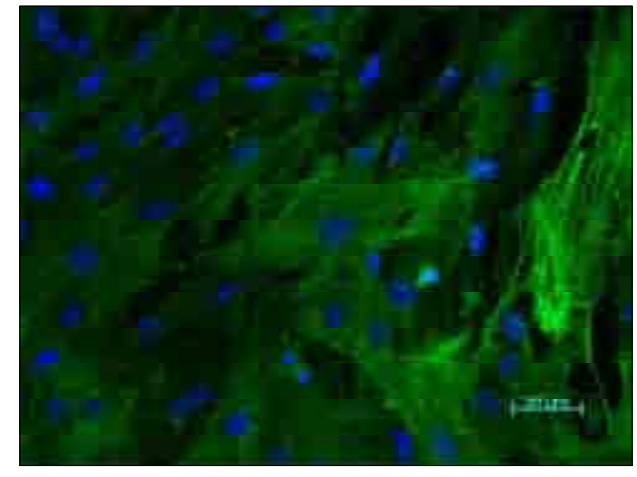

C)

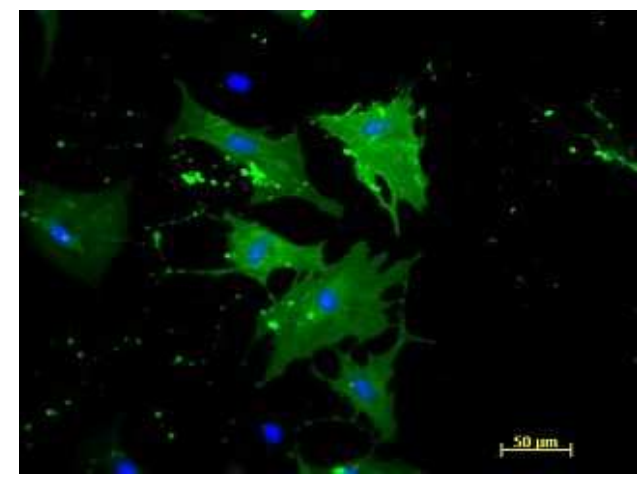

B)

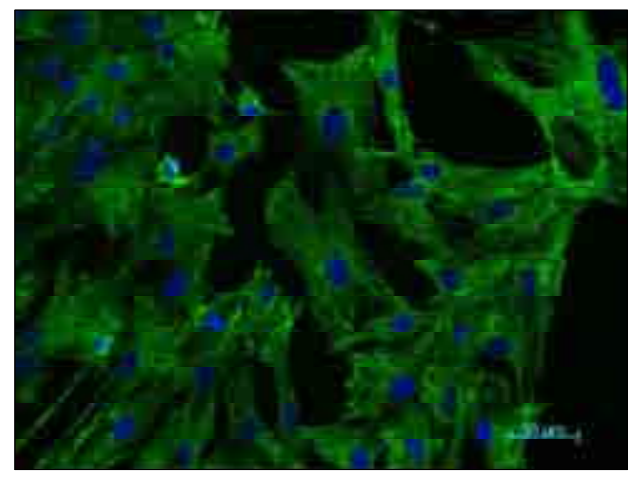

D)

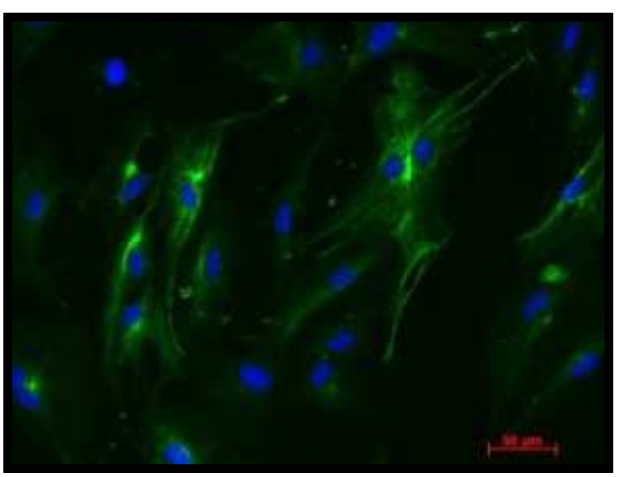

Abb. 09: Pankreas-MF, fluoreszenzmikroskopische Darstellung einer repräsentativen Färbung der auf Labtex kultivierten Zellen. Vergrößerung: 200-fach (A) a-SMA, (B) Vimentin, (C) Thy-1(CD90), (D) Desmin. Der jeweilige Antikörper ist in Grün dargestellt. Gegenfärbung der Zellkerne mit DAPI (blau).

Leber

Fluoreszenzmikroskopische Darstellung der Leber-MF-Kulturen nach Passage auf Labteks. Erwartungsgemäß sind sowohl die Aktin- als auch die Vimentinfilamente homogen verteilt. In der Thy-1-Darstellung ist die Mehrheit der Zellen markiert. Hingegen können die Desminfilamente nur in wenigen Zellen nachgewiesen werden. 
A)

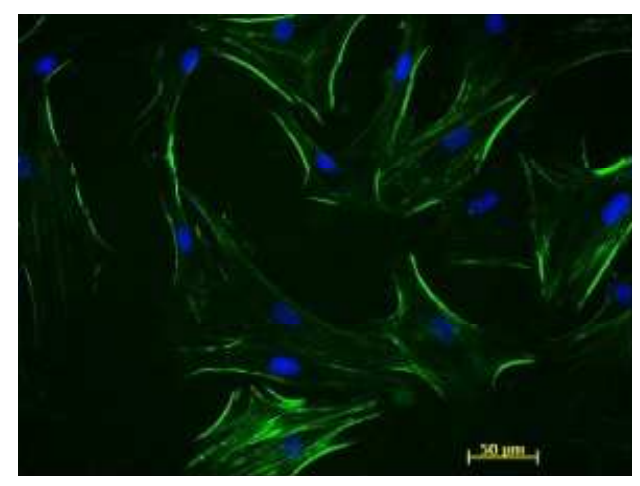

C)

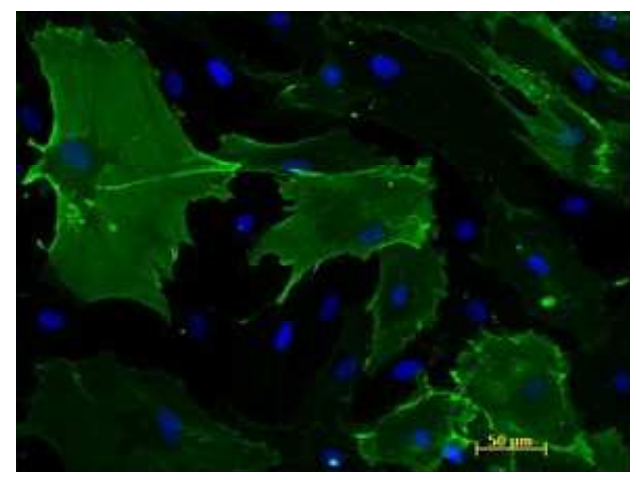

B)

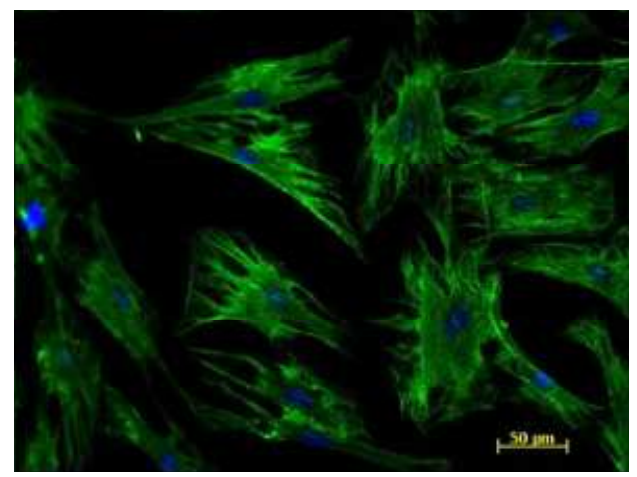

D)

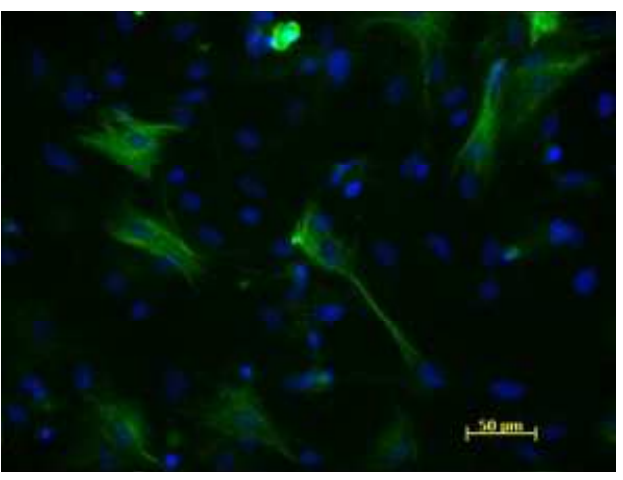

Abb. 10: Leber-MF, fluoreszenzmikroskopische Darstellung einer repräsentativen Färbung der auf Labtex kultivierten Zellen. Vergrößerung: 200-fach (A) $\alpha$ SMA, (B) Vimentin, (C) Thy-1(CD90), (D) Desmin.

Der jeweilige Antikörper ist in Grün dargestellt. Gegenfärbung der Zellkerne mit DAPI (blau).

\subsection{In-vivo-Darstellung}

In einem nächsten Schritt wurden mikroskopische Präparate der zu untersuchenden Organe angefertigt und gefärbt. Für die Darstellung wurden a-SMA-, Thy-1- und Desmin-Fluoreszenzmarker verwendet. Es stellt sich die Frage, ob die gesuchten Zellen bei einer in-vivo-Darstellung lokalisierbar sind. Die intestinalen MF liegen nach Mahida (Mahida et al. 1997b) in der Tunica mucosa, direkt unter der Basalmembran in der Lamina propria mucosae. Die Lage der MF in den übrigen Organen ist nicht genau beschrieben. Ihrer Funktion nach müssten die MF in Ösophagus und Magen jedoch eine ähnliche Beziehung zum Epithel haben. Da das Pankreas sowie die Leber eine andere Histologie aufweisen als die Abschnitte des Verdauungskanals, müssen die Gewebsschnitte hier differenzierter betrachtet werden. 

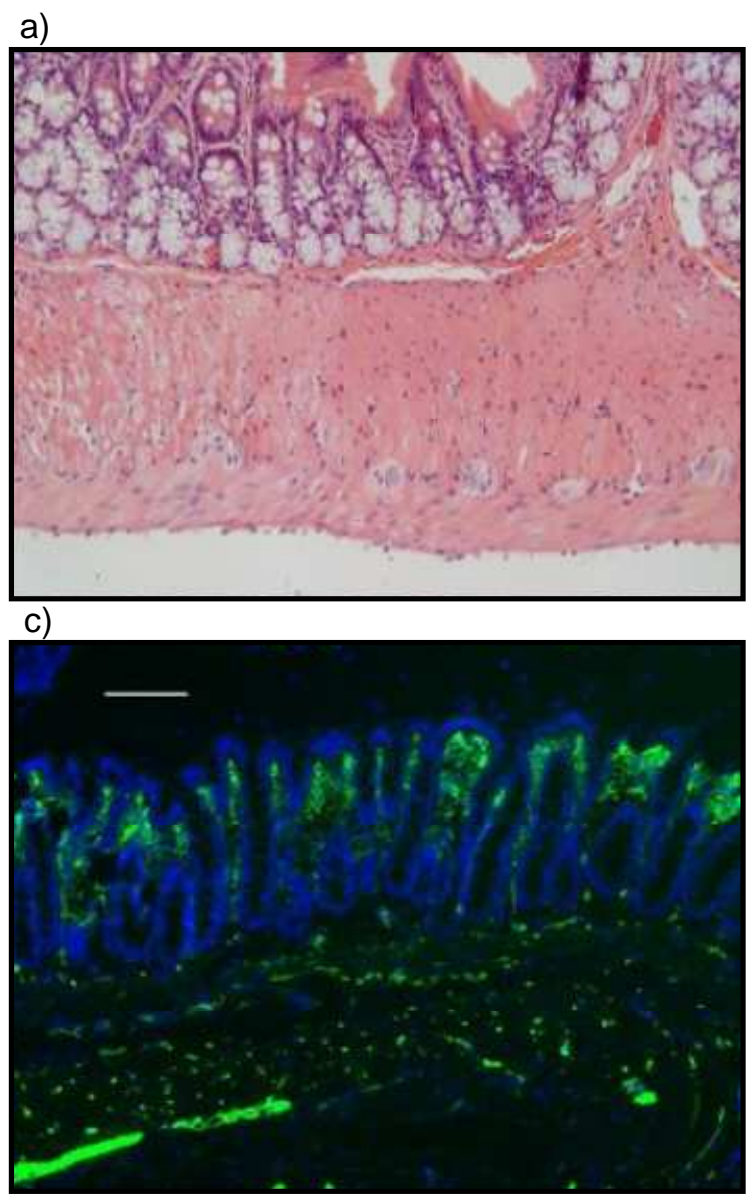

b)

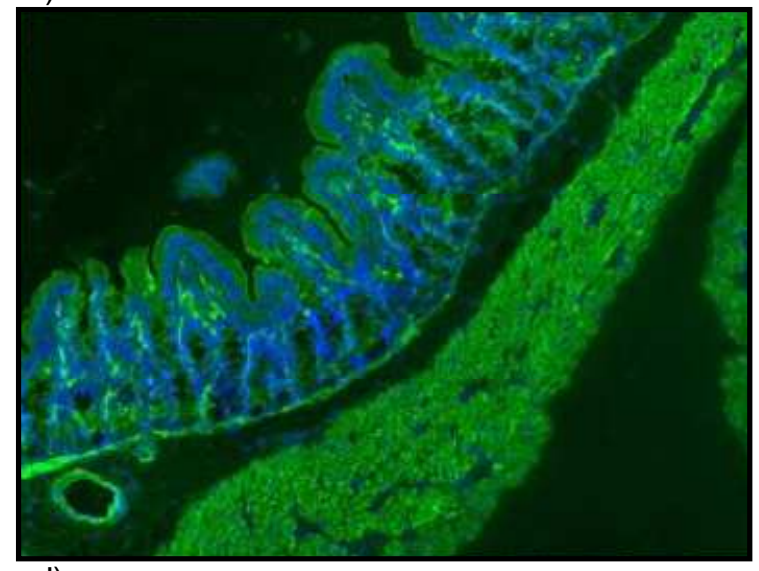

d)

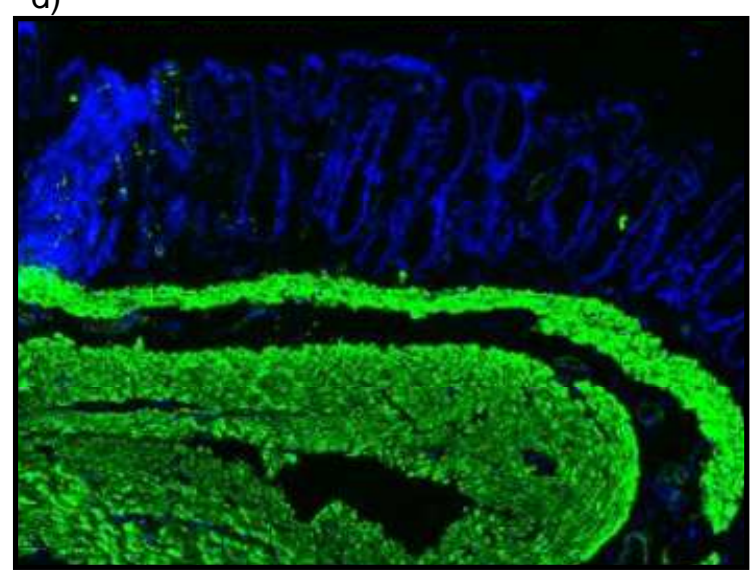

Abb. 11: Darm-Präparate, a) HE-Färbung; Fluoreszenzfärbung: b) a-SMA, c) Thy-1, d) Desmin, Vergrößerung: 100-fach, Der jeweilige Antikörper ist in Grün dargestellt. Gegenfärbung der Zellkerne mit DAPI (blau).

Die HE-Färbung (a) zeigt den typischen Wandaufbau des Verdauungskanals. Man sieht die Tunica mucosa mit der charakteristischen Kryptenarchitektur und reichlich Becherzellen. Dabei ist die Lamina muscularis mucosae klar abgrenzbar. Es folgt die Tela submucosa und die ausgeprägte Tunica muscularis. In der a-SMA-Färbung (b) ist der Wandaufbau ebenfalls erkennbar. Die Aktinfilamente der glatten Muskelzellen in der Muscularis mucosae, der Tunica muscularis sowie in den Gefäßwänden sind gut abgrenzbar. Daneben finden sich Signale unterhalb des Epithels, die die Krypten durchziehen. Ein ähnliches Muster findet sich in der Thy-1-Färbung (c). Während die Muskelanteile der Kolonwand nur noch schlecht zu erkennen sind, finden wir wieder die subepithelialen Fluoreszenzsignale. Interessanterweise sind in der 
Desminfärbung (d) neben den Muskelanteilen nur vereinzelt Signale in der Tunica mucosa zu sehen.

Magen

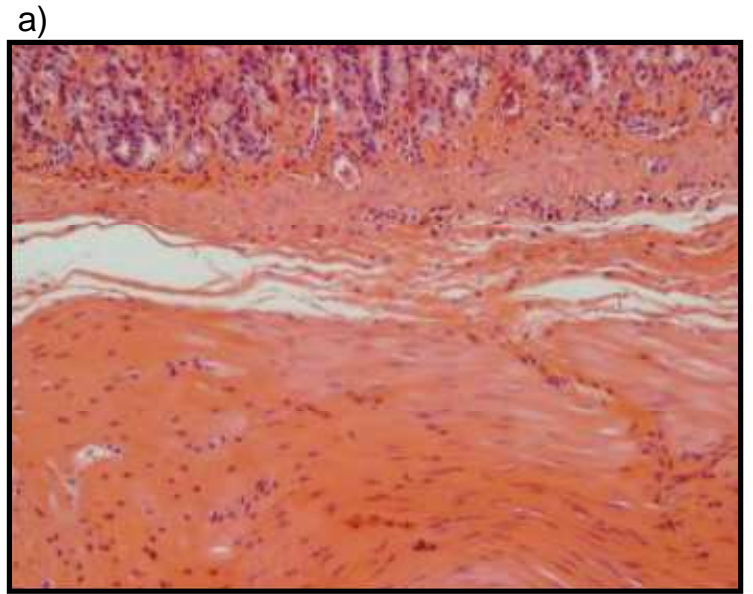

b)
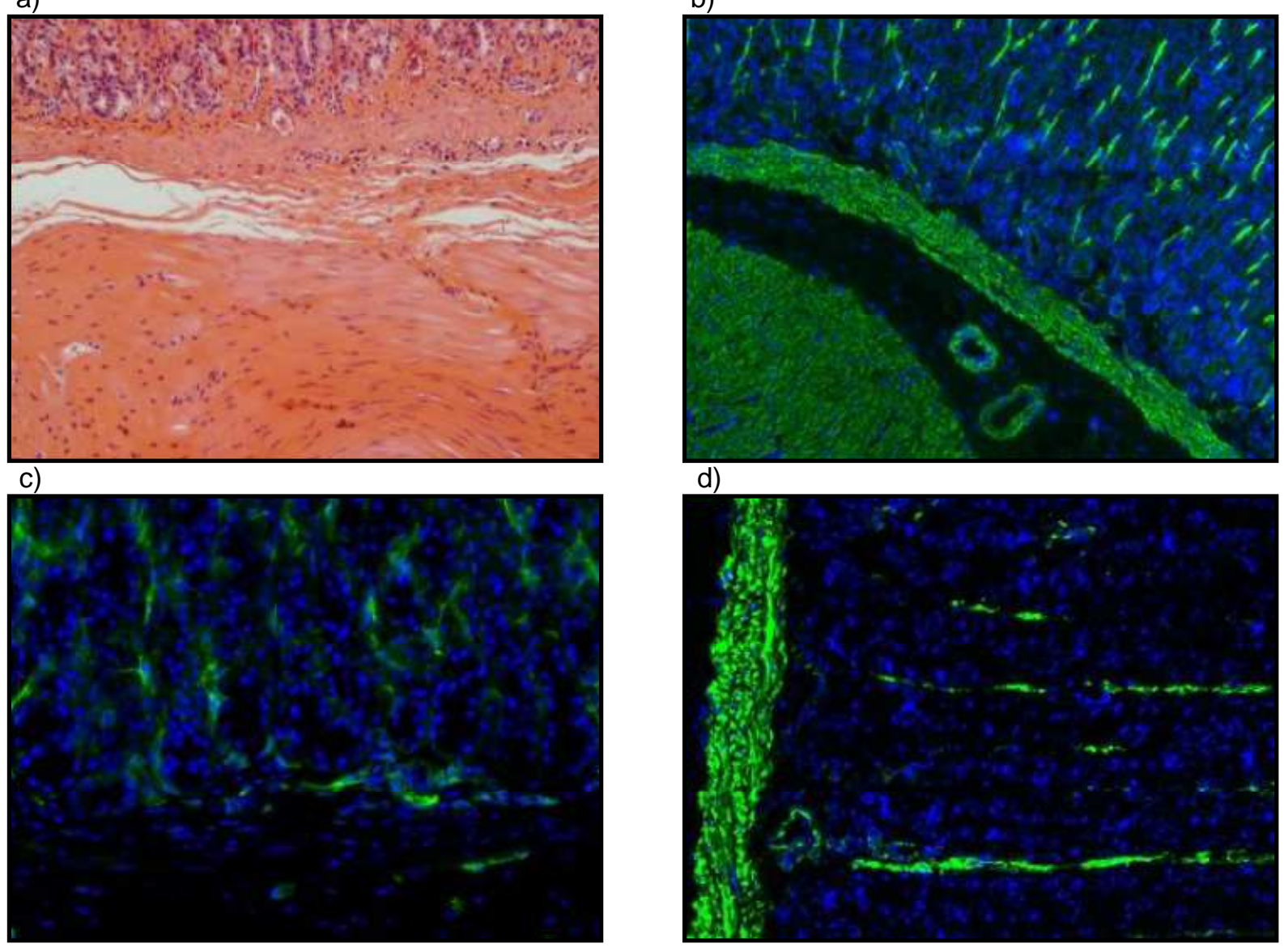

Abb. 12: Magen-Präparate, a) HE-Färbung; Fluoreszenzfärbung: b) $\alpha$-SMA, c) Thy1, d) Desmin, Vergrößerung: 100-fach (a,b,d) 200 -fach (c), der jeweilige Antikörper ist in Grün dargestellt. Gegenfärbung der Zellkerne mit DAPI (blau).

Ähnliche Beobachtungen finden wir bei der in vivo Darstellung der Magenpräparate. Der Wandaufbau entspricht im Wesentlichen dem des Kolons. In der HE-Färbung (a) sind die Tunica mucosa, die Tela submucosa und die Tunica muscularis gut erkennbar. Das Epithel wird von einer Schicht hochprismatischer Zellen gebildet. Becherzellen wie im Kolon sind nicht sichtbar. Die a-SMA-Färbung (b) zeigt neben den Muskelschichten und den Gefäßen, viele Signale in der Lamina propria 
mucosae. Die Detailaufnahme des Epithels zeigt in der Thy-1-Färbung (c) ein ähnliches Muster. Man sieht viele Fluoreszenzsignale in enger Beziehung zu den Drüsenkörpern. Subepithelial in der Desmin-Färbung (d) sehen wir neben der Muscularis mucosae vereinzelt kräftige Signale, die die Tela submucosa durchspannen.

\section{Ösophagus}

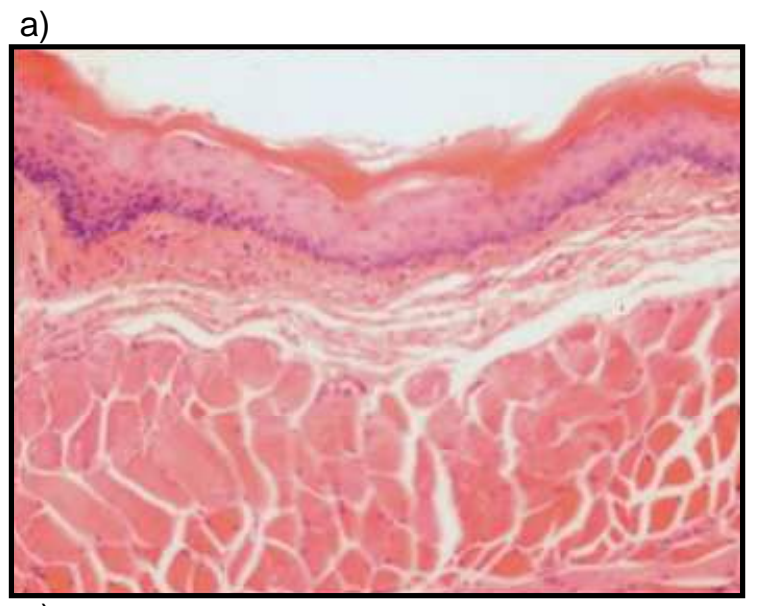

b)
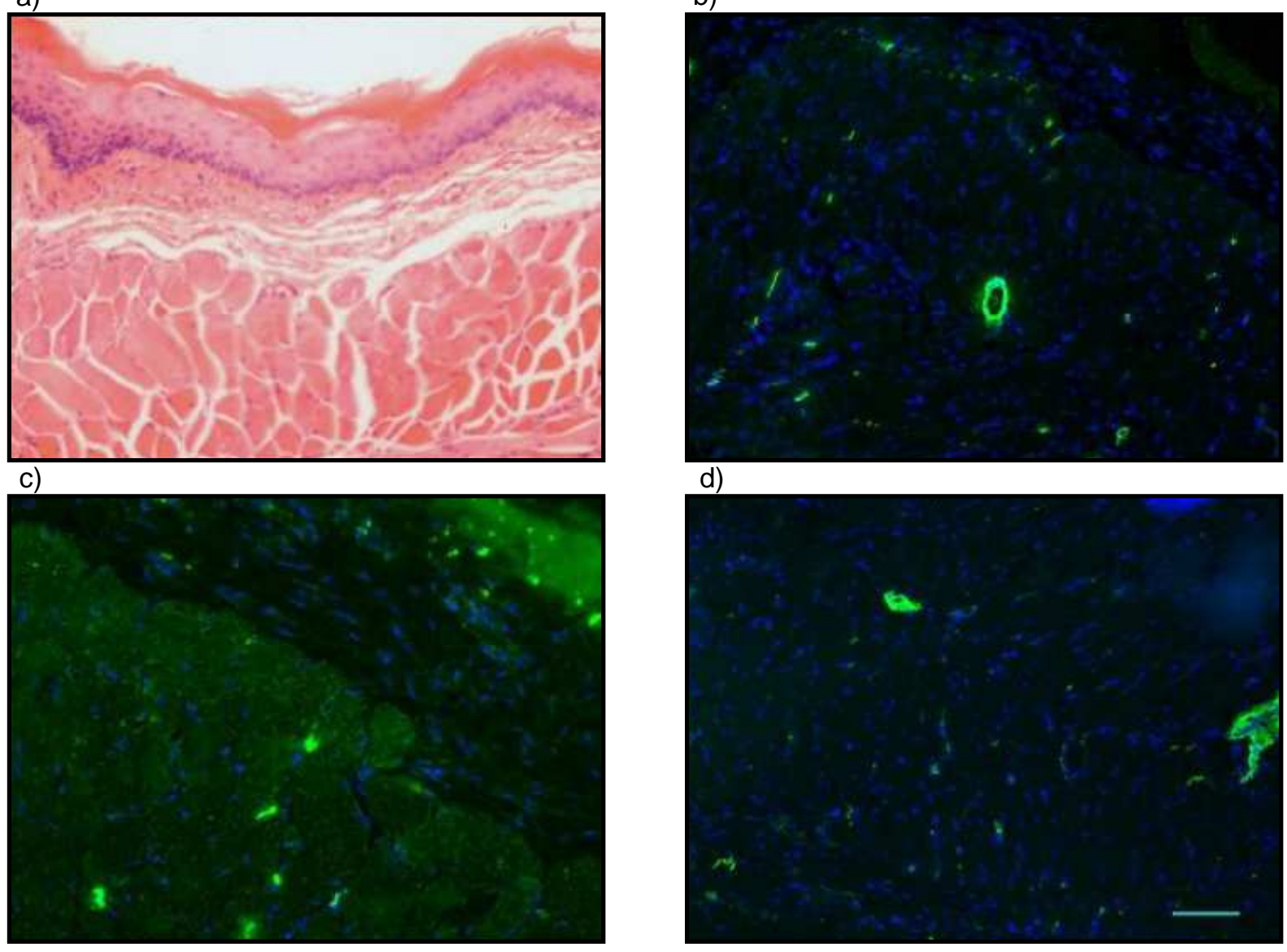

d)

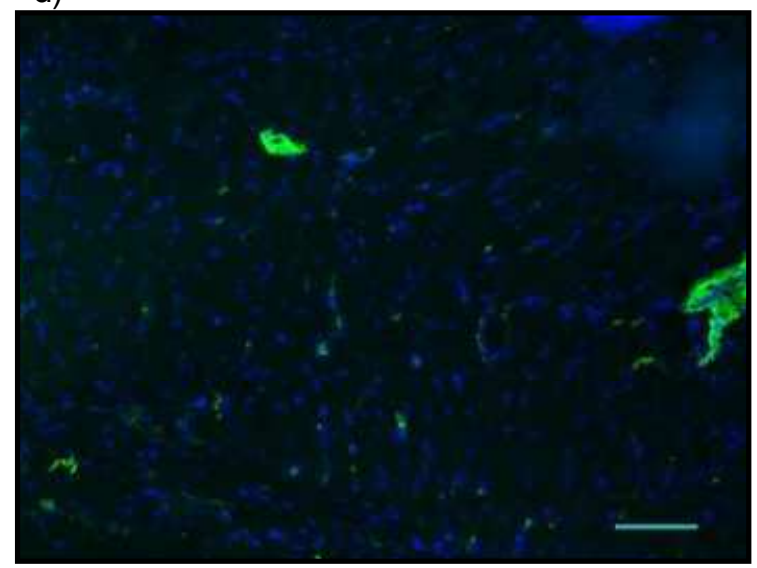

Abb. 13 Ösophagus-Präparate, a) HE-Färbung; Fluoreszenzfärbung: b) a-SMA, c) a-SMA, d) Thy-1, Vergrößerung: 100-fach (a, b, d), 200-fach (c), der jeweilige Antikörper ist in Grün dargestellt. Gegenfärbung der Zellkerne mit DAPI (blau).

Der typische Wandaufbau des Verdauungskanals ist auch im Ösophagus-Präparat sichtbar (a). Im Gegensatz zum einschichtigen Epithel des Magens und Kolons sieht man das mehrschichtig unverhornte Plattenepithel. Darunter erkennt man die Tela 
submucosa sowie eine ausgeprägte Tunica muscularis mit vielen Muskelbündeln. In der a-SMA-Färbung (b, c) finden wir nur vereinzelt Signale in den Muskelschichten. Lediglich die Gefäßstrukturen sind gut abgrenzbar. Dies lässt annehmen, dass ein proximaler Ösophaugsanteil mit vorwiegend gestreifter Muskulatur vorliegt. Die Thy-1 Färbung zeigt vereinzelt positive Zellen, ohne dass eine genaue Zuordnung zu histologischen Strukturen erfolgen kann. Einen Hinweis auf die Lokalisation der MF ergibt sich somit nicht.

Pankreas

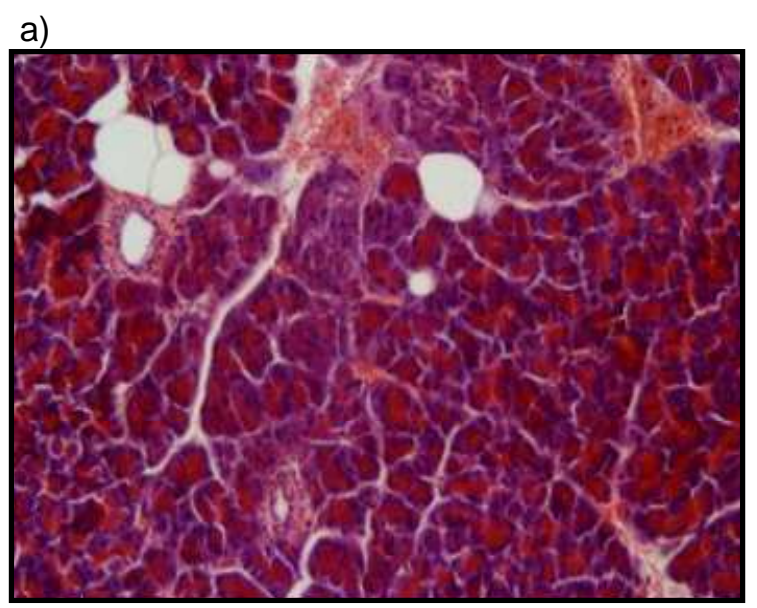

c)

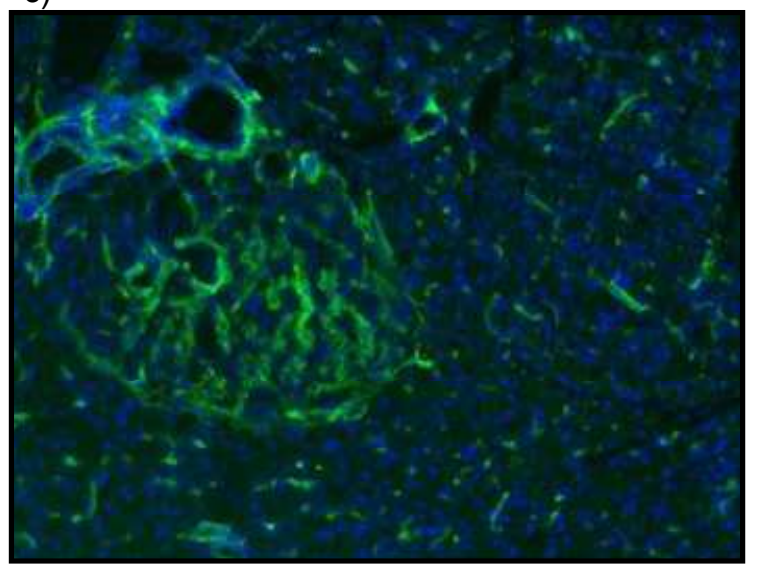

b)

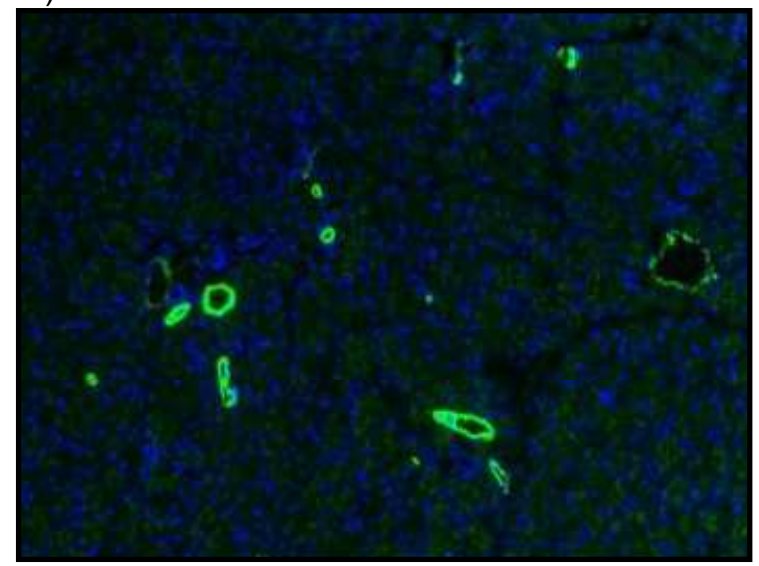

d)

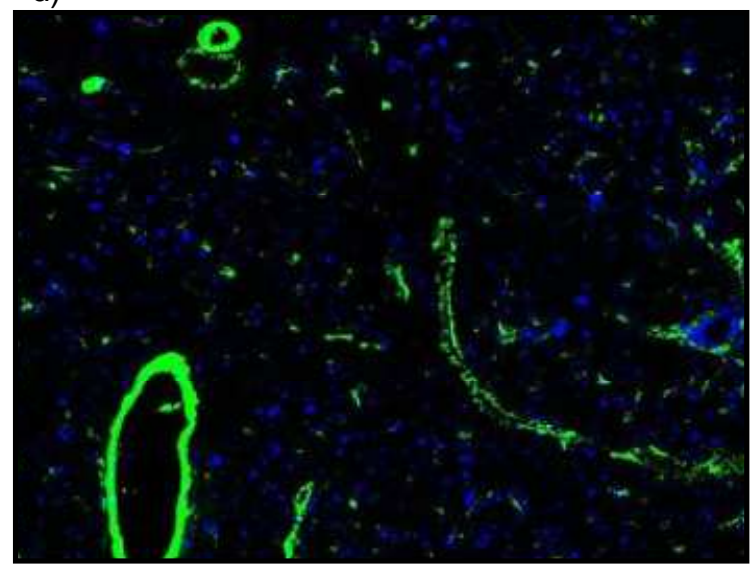

Abb. 14: Pankreas-Präparate, a) HE-Färbung; Fluoreszenzfärbung: b) a-SMA, c) Thy-1, d) Desmin, Vergrößerung: 100-fach, der jeweilige Antikörper ist in Grün dargestellt. Gegenfärbung der Zellkerne mit DAPI (blau).

Die HE-Färbung zeigt exokrine Anteile des Pankreas mit den typischen Azini und den unterschiedlichen Abschnitten der Ausführungsgänge. Daneben erkennt man 
Gefäße und Bindegewebssepten. In der a-SMA-Färbung (b) sehen wir lediglich Signale im Bereich der Ausführungsgänge und Gefäße. Die Thy-1-Darstellung (c) zeigt außerdem einen endokrinen Anteil des Pankreas mit einer Langerhans-Insel. Das Fluoreszenzmuster ist hier im endokrinen Anteil besonders deutlich ausgeprägt. Im exokrinen Anteil sehen wir eine diffuse Verteilung der Signale. Sowohl entlang der Ausführungsgänge als auch periazinär sind einzelne Fluoreszenzsignale auszumachen. In der Desmin-Färbung (d) sind die Gefäße und Ausführungsgänge deutlich abgrenzbar, aber auch innerhalb der einzelnen Lobuli sind Signale zu erkennen.

Leber

a)

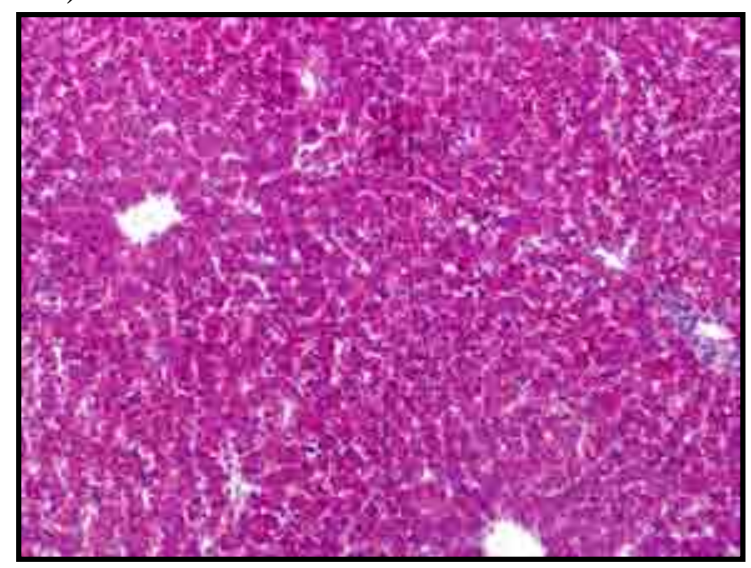

c)

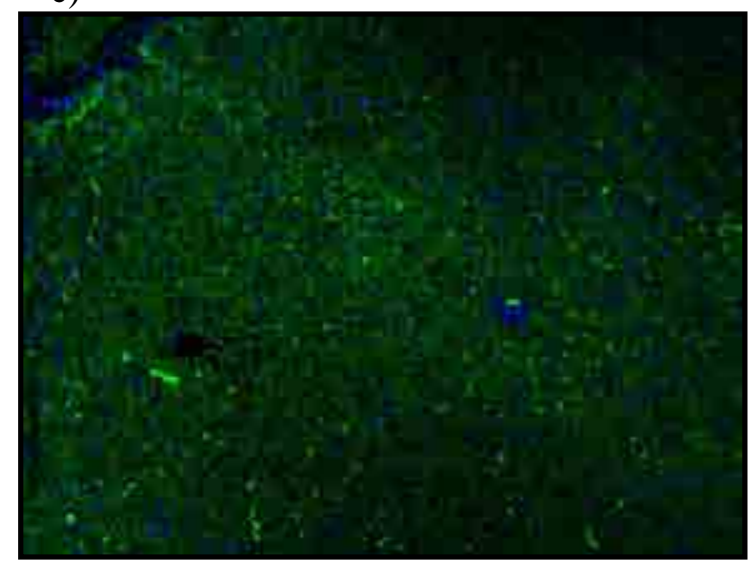

b)

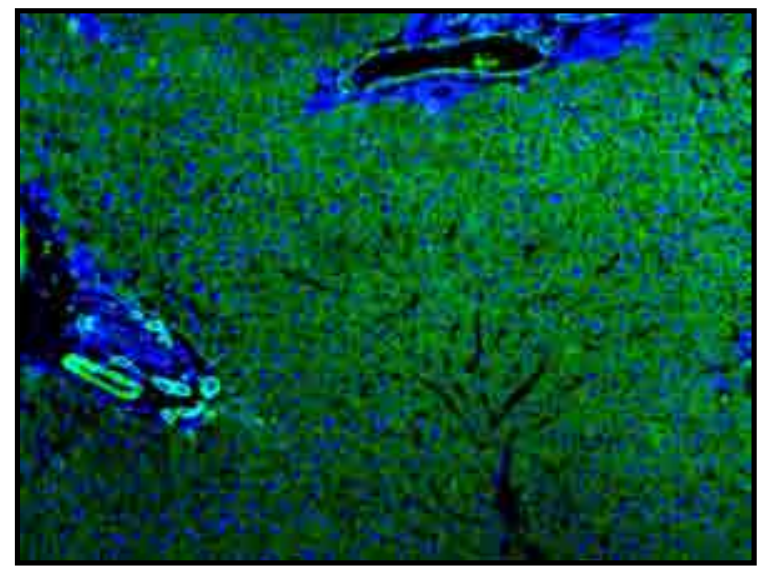

d)

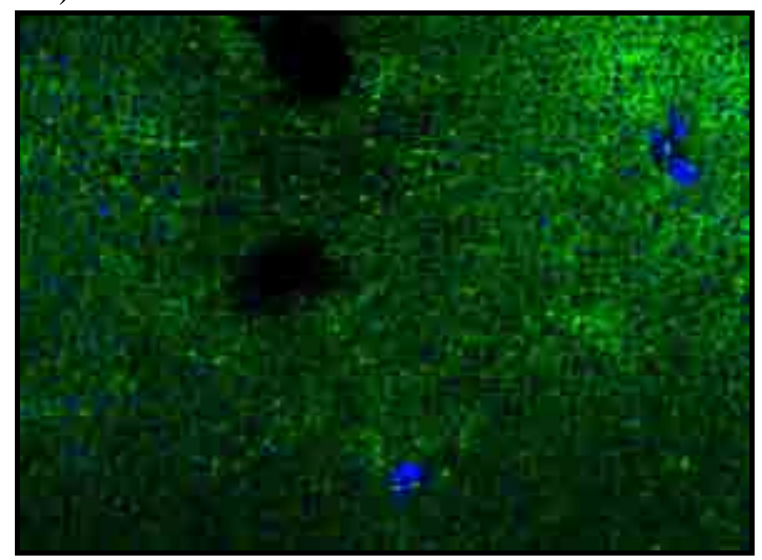

Abb. 15: Leber-Präparate, a) HE-Färbung; Fluoreszenzfärbung: b) a-SMA, c) Thy-1, d) Desmin, Vergrößerung: 100-fach, der jeweilige Antikörper ist in Grün dargestellt. Gegenfärbung der Zellkerne mit DAPI (blau). 
Das lichtmikroskopische Präparat zeigt die charakteristische Leberarchitektur mit Portalfeldern und Zentralvenen sowie den zuführenden Sinusoiden (a). In der $\alpha$ SMA-Färbung sehen wir hauptsächlich Signale im Bereich der vaskulären Strukturen. Das übrige Leberparenchym zeigt nur vereinzelt Fluoreszenzen (b). Ein ähnliches Bild zeigt die Thy-1-Färbung. Abzugrenzen vom eher diffusen Fluoreszenzmuster sind lediglich die Portalfelder sowie die Bindegewebssepten (c). Auch die Desmin-Färbung lässt Portalfelder und Zentralvenen erkennen, jedoch ohne dass die Fluoreszenzsignale einzelnen Strukturen zugeordnet werden können (d). 


\subsection{Ergebnisse Elektronenmikroskopie}

Die elektronenmikroskopische Darstellung der MF erfolgt mit der Fragestellung, inwiefern die postulierten Eigenschaften (Kontraktilität, Modulation der Immunantwort, Aufbau der Extrazellularmatrix usw.) auch ultrastrukturell nachvollzogen werden können. Natürlich ist die Aussagekraft einer rein optischen Darstellung eingeschränkt, sie dient jedoch der Untermauerung der bisherigen Ergebnisse.

Darm-MF

a)

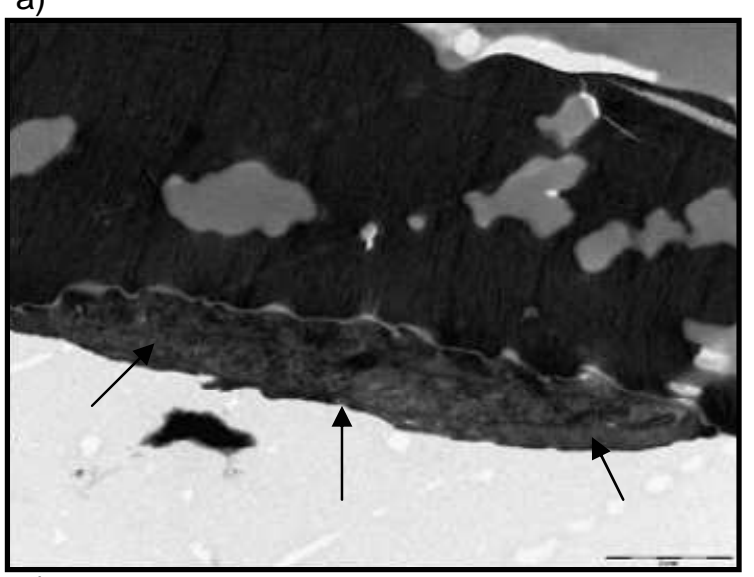

c)

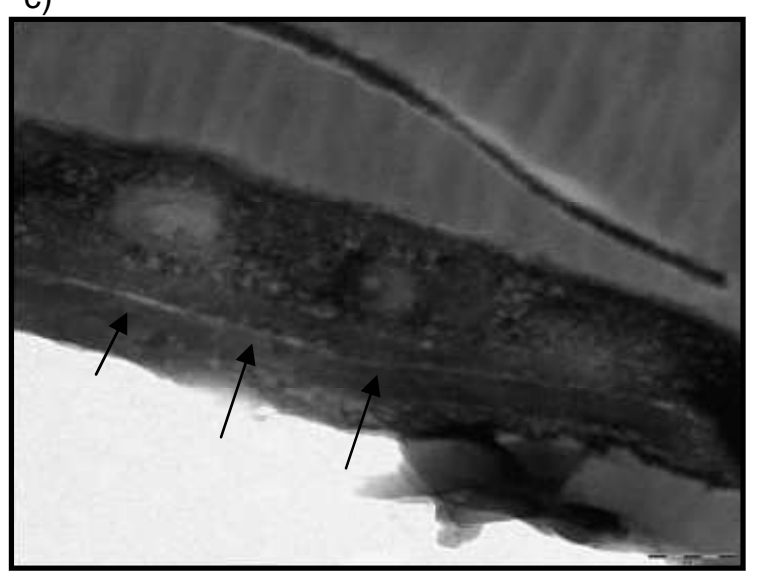

b)

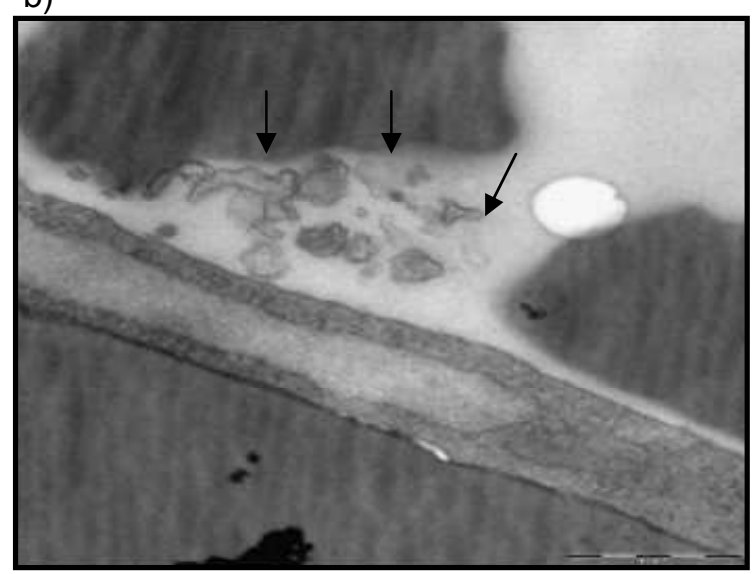

d)

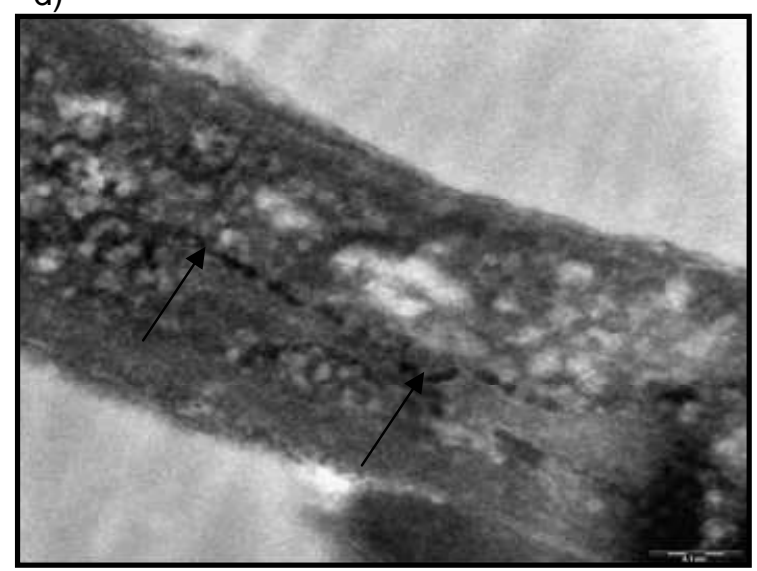

Abb. 16: EM-Darstellung Darm-MF, Osmiumtetroxidfärbung

Die Übersichtsaufnahme zeigt einen Darm-MF in Angrenzung zu Resten des LRGold-Kunststoffs (a). Die Zelle erscheint länglich, viele Zellausläufer sind in dieser 
Schnittrichtung jedoch nicht sichtbar. Bemerkenswert hier ist der verhältnismäßig große Zellkern im Vergleich zum Zytoplasma, hinweisend auf eine hohe Transskriptionsaktivität. Dementsprechend finden sich bei höherer Vergrößerung neben den Zellen reichlich Vesikel (b). Weiterhin sieht man Aktinfilamente, welche die Zellkörper durchspannen, und viel rER (c,d).

\section{Ösophagus-MF}
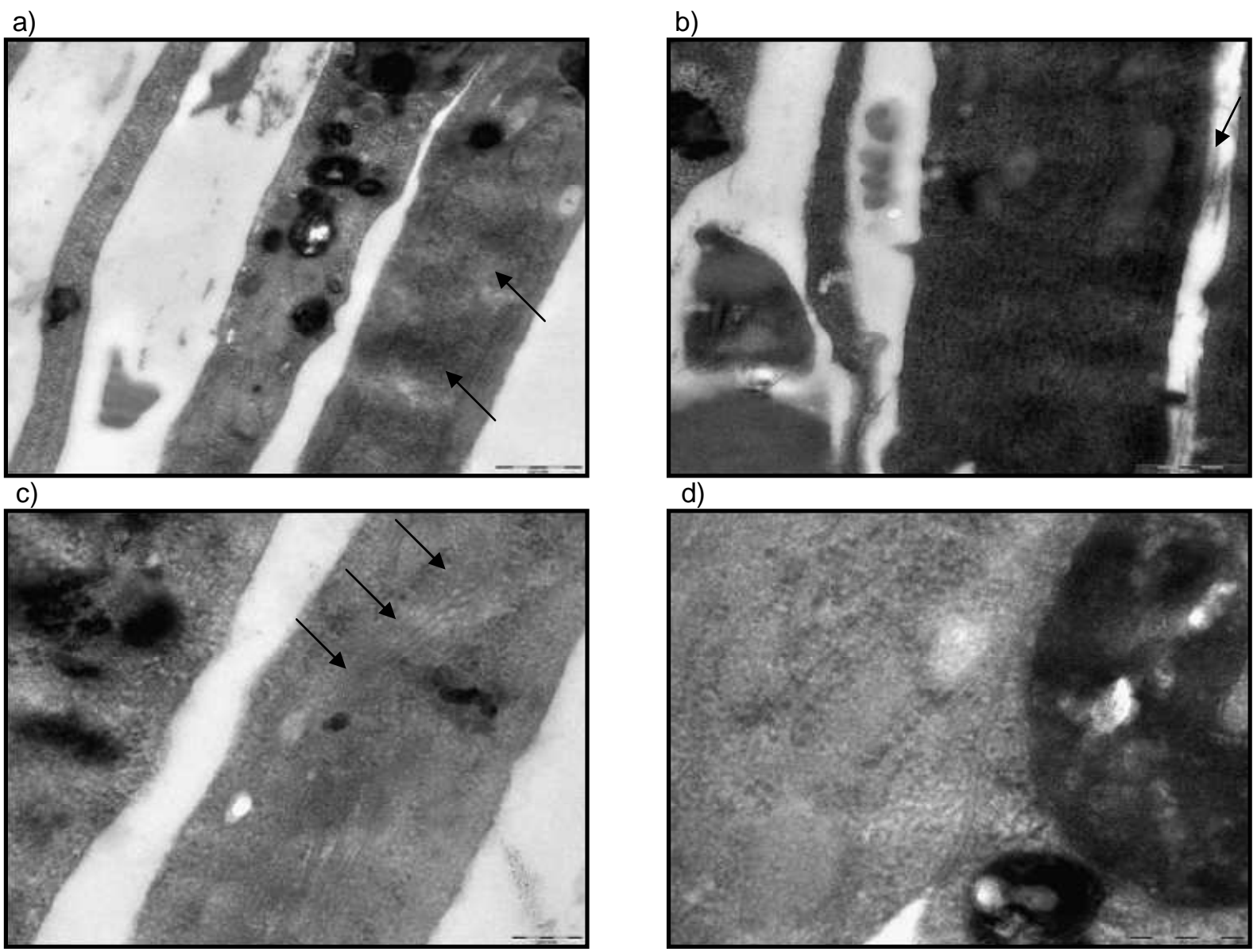

Abb. 17: EM-Darstellung Ösophagus-MF, Osmiumtetroxidfärbung

Die MF des Ösophagus imponieren ebenfalls länglich (a). Man erkennt deutlich den großen Zellkern und bei höherer Vergrößerung sehr viel rER bzw. die aufgereihten Ribosomen (b). Die kontraktilen Filamente scheinen an der Längsachse des Zellkörpers ausgerichtet zu sein (c). Des Weiteren sieht man einen engen 
Zellkontakt, welcher der Kommunikation dienen könnte (d). Extrazellulär sind vereinzelt Bündel von Filamenten erkennbar.

Magen-MF

a)

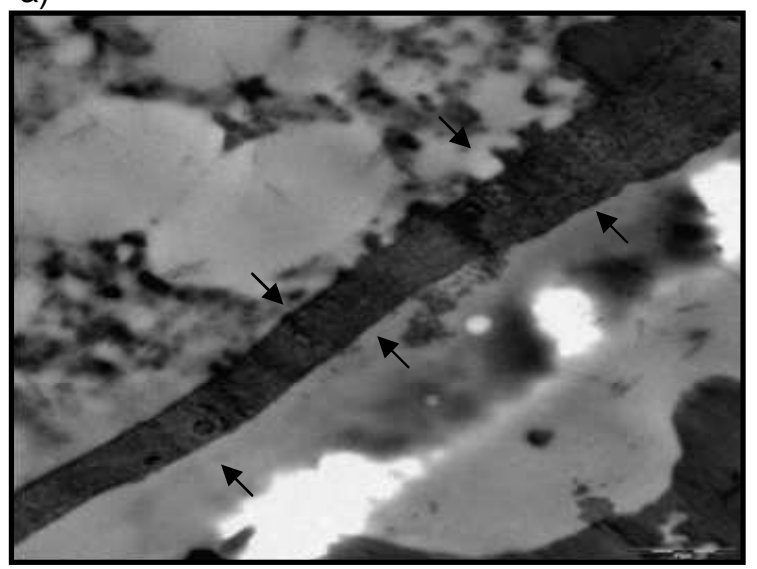

c)

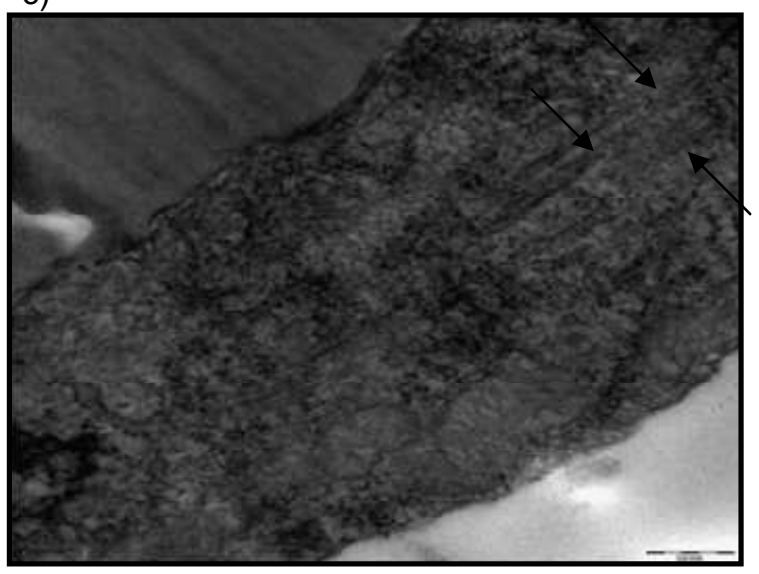

b)

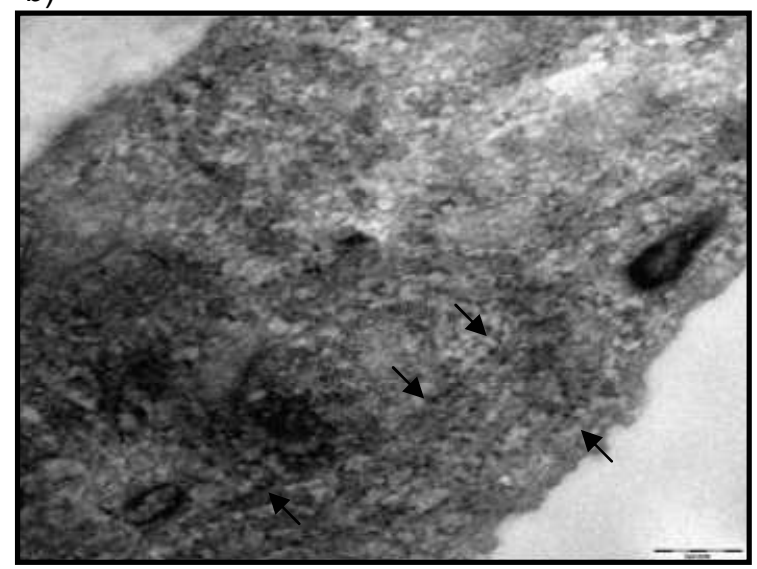

d)

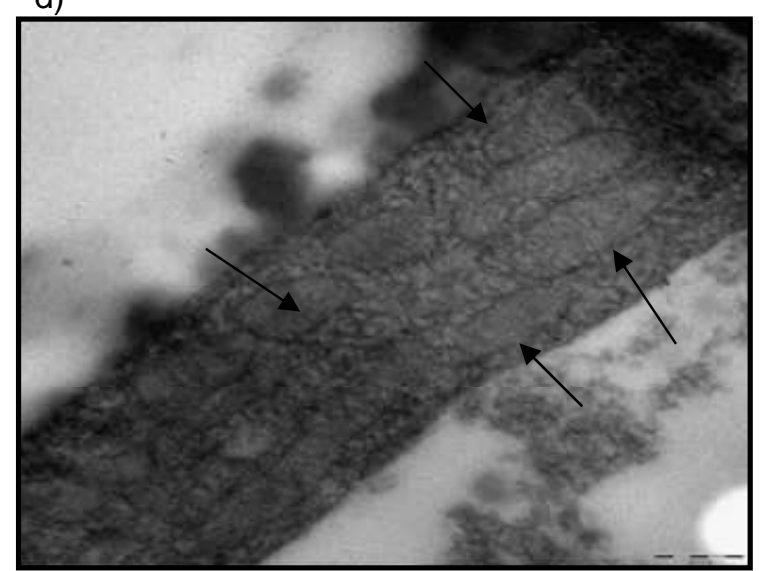

Abb. 18: EM-Darstellung Magen-MF, Osmiumtetroxidfärbung

Die Magen-MF weisen auch die bekannte, längliche Morphologie auf (a). Wiederum ist reichlich $\mathrm{rER}$ sichtbar (b). Dazwischen erkennt man außerdem vereinzelt Filamente (c). Auffällig ist daneben eine Vielzahl von Mitochondrien (d). 
a)
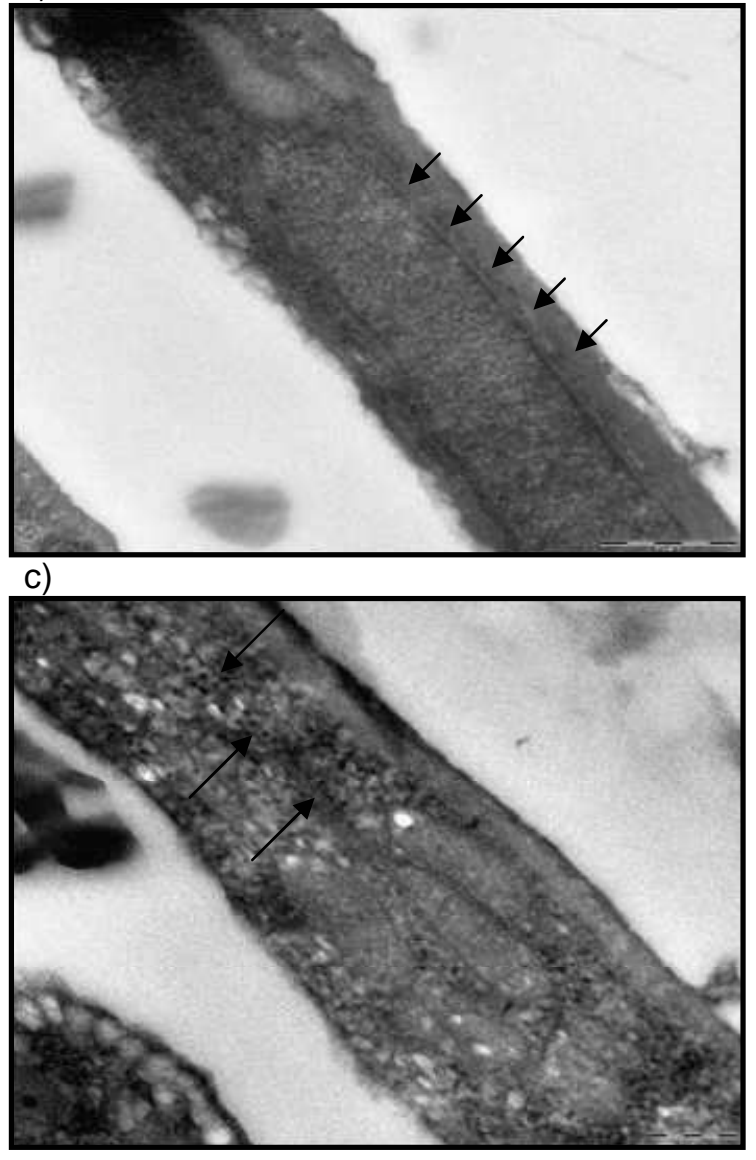

b)

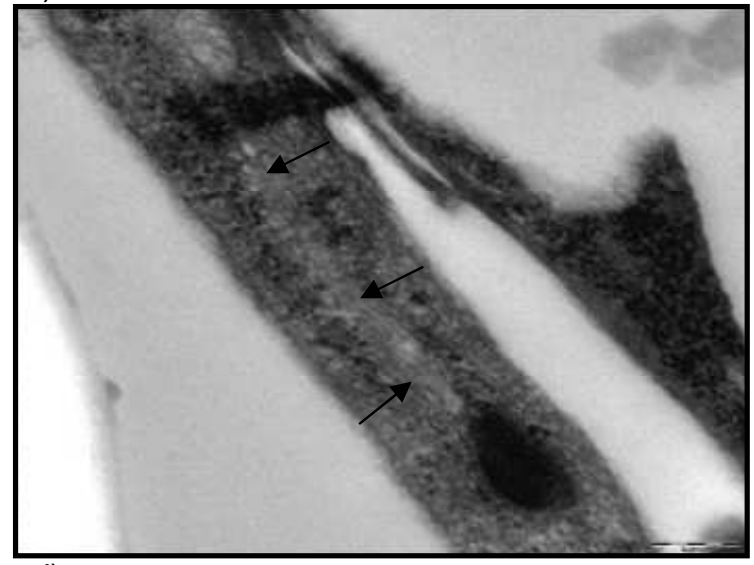

d)

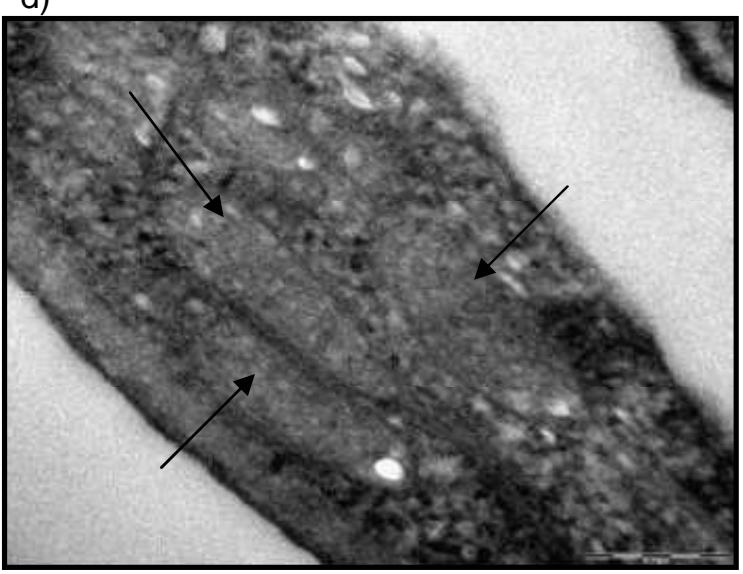

Abb. 19: EM-Darstellung Pankreas-MF, Osmiumtetroxidfärbung

Auch die Pankreas-MF zeigen einen schlanken Zellkörper sowie einen prominenten Zellkern. An der Zellmembran sieht man extrazelluläre Filamente (a). Auch intrazellulär erkennt man streifig wirkende Filamente sowie rER (b, c). Die zahlreichen Zellorganellen entsprechen Mitochondrien (d). 

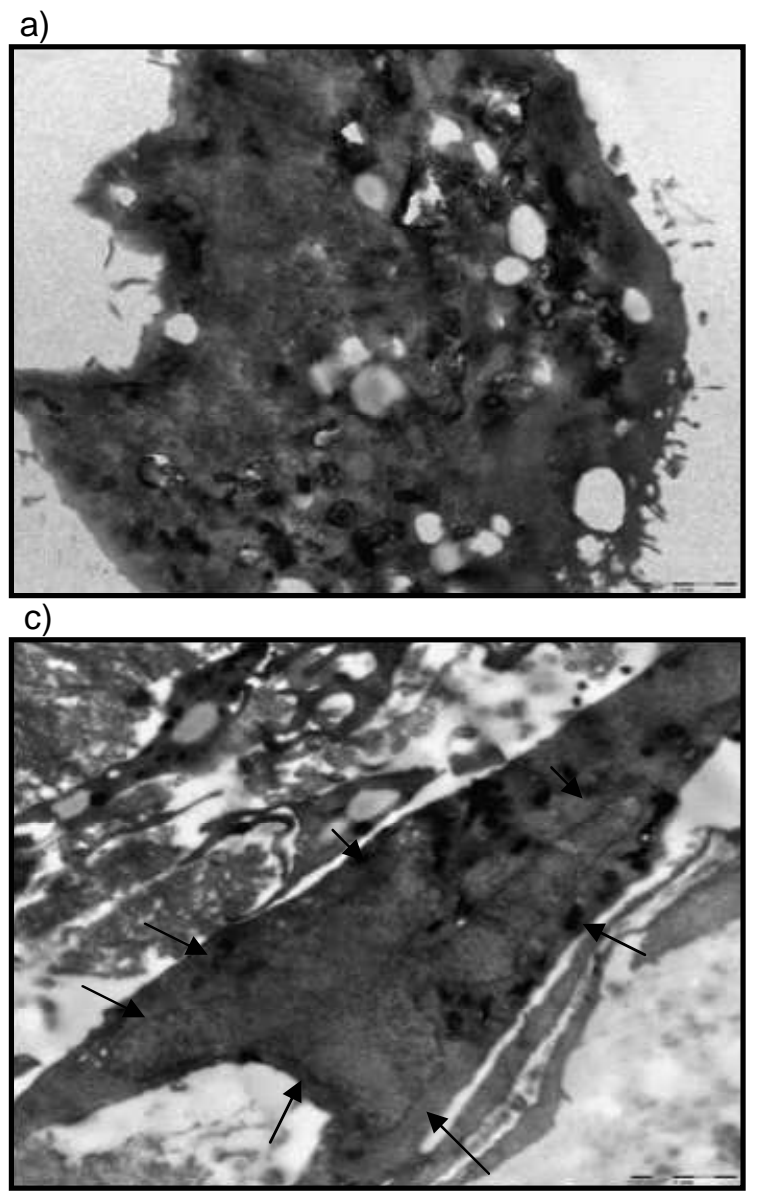

b)

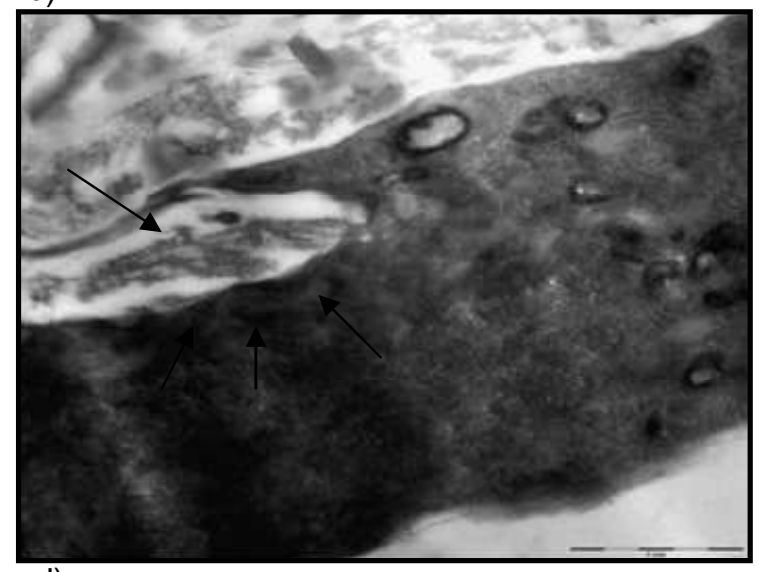

d)

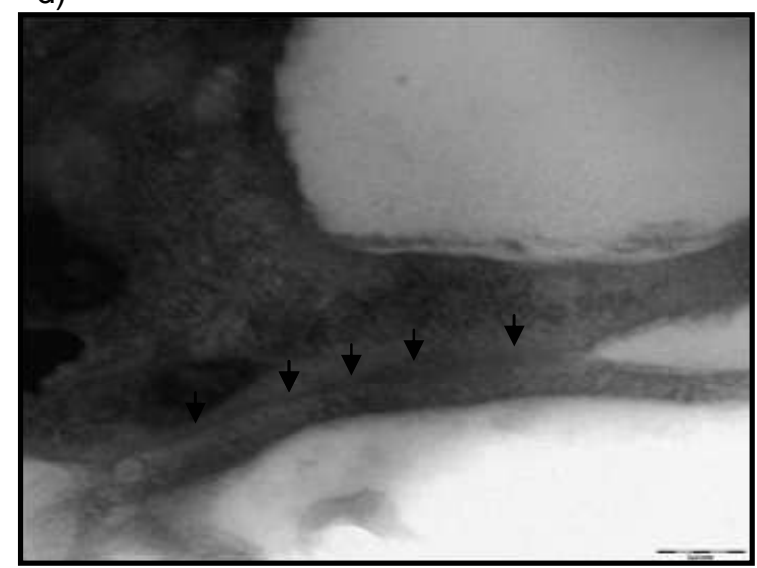

Abb. 20: EM-Darstellung Leber-MF, Osmiumtetroxidfärbung

Im Gegensatz zu den übrigen Zellreihen konnte bei den Leber-MF eine Zelle in einer anderen Schnittebene dargestellt werden (a). Entlang der Zellmembran sind zahlreiche exophytisch wirkende Zellausläufer sichtbar. Die Zelle befindet sich offenbar in Apoptose. Man erkennt außerdem Reste von Zellorganellen und viele Vakuolen, bei denen es sich um Autophagosomen handeln könnte. Eine weitere Abbildung zeigt einen Fibronexus mit extrazellulärem Kollagen (b). In der Übersichtsaufnahme imponiert der große Zellkern der beinahe den gesamten Zellkörper ausfüllt (c). Außerdem erkennt man bei hoher Vergrößerung zwei Zellausläufer in enger räumlicher Beziehung im Sinne eines Zellkontakts sowie einige Filamente $(d)$.

Die Elektronenmikroskopie stützt die bisherigen Beobachtungen an den verschieden Zellpopulationen. Die charakteristischen Merkmale der MF in Bezug auf Morphologie, 
Zytoskelett und Zellorganellen werden auch ultrastrukturell nachgewiesen. Wesentliche Unterscheidungsmerkmale können so jedoch nicht gefunden werden.

\subsection{Ergebnisse Western-Blot}

Zur weiteren Validierung der vorangegangenen Beobachtungen wird bei einem weiteren Experiment der Proteinnachweis einzelner Marker angestrebt. Dabei werden die gleichen Marker ( $\alpha-S M A$, Thy-1, Desmin) wie für die Fluoreszenzmikroskopie verwendet. Lassen sich die Ergebnisse somit objektivieren? Als Kontroll-Protein dient das B-Aktin, welches in jeder Kultur nachweisbar sein sollte.
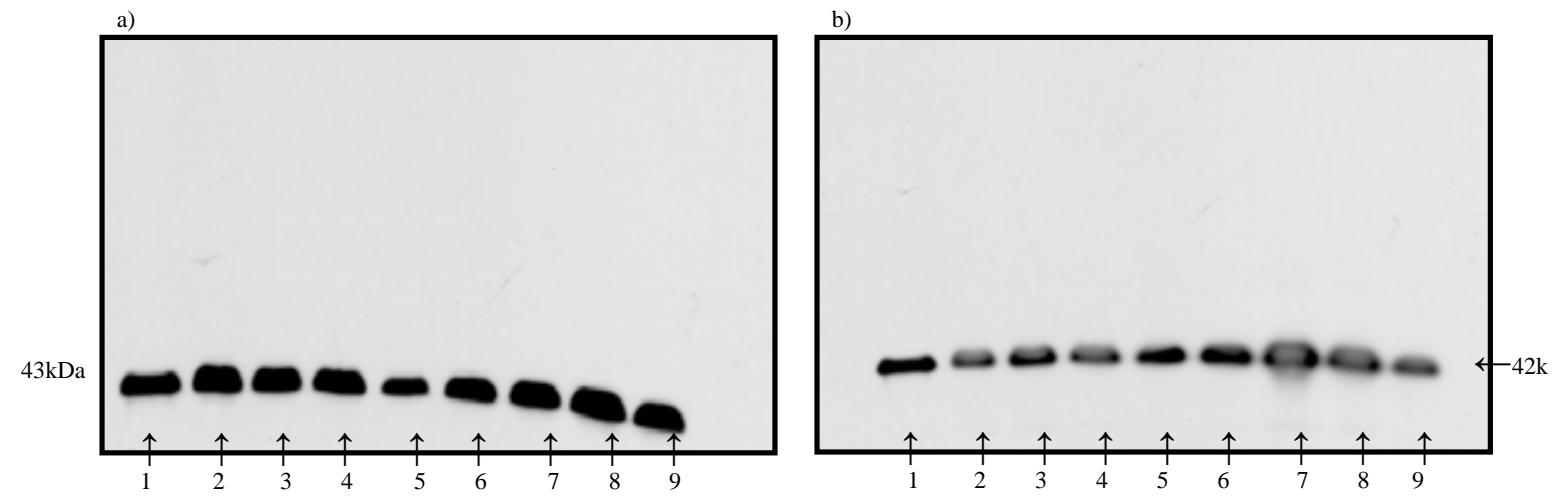

Abb. 21: Western-Blot, a) B-Aktin (1:1000) Belichtungszeit 60s; b) a-SMA (1:1000) Belichtungszeit 30s; (1)(2) Ösophagus; (3) Magen; (4) Pankreas; (5) Darm; (6)(7)(8) Ösophagus; (9) Leber;

Wir sehen im Kontrollblot (a) bei jeder Probe eine deutliche Bande im Bereich von $43 \mathrm{kDa}$, entsprechend dem B-Aktin. Der zweite Blot (b) zeigt für die verschiedenen Proben eine Bande im Bereich von $42 \mathrm{kDa}$, welche dem a-SMA zuzuordnen ist. Erwartungsgemäß gelingt der qualitative Nachweis von $\alpha$-SMA in den unterschiedlichen Kulturen. 

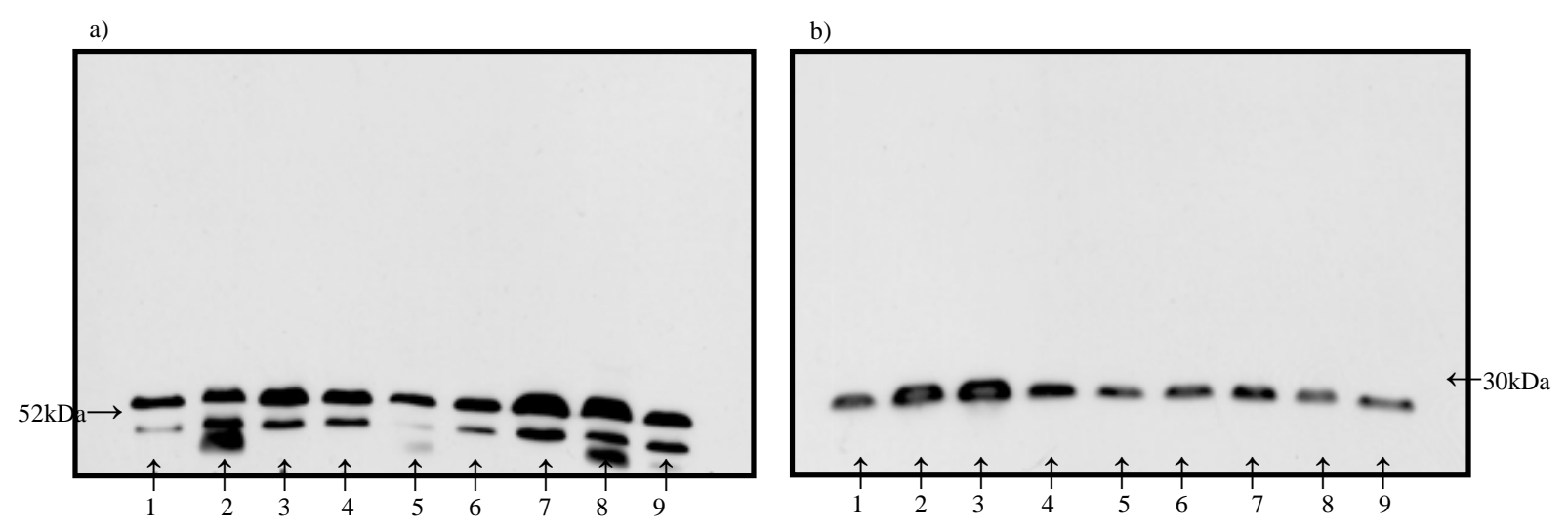

Abb. 22: Western-Blot ,a) Desmin (1:400) Belichtungszeit 60s; b) Thy-1 (1:100) Belichtungszeit 30s; (1)(2) Ösophagus; (3) Magen; (4) Pankreas; (5) Darm; (6)(7)(8) Ösophagus; (9) Leber;

Auch der Nachweis von Desmin (a) bzw. Thy-1 (b) gelingt. Die Banden bei $52 \mathrm{kDa}$ entsprechen hierbei dem Desmin. Die leichteren Banden sind am ehesten Degradiationsprodukten zuzuschreiben. Nach kurzer Belichtungszeit findet sich das Thy-1-Protein im Bereich von 30kDa.

In allen MF aus den unterschiedlichen Organen lassen sich also, die zu untersuchenden Proteine nachweisen. Objektive Unterschiede zwischen den verschiedenen Zellpopulationen können weder fluoreszenzmikroskopisch noch mithilfe des Western-Blots gefunden werden.

\subsection{Ergebnisse der Expressionsuntersuchung}

Für die weitere Analyse der PCR-Ergebnisse wurden die erhaltenen Daten in Beziehung zum Housekeeping-Gen (B-Aktin) (siehe 2.2.5, S. 27) gesetzt, mit der Frage, ob die Ergebnisse der Immunfluoreszenz-Mikroskopie durch die PCR verifizierbar sind. Da sich die errechnete Genexpression proportional zur Menge der mRNA verhält, ist eine quantitative Analyse möglich. Diese Analyse sollte weitere Marker hinsichtlich der Charakterisierung der MF-Kulturen zeigen. MF nehmen Einfluss auf die Zusammensetzung der Extrazellularmatrix, auf Wachstum und Differenzierung des Gewebes sowie auf die Immunantwort (Crowston et al. 1997, Desmoulière et al. 2004, Furuya and Furuya 2007). Exemplarisch wurde deshalb die Genexpression von Fibulin-1, Fibrillin-2, MIP-1, MIP-3 und MCP-3 untersucht. 
Für die Darstellung wurde eine Gliederung in Strukturproteine, Matrixproteine sowie Mediatoren bzw. Chemokine vorgenommen. Um die Darstellung zu vereinfachen wurde das Fibrillin-2 hierbei den Strukturproteinen zugeordnet.

PCR-Produkte der Darm-MF

a)

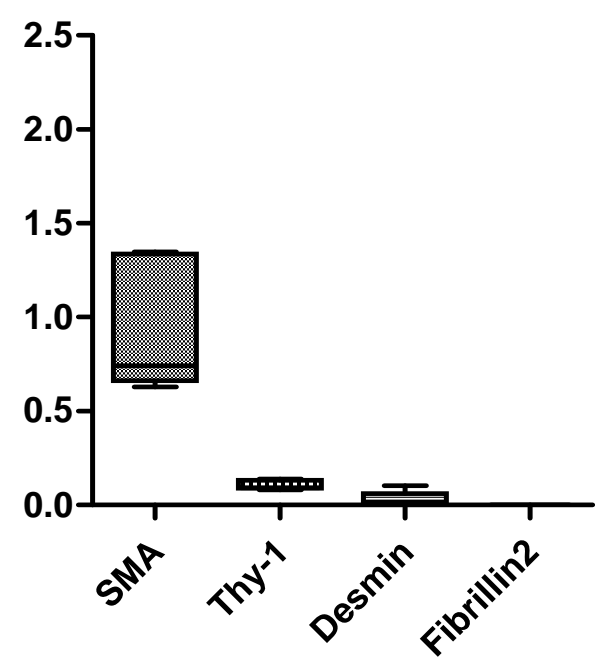

b)

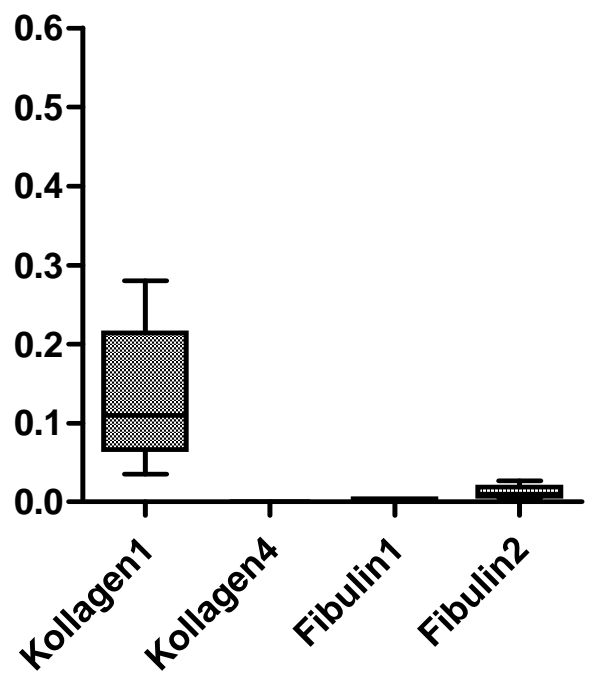


c)

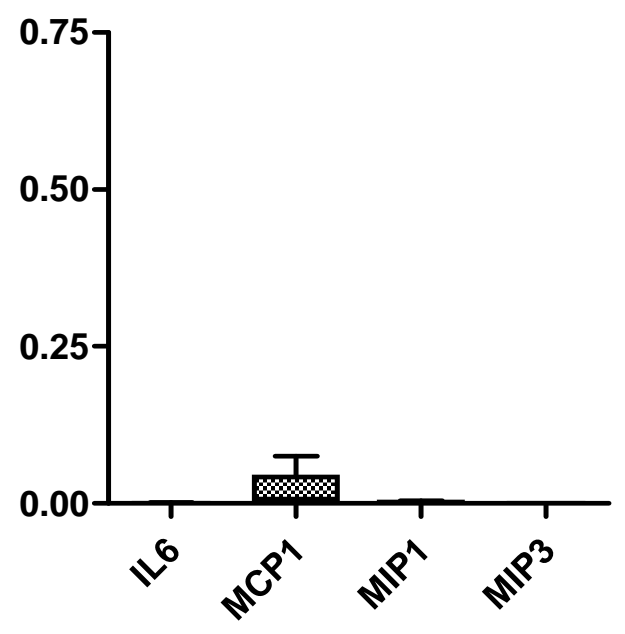

Abb. 23: Darm-MF, Genexpression nach der $\Delta$ CT-Methode, Mittelwerte und Standardabweichung,
(a) a-SMA ( $n=5)$, Thy1 ( $n=5)$, Desmin $(n=4)$, Fibrillin-2 $(n=5)$
(b) Kollagen-1 $(n=5)$, Kollagen-4 $(n=5)$, Fibulin-1 $(n=5)$, Fibulin-2 $(n=5)$,
(c) Interleukin-6 ( $n=5), \operatorname{MCP}-1 \quad(n=5), \operatorname{MIP-1}(n=5), \operatorname{MIP}-3(n=4)$,

Man sieht die Genexpression der verschiedenen Marker. Bei den Strukturproteinen ist gegenüber den anderen Markern auffallend deutlich die a-SMA-Expression ausgeprägt. Nachgewiesen werden kann darüber hinaus Thy-1 sowie Desmin. Die Beobachtung korreliert mit den Ergebnissen der Fluoreszenz-Mikroskopie. Bei den Matrixproteinen können Kollagen-1 sowie in geringem Maße Fibulin-2 detektiert werden. Bei den Chemokinen zeigt sich lediglich für das MCP-1 eine relevante Expression. 
PCR-Produkte der Ösophagus-MF

a)

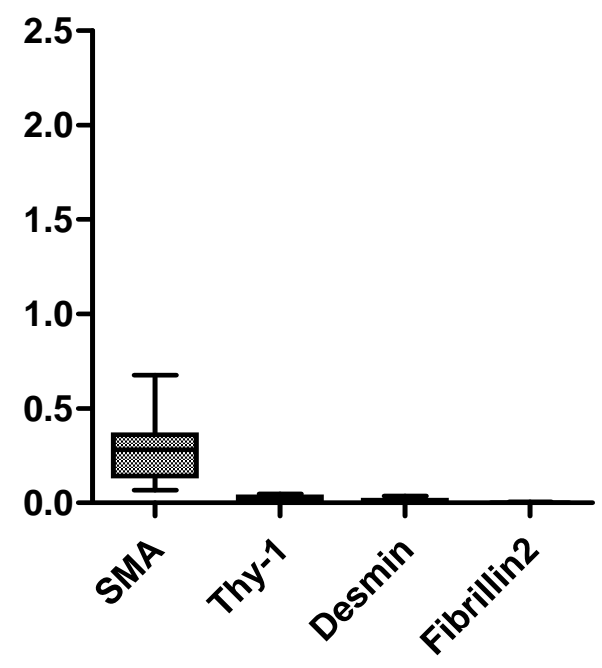

b)

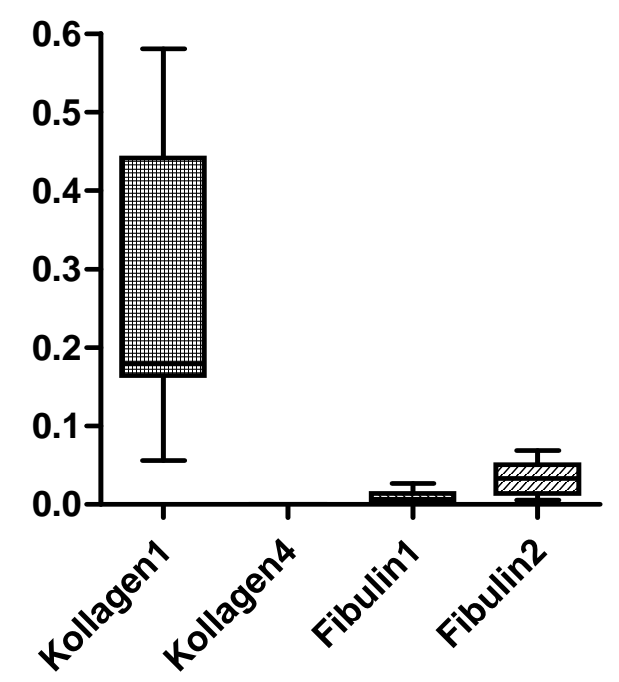

c)

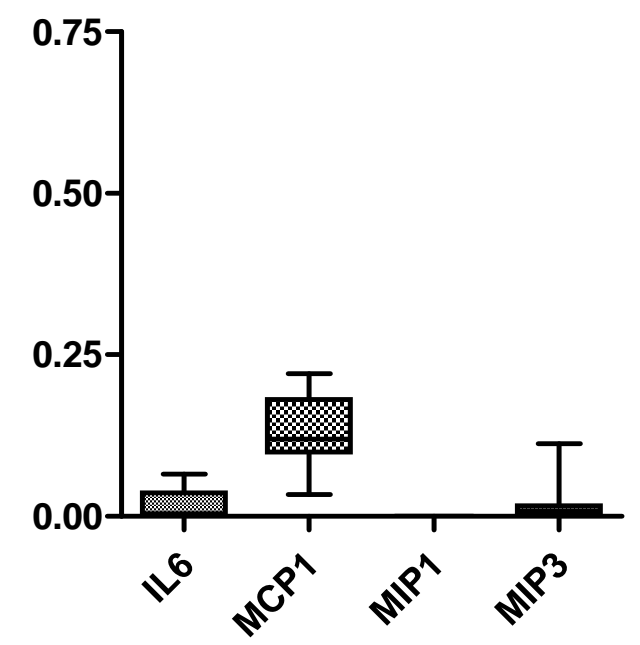


Abb. 24: Ösophagus-MF, Genexpression nach der $\Delta$ CT-Methode, Mittelwerte und Standardabweichung,
(a) a-SMA ( $n=14)$, Thy1 ( $n=14)$, Desmin ( $n=13)$, Fibrillin-2 $(n=14)$
(b) Kollagen-1 $(n=15)$, Kollagen-4 $(n=9)$, Fibulin-1 $(n=13)$, Fibulin-2 $(n=14)$
(c) Interleukin-6 ( $n=14), M C P-1$ ( $n=15), \operatorname{MIP-1}(n=8), \operatorname{MIP-3}(n=15)$,

Bei den Strukturproteinen sieht man auch hier deutlich die Expression von a-SMA. Analog zu den fluoreszenz-mikroskopischen Beobachtungen sehen wir daneben die Thy-1-Expression, sowie eine sehr geringe Desmin-Expression. Eine Expression von Fibrillin-2 findet sich nicht. Bei den Matrixproteinen zeigt sich die stärkste Expression für das Kollagen-1. Fibulin-1 und Fibulin-2 werden ebenfalls nur zu einem geringen Maß exprimiert. Bei den Mediatoren ist die Expression von MCP-1 auffallend ausgeprägt. Es zeigt sich außerdem eine IL-6-Expression.

PCR-Produkte der Magen-MF

a)

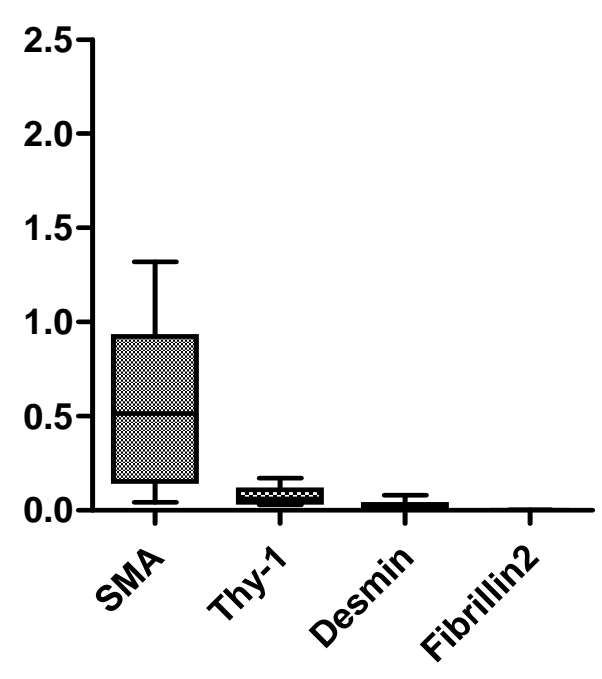


b)

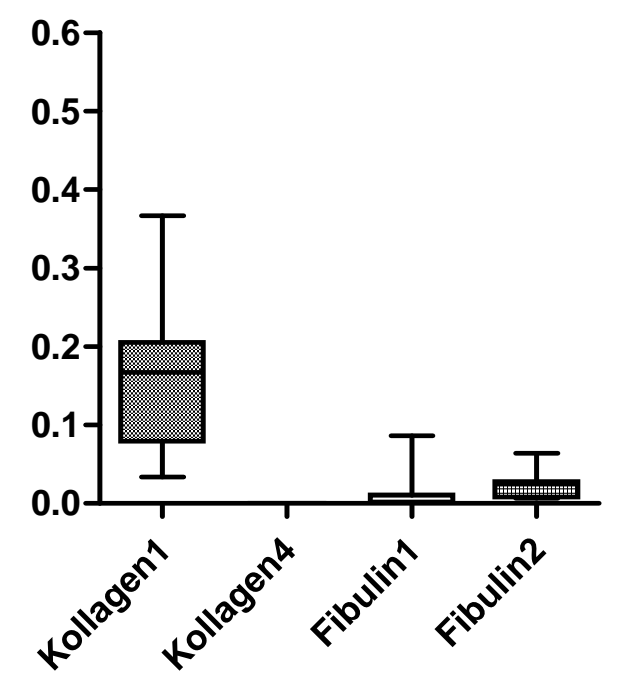

c)

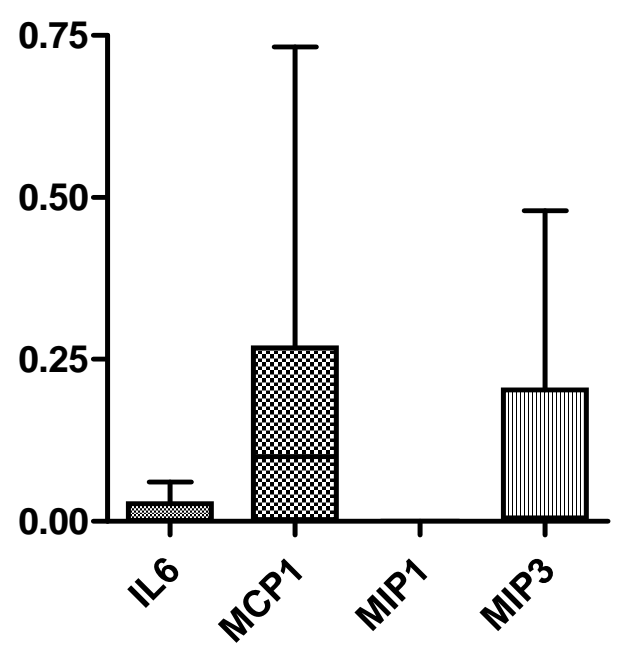

Abb. 25: Magen-MF, Genexpression nach der $\Delta$ CT-Methode, Mittelwerte und Standardabweichung,
(a) a-SMA ( $n=11)$, Thy1 $(n=11)$, Desmin $(n=10)$, ) Fibrillin-2 $(n=11)$
(b) Kollagen-1 ( $n=11)$, Kollagen-4 ( $n=11)$, Fibulin-1 $(n=11)$, Fibulin-2 $(n=11)$
(c) Interleukin-6 ( $n=10), M C P-1$ ( $n=11$,$) MIP-1 (n=9), \operatorname{MIP-3}(n=9)$,

Auch bei den Magen-MF lassen sich die bisherigen Ergebnisse reproduzieren. Die Darstellung der Strukturproteine zeigt eine ausgeprägte Expression von a-SMA. Wiederum kann eine signifikante Thy-1-Expression nachgewiesen werden, während nur wenig Desmin exprimiert wird. Bei den Matrixproteinen wird Kollagen-1 deutlich exprimiert. Vergleichsweise gering ist die Expression von Fibulin-1 und Fibulin-2. 
Bei den Chemokinen findet sich eine deutliche Expression von MCP-1 sowie MIP-1. Außerdem nachweisbar ist eine IL-6-Expression.

PCR-Produkte der Pankreas-MF

a)

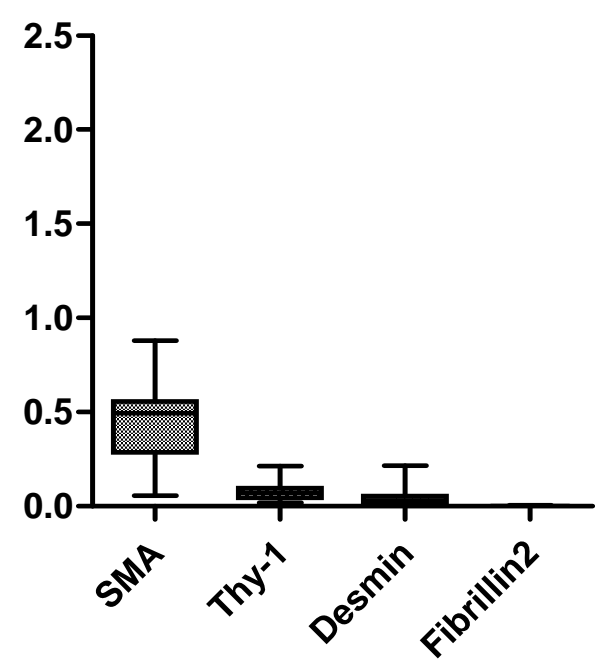

b)

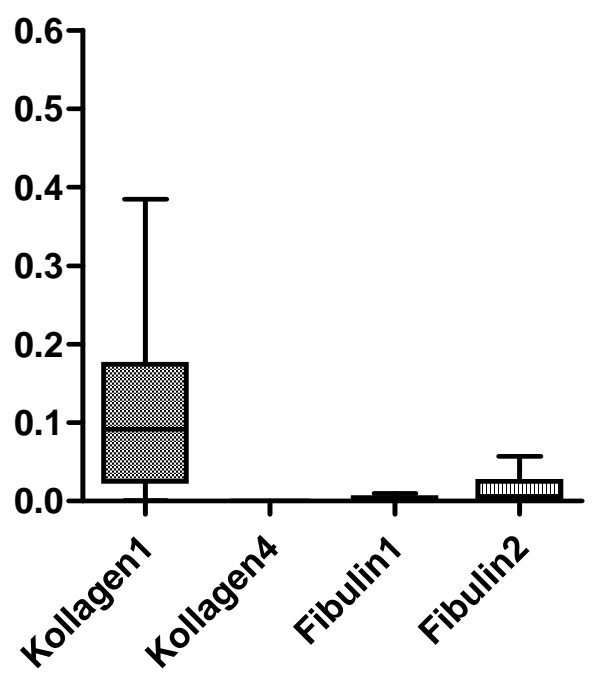


c)

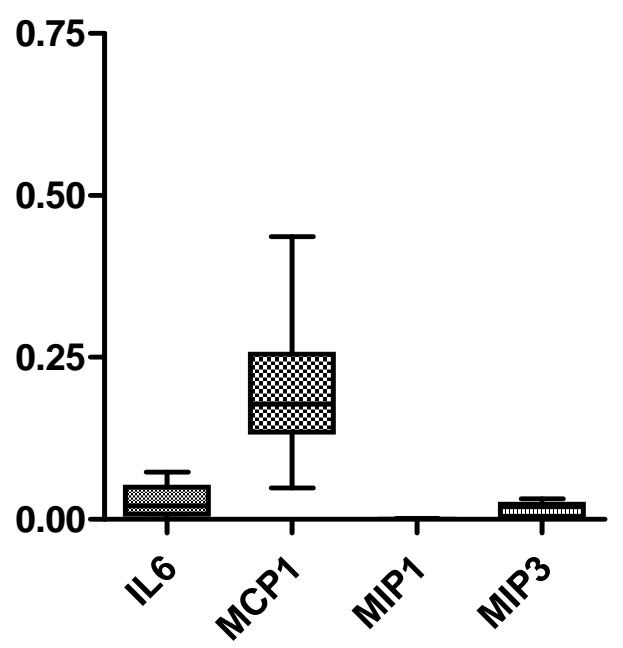

Abb. 26: Pankreas-MF, Genexpression nach der $\triangle \mathrm{CT}$-Methode, Mittelwerte und Standardabweichung,
(a) a-SMA ( $n=12)$, Thy1 ( $n=12)$, Desmin ( $n=12)$, Fibrillin-2 $(n=12)$
(b) Kollagen-1 $(n=12)$, Kollagen-4 ( $n=11)$, Fibulin-1 $(n=12)$, Fibulin-2 $(n=12)$
(c) Interleukin-6 ( $n=12), M C P-1$ ( $n=12), M I P-1$ ( $n=12), \operatorname{MIP-3}(n=11)$

Das Genexpressionsmuster der Pankreas-MF ähnelt den Zellpopulationen der anderen Organe. Bei den Strukturproteinen findet sich auch hier die charakteristische a-SMA-Expression. Ebenfalls ist eine Thy-1-Expression nachweisbar. Daneben wird wenig Desmin exprimiert. Die Darstellung der Matrixproteine zeigt eine Expression von Kollagen-1 und Fibulin-2. Bei den Mediatoren findet sich neben dem IL-6 und MIP-3 eine deutlich ausgeprägte MCP-1-Expression. 
PCR-Produkte der Leber-MF

a)

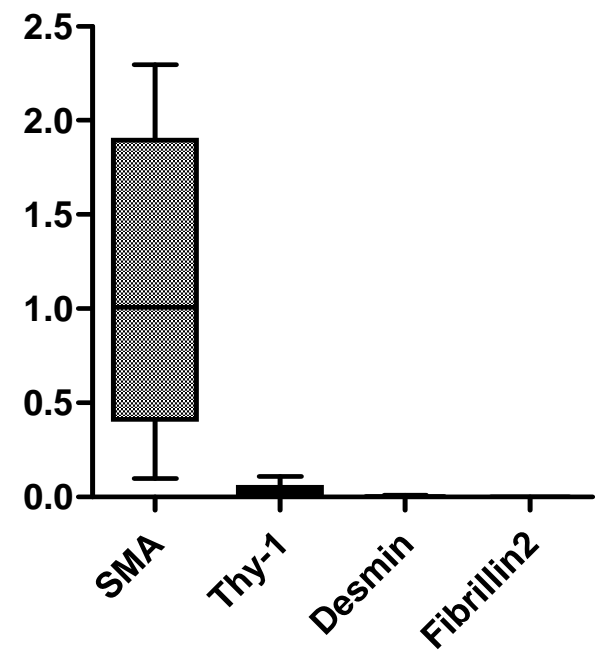

b)

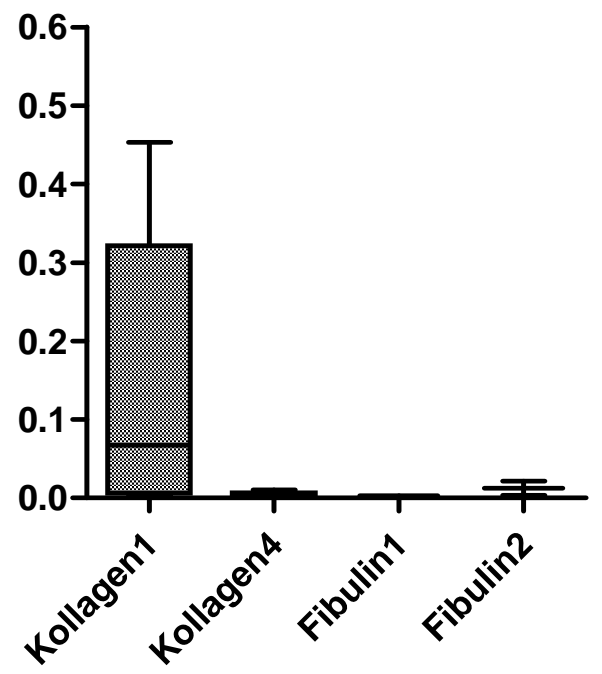

c)

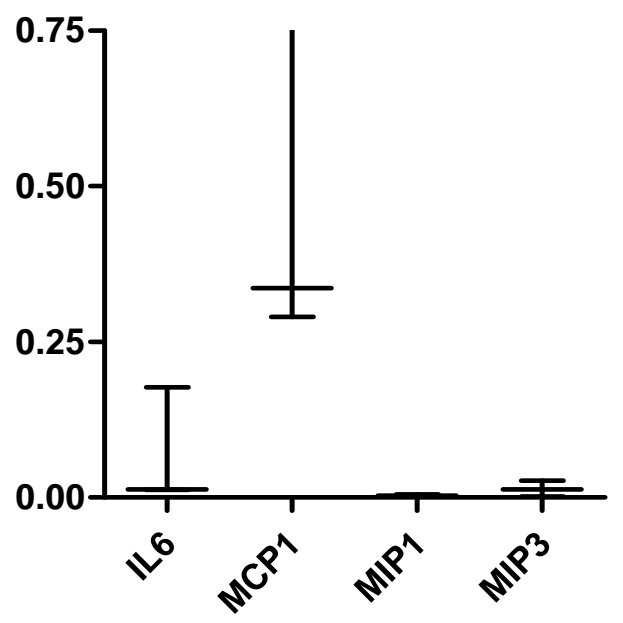


Abb. 27: Leber-MF, Genexpression nach der $\triangle \mathrm{CT}$-Methode, Mittelwerte und Standardabweichung,
(a) a-SMA (n=9), Thy1 ( $n=37)$, Desmin ( $n=3)$, Fibrillin-2 ( $n=23)$
(b) Kollagen-1 $(n=12)$, Kollagen-4 ( $n=11)$, Fibulin-1 $(n=3)$, Fibulin-2 $(n=3)$
(c) Interleukin-6 ( $n=3), \operatorname{MCP}-1$ ( $n=3), \operatorname{MIP-1}(n=2), \operatorname{MIP-3}(n=3)$

Auch die Leber-MF weisen bei den Strukturproteinen eine starke a-SMA-Expression auf. Wie postuliert kann außerdem Thy-1 detektiert werden. Eine signifikante Desmin-Expression findet sich nicht. Bei den Matrixproteinen ist die Expression von Kollagen-1 deutlich ausgeprägt. Es findet sich außerdem eine Kollagen-4- und Fibulin-2-Expression. Die Darstellung der Chemokine zeigt sich eine deutliche MCP1-Expression. $\mathrm{Zu}$ einem geringen Maße sind außerdem IL-6, und MIP-3 nachweisbar.

Wir sehen in allen Zellpopulationen eine deutliche a-SMA- und Kollagen-1Expression. Hingegen ist die Desmin-Expression in den verschiedenen Organproben nur relativ gering ausgeprägt. Bestätigt hat sich daneben, dass Thy-1 konsekutiv in allen Organen exprimiert wird. Von den Strukturproteinen finden wir vor allem Kollagen-1 und geringer ausgeprägt Fibulin-2. Bei den Chemokinen zeigt sich in allen Zellpopulationen eine deutliche MCP-1-Expression und daneben IL-6. Im Weiteren werden die PCR-Produkte der verschiedenen Zelllinien untereinander verglichen, um Unterschiede und Gemeinsamkeiten zu verdeutlichen. 
SMA

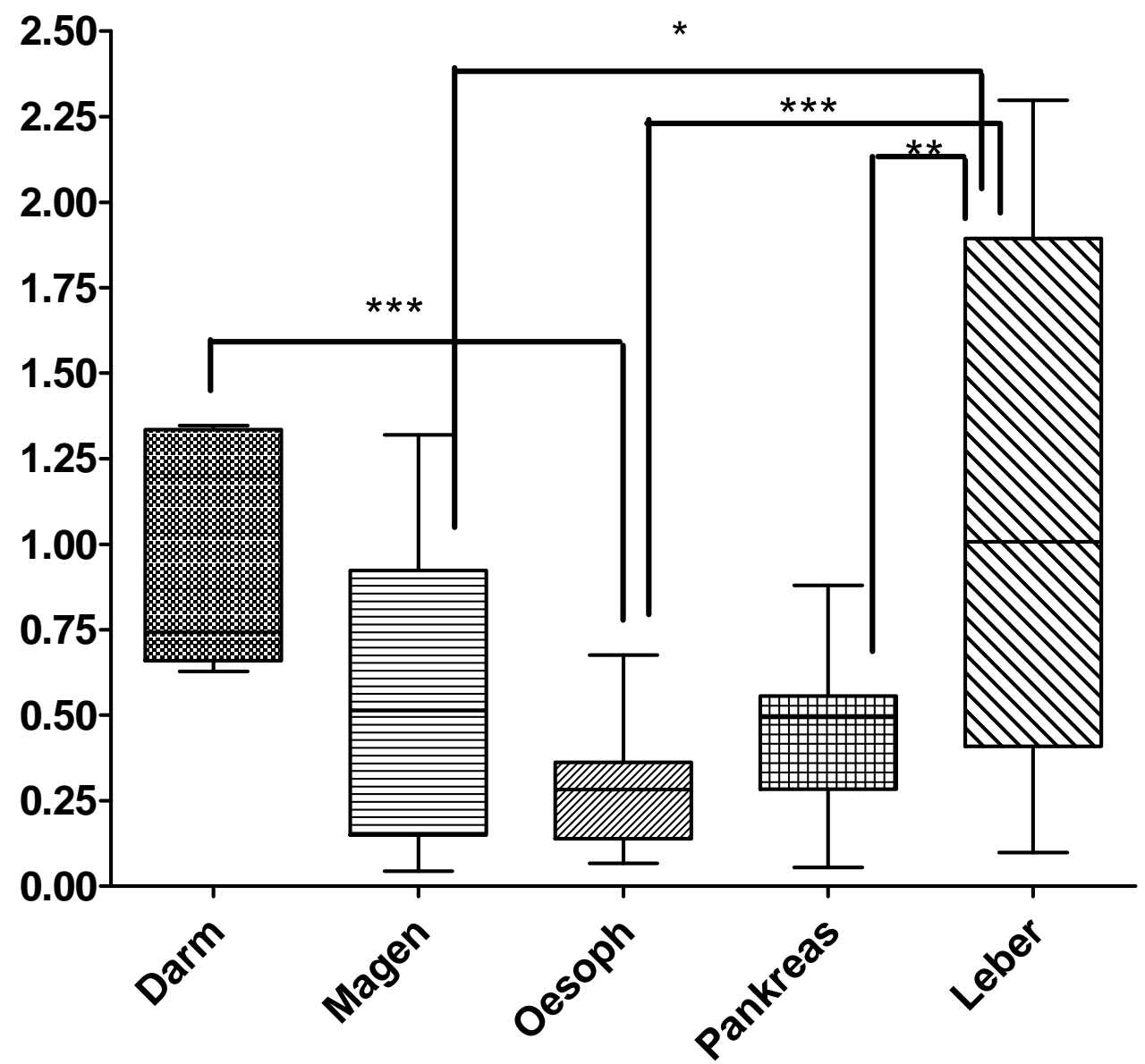

Abb. 28: Vergleich der a-SMA-Genexpression der MF der unterschiedlichen Organe

${ }^{*}: p<0,05 ;{ }^{* *}: p<0,01 ;{ }^{* * *}: p<0,001$

Die Expressionsdaten sind mit Ausnahme der Daten des Darms normalverteilt.

Die a-SMA-Expression ist am stärksten in der Leber ausgeprägt, gefolgt von Darm und Magen. Die niedrigste $\alpha$-SMA-Expression finden wir im Ösophagus. Die weitere Analyse zeigte signifikante Unterschiede vor allem der Leber-MF gegenüber den anderen Zellpopulationen. Weiterhin sehen wir deutliche Unterschiede bei der Genexpression von Darm und Ösophagus. 


\section{Thy-1}

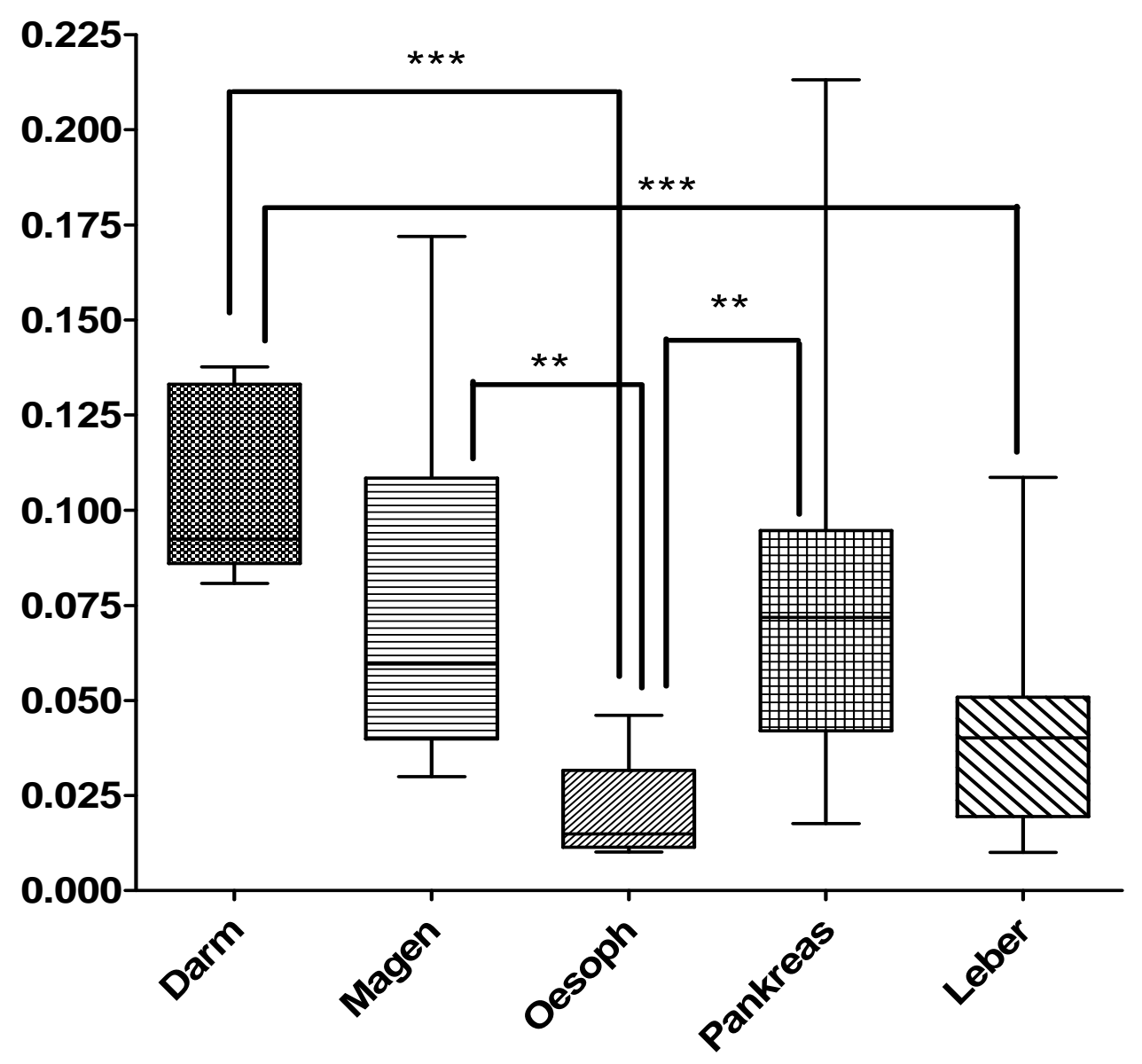

Abb. 29: Vergleich der Thy-1-Genexpression der MF der unterschiedlichen Organe ${ }^{*}: p<0,05 ;{ }^{* *}: p<0,01 ;{ }^{* * *}: p<0,001$

Die Analyse der Expressionsdaten zeigt normalverteilte Werte von Darm, Magen und Ösophagus. Entsprechend sind die Daten von Pankreas und Leber nicht normalverteilt. Interessant ist hier vor allem die vergleichsweise niedrige Genexpression in Ösophagus und Leber. Ein Unterschied in der Expression zwischen den beiden Organen kann nicht belegt werden. Signifikante Unterschiede zeigen sich zwischen Darm und Leber sowie zwischen Darm und Ösophagus. Des Weiteren ist die Expression in Magen und Pankreas gegenüber dem Ösophagus signifikant stärker ausgeprägt. 


\section{Desmin}

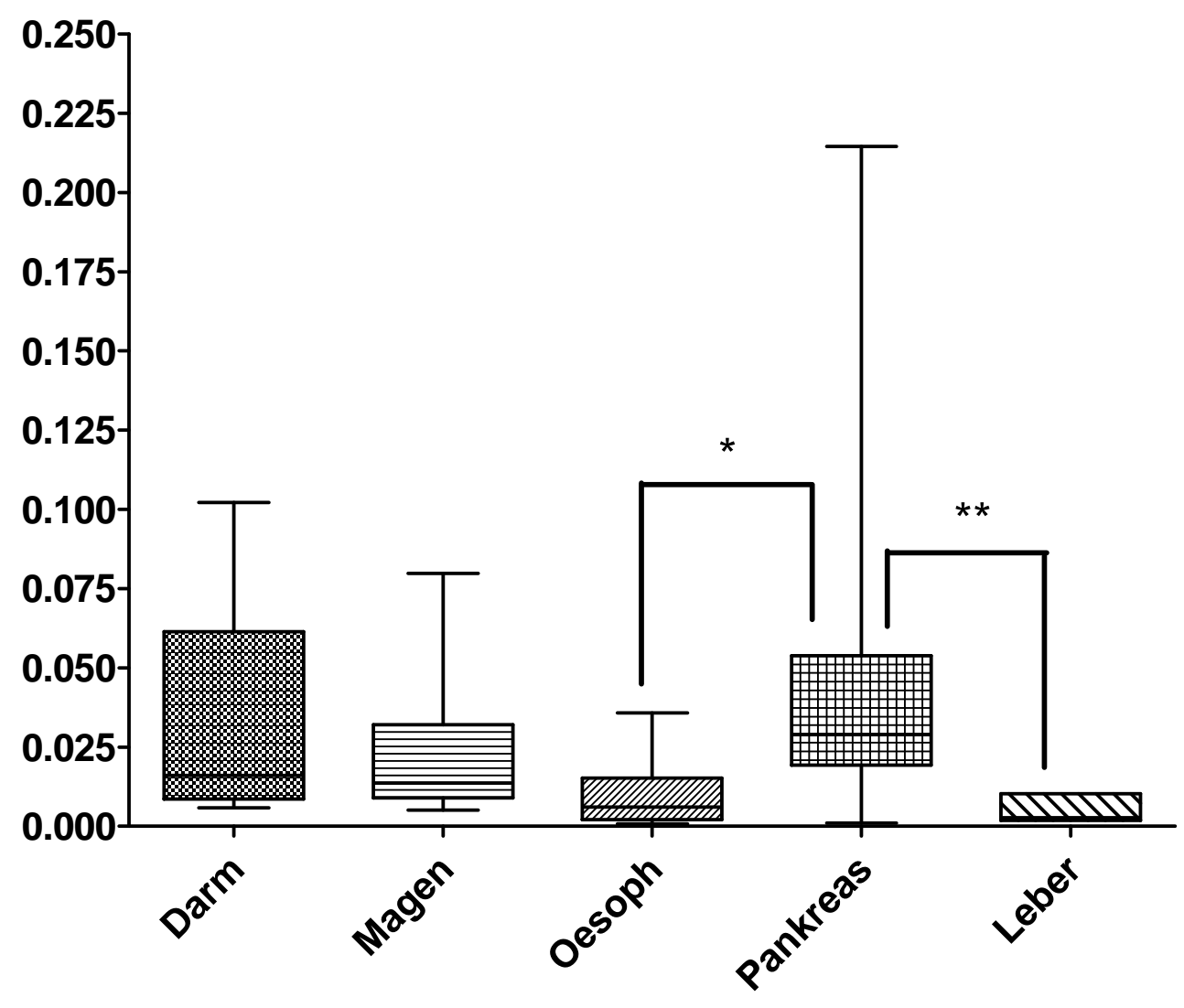

Abb. 30: Vergleich der Desmin-Genexpression der MF der unterschiedlichen Organe *: $p<0,05 ;{ }^{* *}: p<0,01 ;{ }^{* * *}: p<0,001$

Nur die Expressionsdaten des Darms sind normalverteilt. Die graphische Darstellung lässt nur geringe oder keine Unterschiede in der Expression vermuten. Die nichtparametrische Varianzanalyse zeigte signifikante Unterschiede, welche weiter untersucht wurden. Signifikante Unterschiede zeigen sich bei Pankreas und Leber sowie bei Pankreas und Ösophagus. 


\section{Fibrillin2}

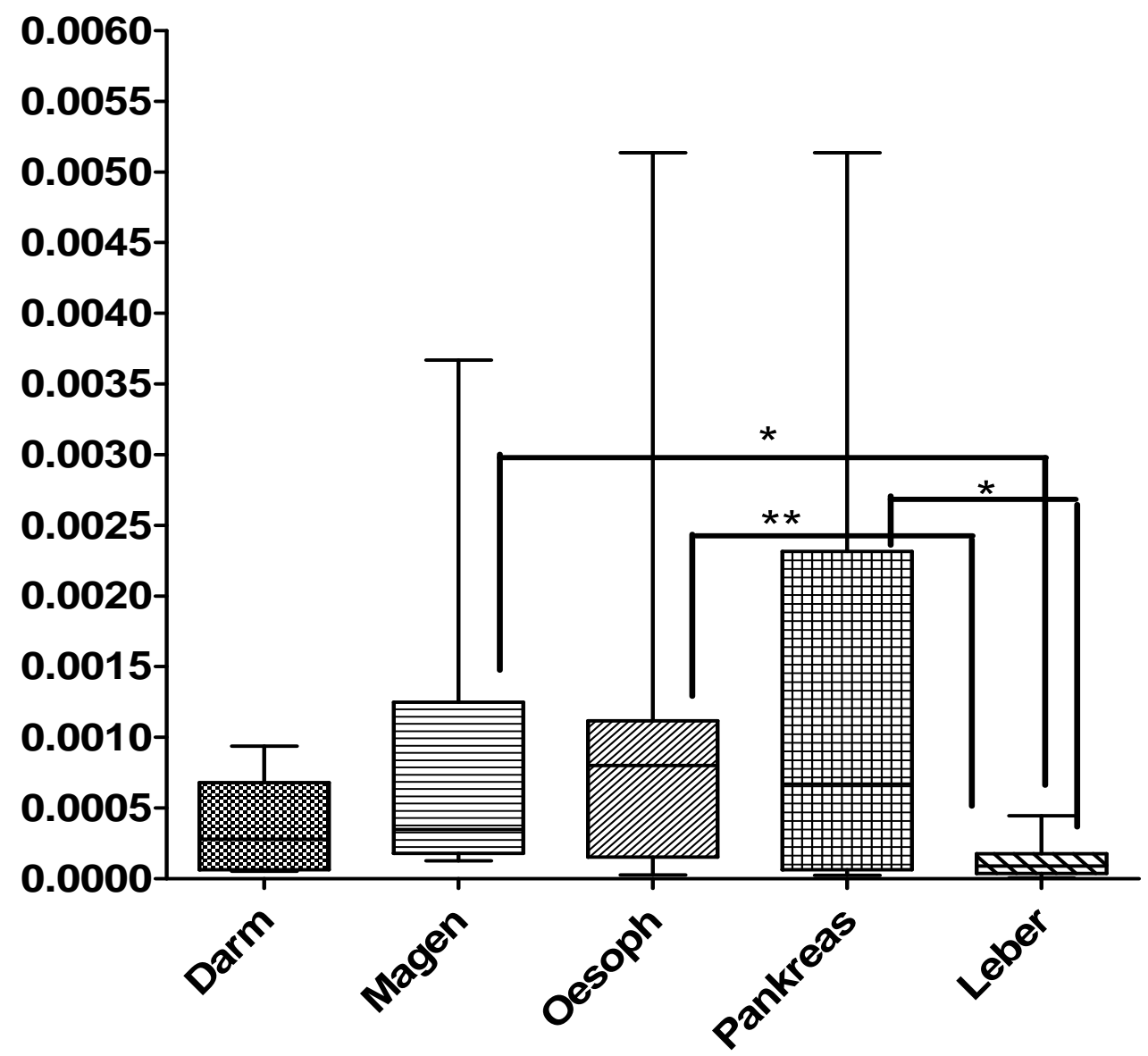

Abb. 31: Vergleich der Fibrillin-2-Genexpression der MF der unterschiedlichen Organe

*: $p<0,05 ;{ }^{* *}: p<0,01$

Die Expressionsdaten von Magen, Ösophagus und Leber sind nicht normalverteilt. Die niedrigste Fibrillin-2-Expression findet sich in der Leber. Um die im Graphen dargestellten Unterschiede auf Signifikanz zu untersuchen, wurde eine nichtparametrische Varianzanalyse durchgeführt. Die Leberzellen exprimieren demnach deutlich weniger Fibrillin-2 als die Zellen von Magen, Ösophagus und Pankreas. 


\section{Kollagen 1}

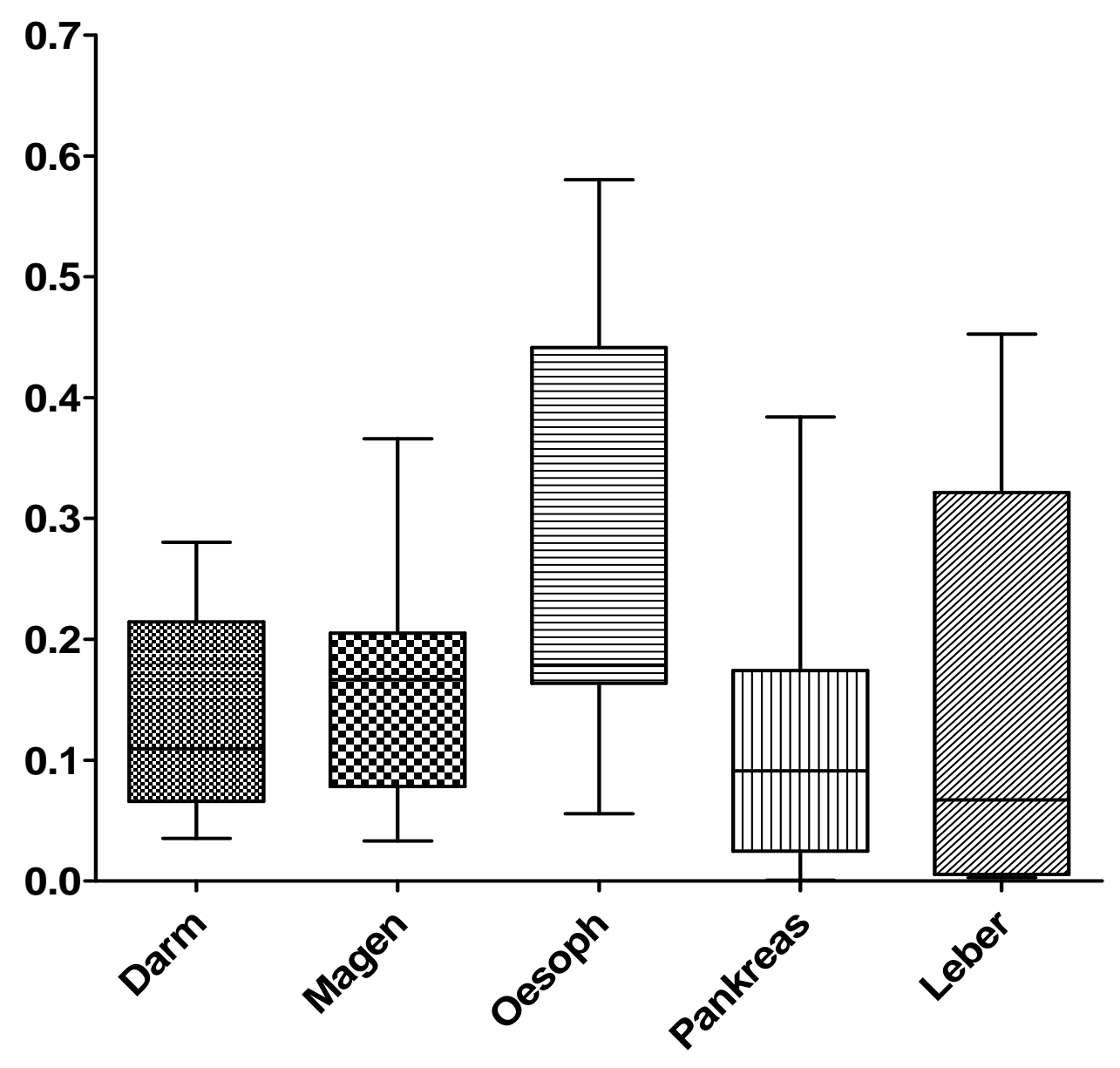

Abb. 32: Vergleich der Kollagen-1-Genexpression der MF der unterschiedlichen Organe

Die Expressionsdaten von allen Organen sind normalverteilt. Optische Unterschiede können mittels der genannten Testverfahren nicht weiter bestätigt werden. Es findet sich also in allen Zellpopulationen eine gleichmäßige Kollagen-1-Expression. 


\section{Kollagen 4}

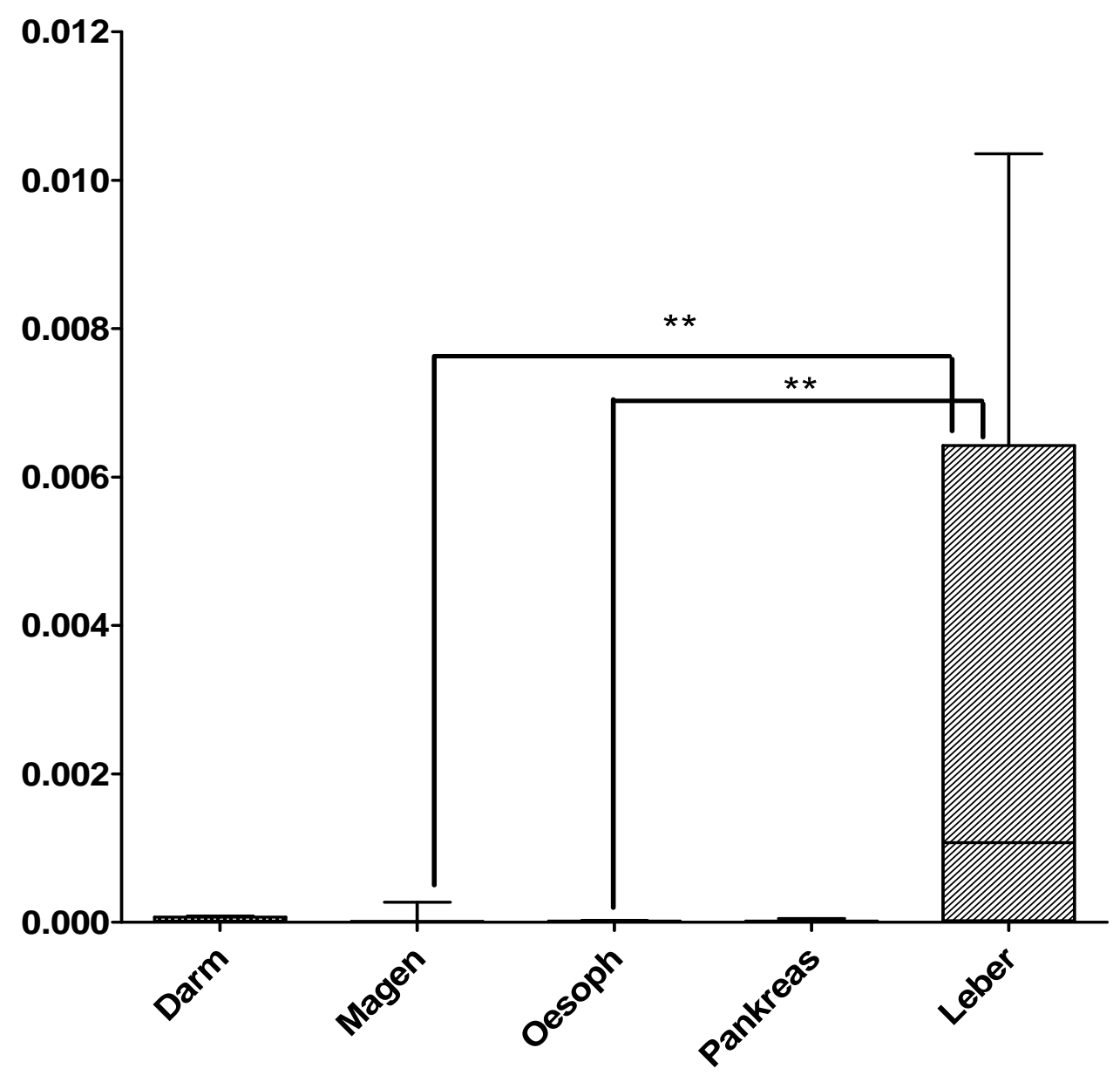

Abb. 33: Vergleich der Kollagen-4-Genexpression der MF der unterschiedlichen Organe

*: $p<0,05 ;{ }^{* *}: p<0,01$;

Die Expressionsdaten des Kollagen-4 sind in Magen und Pankreas nicht normalverteilt, weshalb ein nichtparametrisches Testverfahren angewandt wurde. Die graphischen Unterschiede lassen sich somit belegen. Die Expression ist auffällig stark in der Leber ausgeprägt. 


\section{Fibulin1}

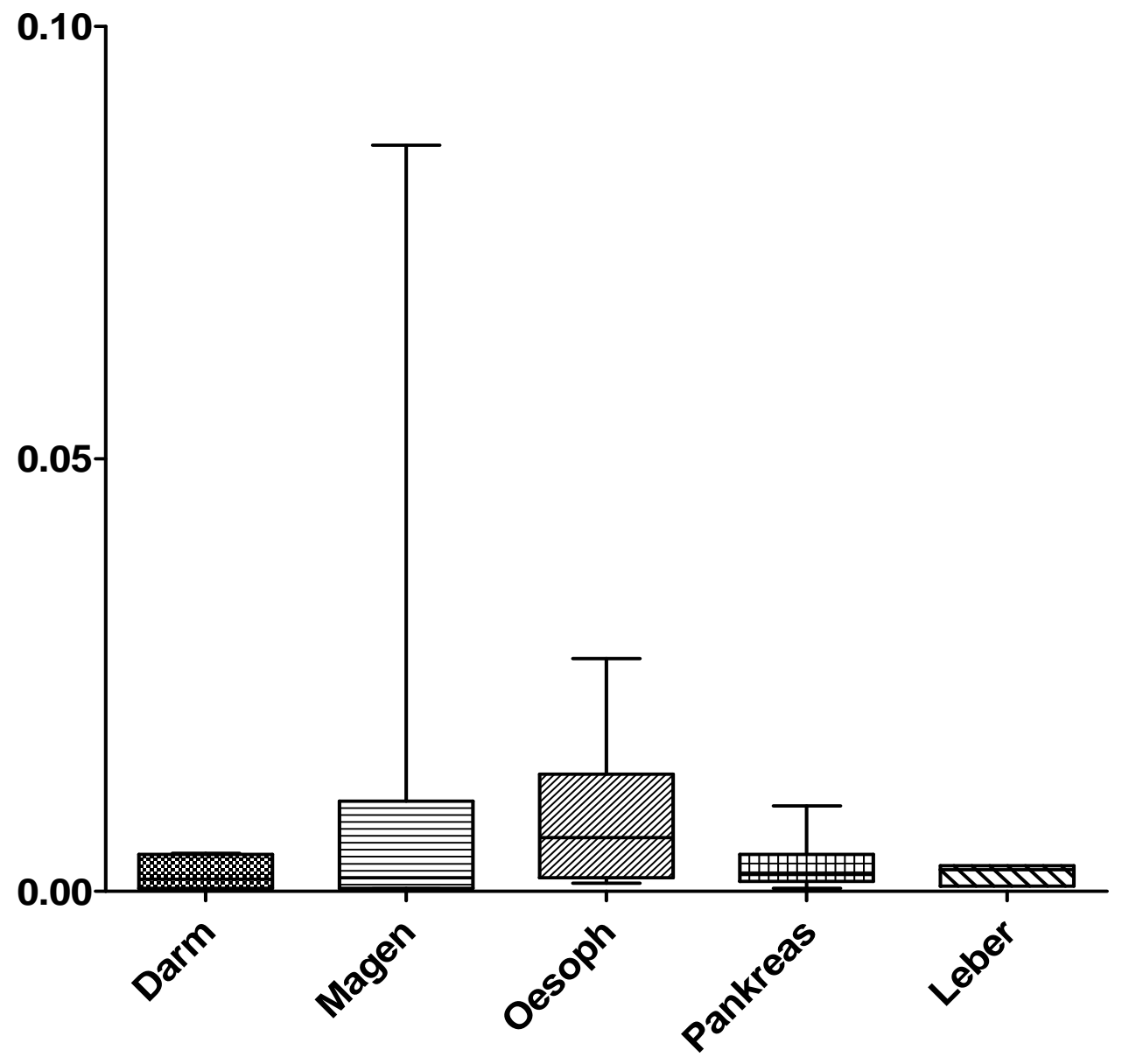

Abb. 34: Vergleich der Fibulin-1-Genexpression der MF der unterschiedlichen Organe

Die Expressionsdaten des Fibulin-1 waren mehrheitlich nicht normalverteilt. Optisch entsteht der Eindruck einer gleichmäßigen Expression in allen Organen. Die Varianzanalyse kann keine signifikanten Unterschiede nachweisen. Eine weitere Analyse erfolgte deshalb nicht. 
Fibulin2

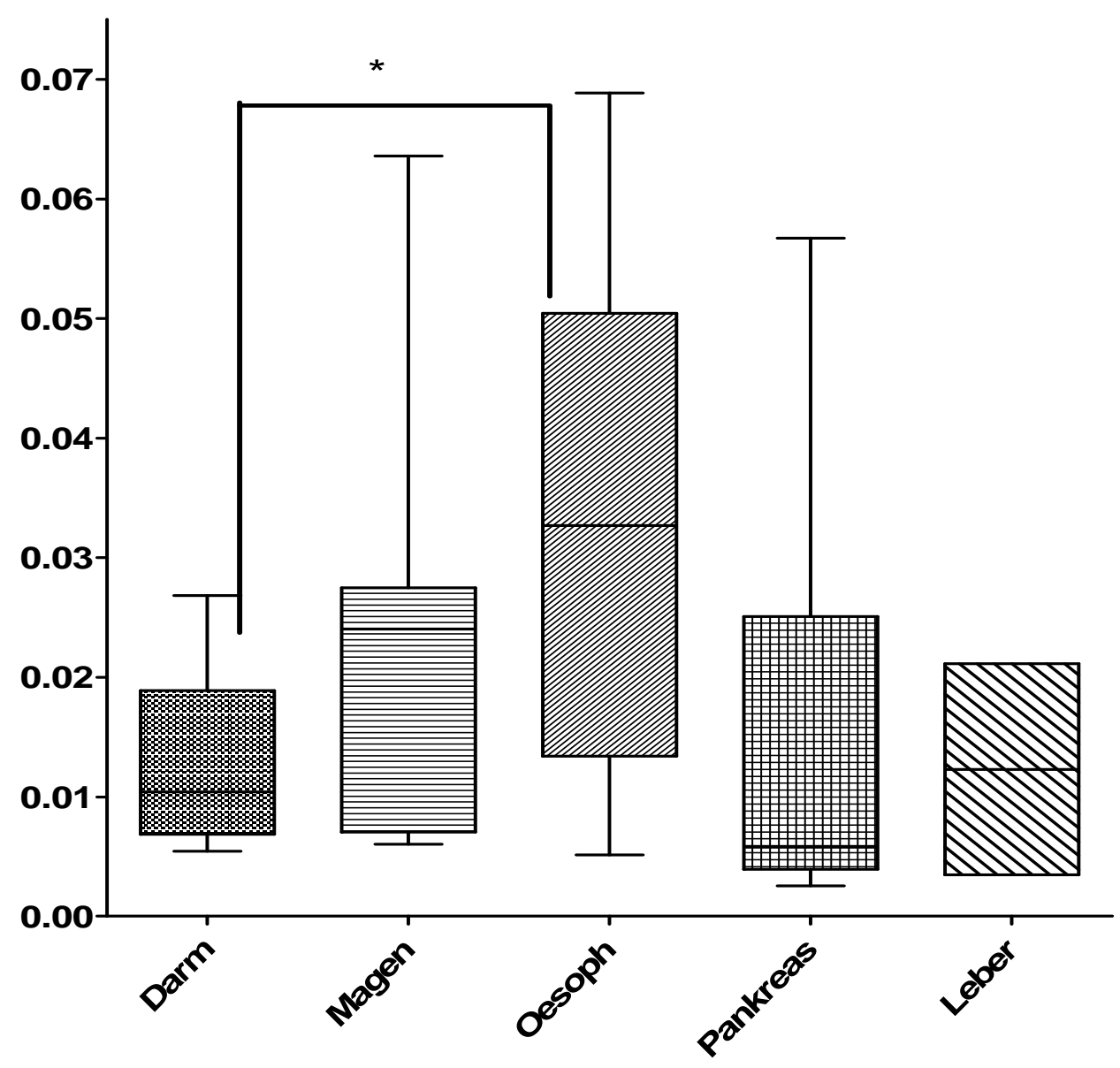

Abb. 35: Vergleich der Fibulin-2-Genexpression der MF der unterschiedlichen Organe *: $p<0,05$

Für das Fibulin-2 finden wir normalverteilte Expressionsdaten für alle Organpopulationen außer der Leber. Die stärkste Ausprägung der Fibulin-2Expression sehen wir im Ösophagus, wobei lediglich im Vergleich zum Darm eine Signifikanz nachgewiesen werden kann. Am geringsten ist die Expression in der Leber ausgeprägt. 


\section{IL6}

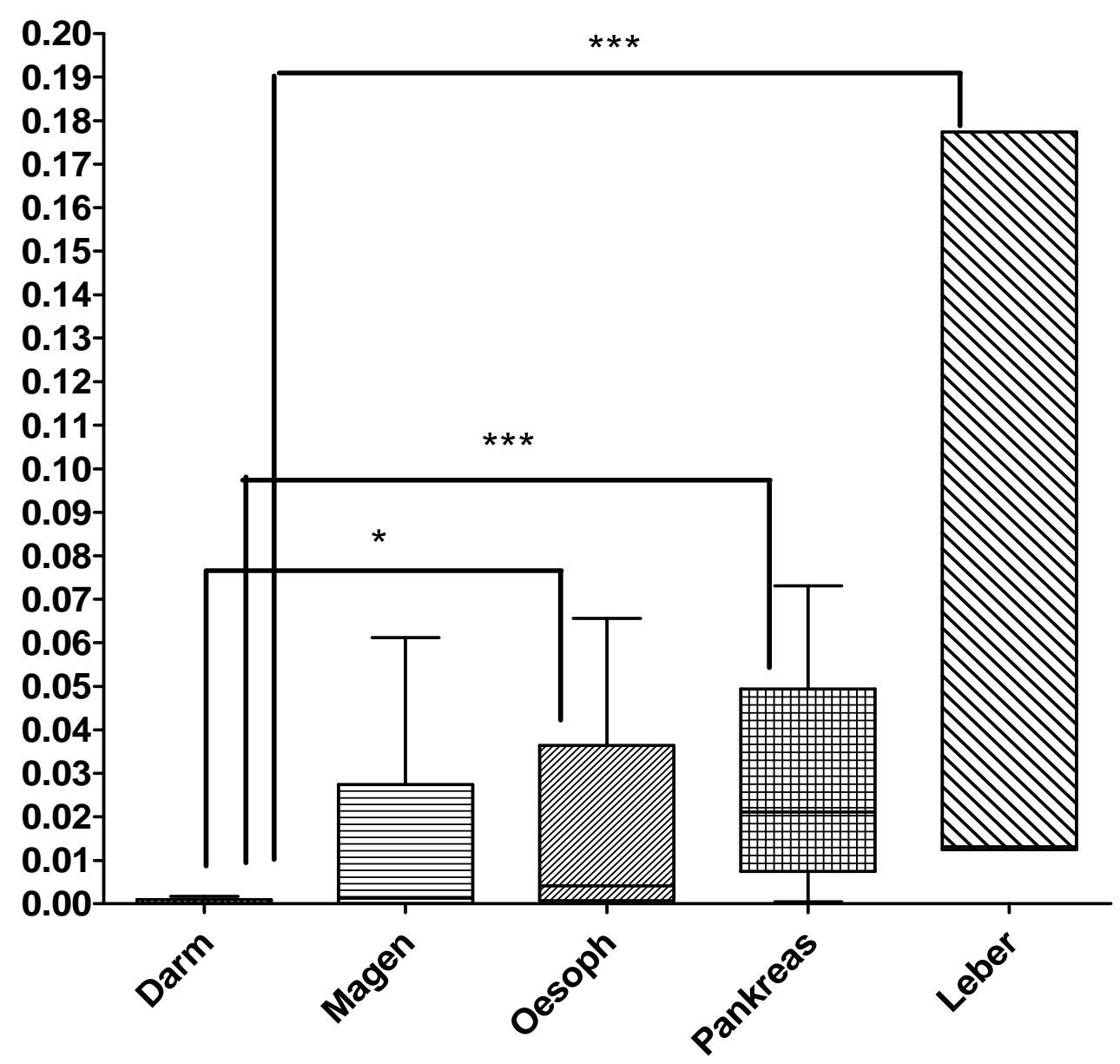

Abb. 36: Vergleich der IL-6-Genexpression der MF der unterschiedlichen Organe *: $p<0,05 ;{ }^{* *}: p<0,01 ;{ }^{* * *}: p<0,001$

Eine Normalverteilung der Expressionsdaten für das IL-6 sehen wir nur im Ösophagus und Pankreas. Die IL-6-Expression ist am stärksten in der Leber ausprägt. Auffällig ist daneben vor allem die geringe Expression der Darmzellen. Die genauere Analyse zeigt signifikante Unterschiede zu Ösophagus, Pankreas und Leber. 


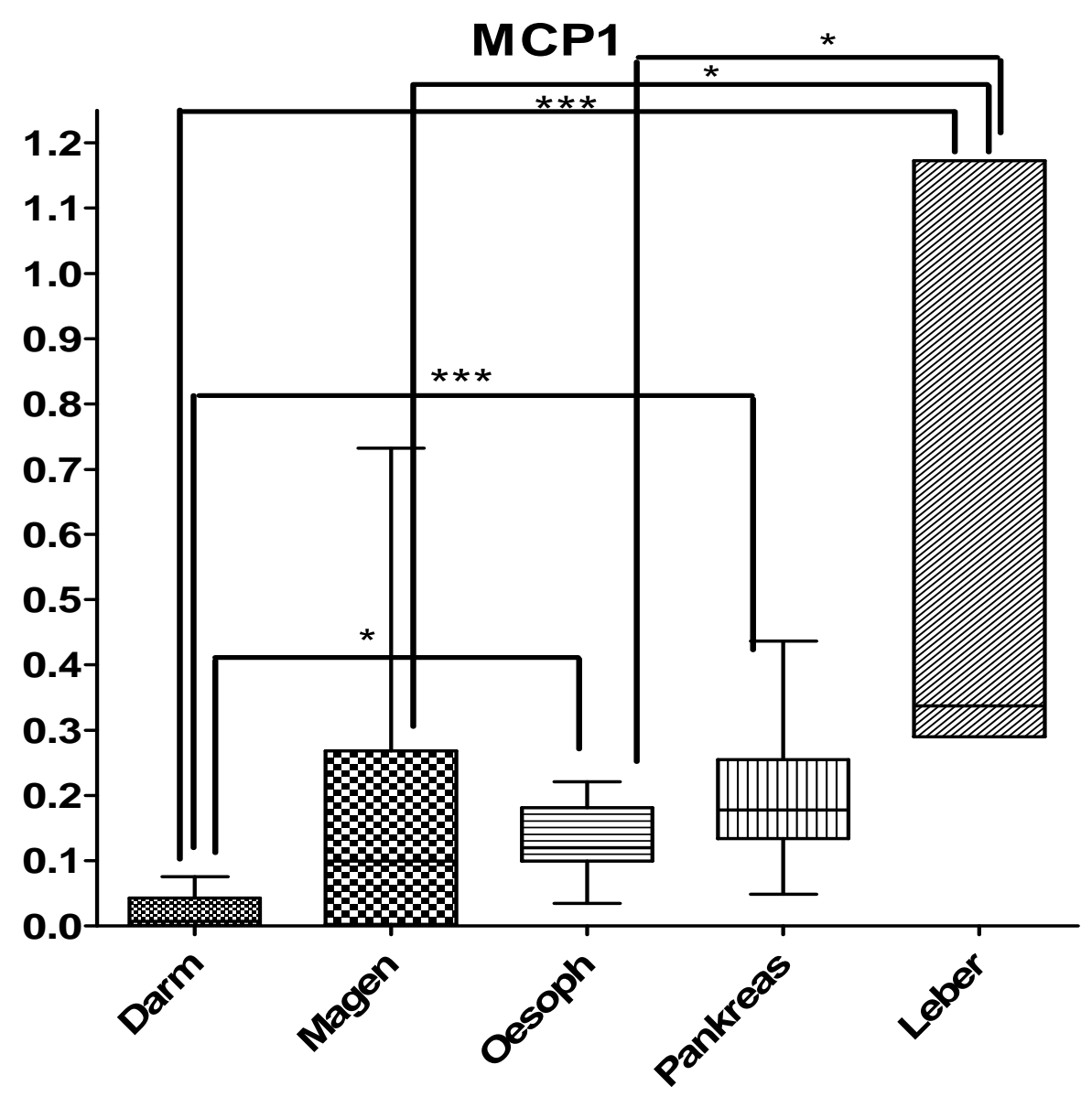

Abb. 37: Vergleich der MCP-1-Genexpression der MF der unterschiedlichen Organe

${ }^{*}: p<0,05 ;{ }^{* *}: p<0,01 ;{ }^{* * *}: p<0,001$

Eine Normalverteilung der Expressionsdaten finden wir nur in Ösophagus und Pankreas, so dass eine nichtparametrische Analyse erfolgt. Es zeigen sich die markierten, signifikanten Unterschiede. Bemerkenswert ist vor allem die starke MCP1-Expression in der Leber. Demgegenüber finden wir die geringste Expression in den Darmzellen. 


\section{MIP1}

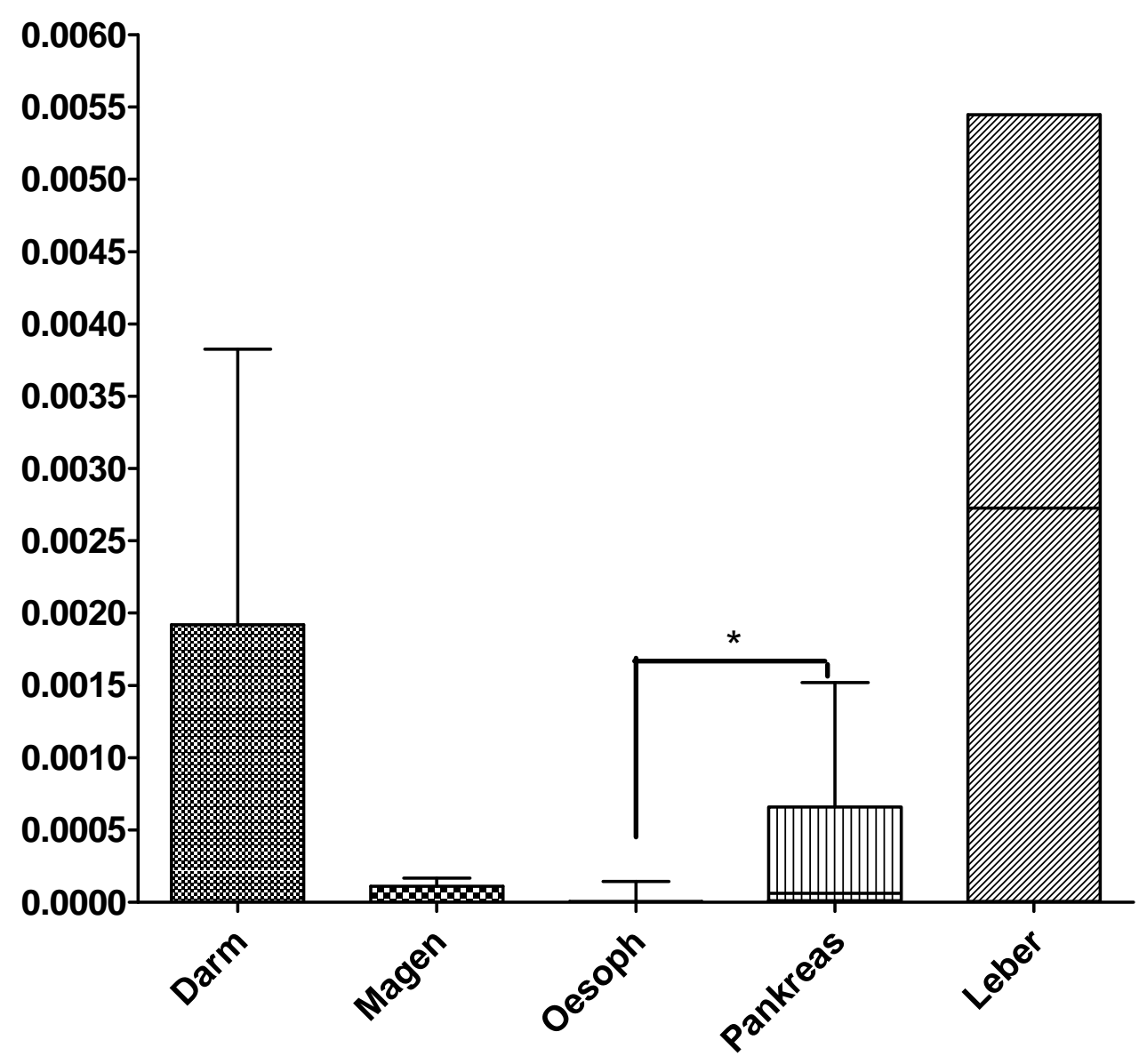

Abb. 38: Vergleich der MIP-1-Genexpression der MF der unterschiedlichen Organe *: $p<0,05$

Die Expressionsdaten des MIP-1 sind mit Ausnahme des Darms nicht normalverteilt. Zwar zeigt die Analyse Unterschiede der Mittelwerte, eine dem optischen Eindruck entsprechende Signifikanz kann hier nicht belegt werden. Lediglich zwischen Ösophagus und Pankreas finden wir statistische Unterschiede. 


\section{MIP3}

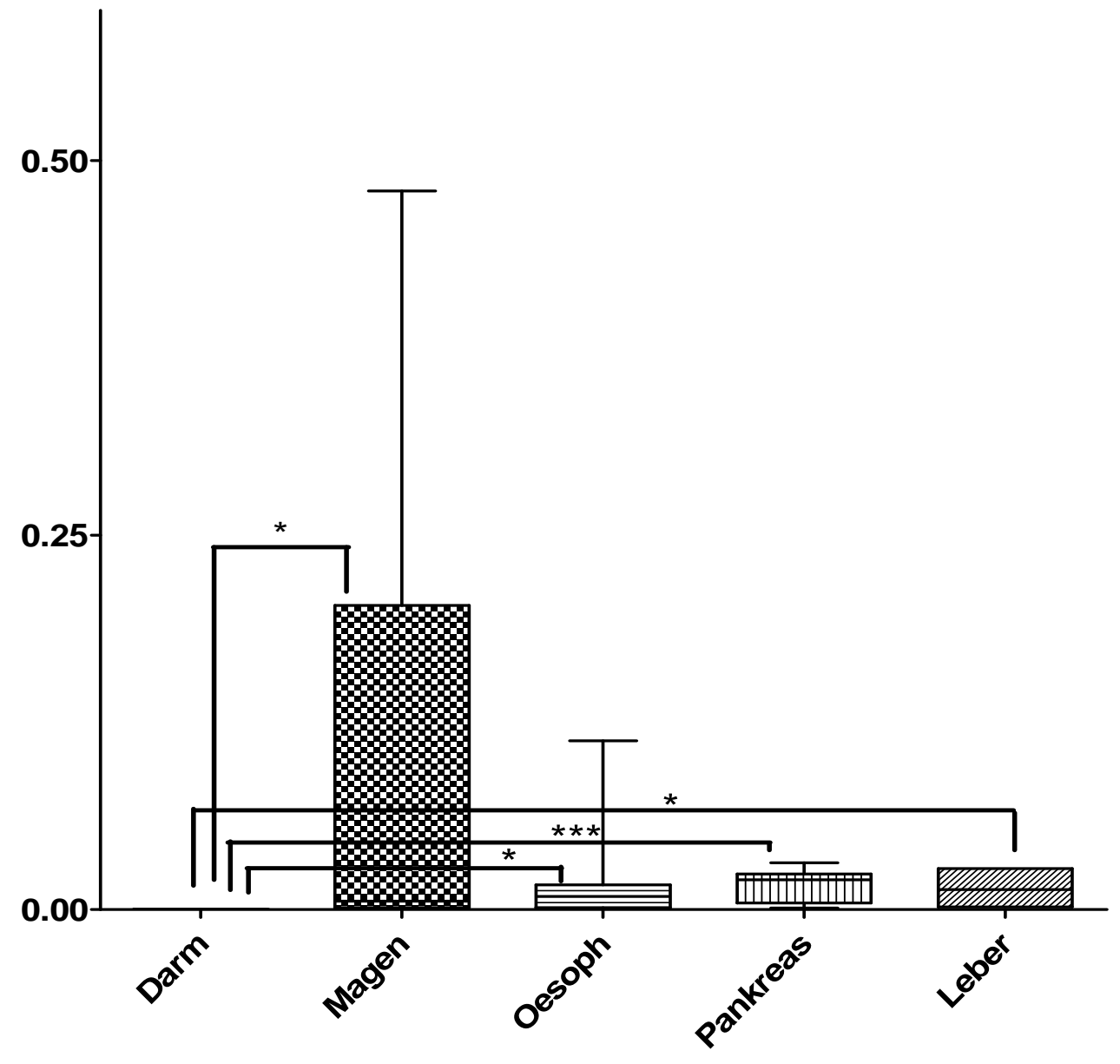

Abb. 39: Vergleich der MIP-3-Genexpression der MF der unterschiedlichen Organe ${ }^{*}: p<0,05 ;{ }^{* *}: p<0,01 ;{ }^{* * *}: p<0,001$

Nur die Daten der MIP-3-Genexpression von Darm und Pankreas waren normalverteilt. Bereits graphisch fällt hier die geringe Expression der Darmzellen auf. Die weitere Analyse bestätigt diese deutlichen Unterschiede gegenüber den anderen Zellpopulationen.

Für eine Übersicht der Ergebnisse werden die berechneten Mittelwerte der Genexpression in eine Tabelle übertragen. Somit ergibt sich folgendes Bild: 


\begin{tabular}{l|l|l|l|l} 
Strukturproteine & a-SMA & Thy-1 & Desmin & Fibrillin-2 \\
\hline Ösophagus & 0,2825 & 0,02141 & 0,01045 & 0,0009937 \\
\hline Magen & 0,5583 & 0,07486 & 0,02223 & 0,0008055 \\
\hline Darm & 0,9465 & 0,1061 & 0,03506 & 0,0003535 \\
\hline Pankreas & 0,4482 & 0,07783 & 0,04713 & 0,001317 \\
\hline Leber & 1,118 & 0,04181 & 0,004985 & 0,0001155
\end{tabular}

\begin{tabular}{l|l|l|l|l} 
Matrixproteine & Kollagen-1 & Kollagen-4 & Fibulin-1 & Fibulin-2 \\
\hline Ösophagus & 0,2641 & $8,933 \times 10^{-6}$ & 0,008836 & 0,03348 \\
\hline Magen & 0,1648 & $3,215 \times 10^{-5}$ & 0,01289 & 0,02403 \\
\hline Darm & 0,1340 & $3,414 \times 10^{-5}$ & 0,002127 & 0,01237 \\
\hline Pankreas & 0,1172 & $1,289 \times 10^{-5}$ & 0,002970 & 0,01609 \\
\hline Leber & 0,1516 & 0,002820 & 0,002031 & 0,01230
\end{tabular}

\begin{tabular}{l|l|l|l|l} 
Mediatoren & IL-6 & MCP-1 & MIP-1 & MIP-3 \\
\hline Ösophagus & 0,01663 & 0,1298 & $2,015 \times 10^{-5}$ & 0,01783 \\
\hline Magen & 0,01208 & 0,1760 & $4,476 \times 10^{-5}$ & 0,1020 \\
\hline Darm & 0,0003820 & 0,01866 & 0,0007691 & $7,573 \times 10^{-5}$ \\
\hline Pankreas & 0,02813 & 0,2015 & 0,0003238 & 0,01687 \\
\hline Leber & 0,06764 & 0,5999 & 0,002727 & 0,01404
\end{tabular}

Tbl. 1: $\quad$ Mittelwerte der gemessenen Genexpression für die unterschiedlichen Zellpopulationen

Veranschaulichend werden die absoluten Werte in Symbole umgewandelt. Die Abstufung erfolgt hierbei in 10er Potenzen. Somit ist eine Vergleichbarkeit der unterschiedlichen Marker gewährleistet:

\begin{tabular}{l|l|l|l|l} 
Strukturproteine & a-SMA & Thy-1 & Desmin & Fibrillin-2 \\
\hline Ösophagus & +++ & ++ & ++ & $(+)$ \\
\hline Magen & +++ & ++ & ++ & $(+)$ \\
\hline Darm & +++ & +++ & ++ & $(+)$ \\
\hline Pankreas & +++ & ++ & ++ & + \\
\hline Leber & +++ & ++ & + & $(+)$
\end{tabular}

\begin{tabular}{l|l|l|l|l} 
Matrixproteine & Kollagen-1 & Kollagen-4 & Fibulin-1 & Fibulin-2 \\
\hline Osophagus & +++ & - & + & ++ \\
\hline Magen & +++ & - & ++ & ++ \\
\hline Darm & +++ & - & + & ++ \\
\hline Pankreas & +++ & - & + & ++ \\
\hline Leber & +++ & + & + & ++
\end{tabular}

\begin{tabular}{l|l|l|l|l} 
Mediatoren & IL-6 & MCP-1 & MIP-1 & MIP-3 \\
\hline Osophagus & ++ & +++ & - & ++ \\
\hline Magen & ++ & +++ & - & +++ \\
\hline
\end{tabular}




\begin{tabular}{l|l|l|l|l}
\hline Darm & $(+)$ & ++ & $(+)$ & - \\
\hline Pankreas & ++ & +++ & $(+)$ & ++ \\
\hline Leber & ++ & +++ & + & ++
\end{tabular}

Tbl. 2: $\quad$ Genexpression (objektiv) der unterschiedlichen Zellpopulationen $+++: 10^{0}-10^{-1} ;++: 10^{-2} ;+: 10^{-3} ;(+): 10^{-4} ;-:>10^{-5}$

Da kleinere Unterschiede für den einzelnen Marker im Organvergleich in dieser Darstellung nicht zur Geltung kommen, wird die jeweilige Genexpression deskriptiv in Symbole umgewandelt. Ein Vergleich der verschiedenen Marker untereinander ist bei dieser Darstellung nicht möglich.

\begin{tabular}{l|l|l|l|l} 
Strukturproteine & a-SMA & Thy-1 & Desmin & Fibrillin-2 \\
\hline Ösophagus & + & + & $(+)$ & + \\
\hline Magen & + & ++ & + & + \\
\hline Darm & ++ & +++ & + & + \\
\hline Pankreas & + & ++ & + & ++ \\
\hline Leber & +++ & + & $(+)$ & $(+)$
\end{tabular}

\begin{tabular}{l|l|l|l|l} 
Matrixproteine & Kollagen-1 & Kollagen-4 & Fibulin-1 & Fibulin-2 \\
\hline Ösophagus & +++ & - & + & ++ \\
\hline Magen & + & - & + & + \\
\hline Darm & + & - & $(+)$ & + \\
\hline Pankreas & ++ & - & $(+)$ & + \\
\hline Leber & ++ & ++ & $(+)$ & +
\end{tabular}

\begin{tabular}{l|l|l|l|l} 
Mediatoren & IL-6 & MCP-1 & MIP-1 & MIP-3 \\
\hline Ösophagus & + & + & - & $(+)$ \\
\hline Magen & + & + & - & ++ \\
\hline Darm & - & $(+)$ & + & - \\
\hline Pankreas & + & + & + & $(+)$ \\
\hline Leber & +++ & +++ & ++ & $(+)$
\end{tabular}

Tbl. 3: Genexpression (deskriptiv) der unterschiedlichen Zellpopulationen, Vergleich der jeweiligen Marker

- = keine relevante Expression, $(+)=$ geringe Expression, $+=$ normale

Expression; $++=$ starke Expression; $+++=$ sehr starke Expression

Zusammenfassend liefert der Organvergleich einige interessante Gesichtspunkte. Bei der Darstellung der Strukturproteine ( $\alpha$-SMA, Thy-1, Desmin) können folgende Unterschiede nachgewiesen werden. Eine starke Expression von $\alpha$-SMA in Leber- 
MF sowie eine verhältnismäßig starke Thy-1-Expression in den Darm-MF. Die Betrachtung der Expression von Bestandteilen der EZM (Kollagen-1, Fibulin-1, Fibulin-2, Fibrillin-2) zeigt mit Ausnahme, der Kollagen-4-Expression in der Leber nur geringe Unterschiede in der Ausprägung. Hingegen sehen wir bei den Entzündungsmediatoren und Chemokinen (IL-6, MCP-1, MIP-1, MIP-3) wiederum deutliche Unterscheide der Expression vor allem von Darm und Leber.

\section{Diskussion}

Dies ist die erste Untersuchung, die sich mit der Charakterisierung von Ratten-MF des Gastrointestinaltrakts im Vergleich zu Leber und Pankreas beschäftigt. Im Gegensatz zu Fibroblasten haben MF zusätzliche elastische Eigenschaften vergleichbar den Proteinen der glatten Muskulatur wie Fibrillin und a-SMA (Powell et al. 1999b). Daneben konnten Fibulin-2 und Thy-1 als weitere Marker identifiziert werden, deren Expression als Unterscheidungsmerkmal von den myofibroblast-likecells herangezogen werden (Dudas et al. 2009). MF konnten im Gastrointestinaltrakt, in der Leber, Herz, Lunge, Niere, Pankreas, Mamma und Prostata nachgewiesen werden (Ahmed 1990, Bostrom et al. 1996, Desmoulière et al. 1995, Joyce et al. 1987, Kassen et al. 1996, Peehl and Sellers 1997, Tang et al. 1996, Weber et al. 1997) und finden sich gehäuft im Rahmen entzündlich, fibrotischer Prozesse (Knittel et al. 1999). Mein Experiment hatte zum Ziel die MF von Ösophagus, Magen, Kolon, Pankreas und Leber auf die postulierten Eigenschaften hin zu untersuchen. Weiterhin wurden Unterschiede und Gemeinsamkeiten an den isolierten Zellen von gesunden und nicht vorbehandelten Ratten herausgearbeitet. Hierbei erfordert insbesondere die Betrachtung der molekularbiologischen Ergebnisse eine Strukturierung. Die Einteilung beruht dabei auf charakteristischen Eigenschaften von MF. Die erste Kategorie beinhaltet hierbei die MF-typischen Strukturproteine. Die zweite Kategorie umfasst die Matrixproteine, während in einer dritten Kategorie die Mediatoren bzw. Chemokine betrachtet werden. 


\subsection{Zellkultur}

Die Isolation der einzelnen Zelllinien erfolgte mit unterschiedlichen Versuchsanordnungen. Während die Isolation der MF von Ösophagus, Magen und Pankreas durch eine Kollagenase-Behandlung erfolgte (Mueller et al. 2007), wurde für die Isolation der Darm-MF ein anderes Protokoll verwandt, das darauf abzielte, das Epithel zu lösen und eine Migration der subepithelialen MF möglich zu machen. Somit kann davon ausgegangen werden, dass keine ICC kultiviert wurden (Mahida et al. 1997b). Auch die Isolation der Leber-MF erfolgte anhand eines hierfür etablierten Protokolls (Dudas et al. 2009). Es zeigte sich, dass insbesondere die Zellkulturen des Darms nur durch Zusatz von Antibiotika und Antimykotika dauerhaft frei von mikrobieller Besiedlung gehalten werden konnten. Bereits in dieser frühen Phase der Untersuchung zeigten sich Unterschiede in der Proliferationsaktivität der Zelllinien. Die Dauer bis zum Auftreten eines konfluenten Monolayers und zur ersten Zellpassage reichte von einer (Ösophagus) bis zu drei Wochen (Pankreas). Die Darm-MF erreichten hierbei keine Konfluenz und waren lichtmikroskopisch erst nach 2 Wochen zu identifizieren. Interessanterweise gelang die Isolation nur aus den distalen Abschnitten des Kolon. Der Grund für das unterschiedliche Wachstum mag in den verschiedenen Isolationsverfahren begründet sein, jedoch ist daneben die absolute Zahl von isolierten MF von Bedeutung, zumal eine enge räumliche Beziehung und damit Zellkontakte und parakrine Effekte einen Proliferationsreiz bei Bindegewebszellen darstellen (Powell et al. 1999a). Die Darm-MF scheinen dagegen noch weitere Umgebungsbedingungen zu benötigen, die wir nicht genauer eruieren konnten. Grundsätzlich gehen wir davon aus, dass die isolierten Zellen MF entsprachen. Die Isolationsverfahren für die Darm- und Leber-MF sind sehr spezifisch, hingegen kann nicht sicher ausgeschlossen werden, dass insbesondere die Kulturen von Ösophagus, aber auch von Magen und Pankreas geringe Anteile nicht myofibroblastischer Zellen beinhalteten.

\subsection{Immunfluoreszenz}

Um zu belegen, dass die isolierten Zellreihen MF entsprechen, wurden Immunfluoreszenz-Präparate angefertigt. Neben der a-SMA- und Thy-1-Färbung, wurde außerdem eine Vimentin- und Desmin-Färbung gewählt. Wie bereits 
ausgeführt ist der Nachweis von $\alpha$-SMA essentiell für die Charakterisierung von MF (Powell et al. 1999a). Die a-SMA positiven Zellen können jedoch weiter in MF und myofibroblast-like-cells differenziert werden (Ramadori and Saile 2002). Die Unterscheidung wird durch den Nachweis von Thy-1 möglich (Dudas et al. 2007, Pinchuk et al. 2008). Erwartungsgemäß zeigten unsere Präparate ein homogenes Färbeverhalten für beide Marker. Wir konnten durch die Kernfärbung darüber hinaus einzelne mehrkernige MF nachweisen. Vimentin und Desmin sind ebenfalls vorbeschriebene Marker von MF (Mermall et al. 1998). Jedoch wurde von mehreren Autoren berichtet, dass diese Proteine in ihrer Ausprägung stark variieren können (Kohnen et al. 1996, Powell et al. 1999b, Schmitt-Graff et al. 1994). Durch die Vimentin-Färbung konnten wir in allen Zellreihen große Anteile des Zytoskeletts darstellen. Desmin hingegen fanden wir nur in einzelnen Zellen, hier jedoch teilweise stark ausgeprägt. Dass die Desmin-Expression innerhalb einer MF-Population reguliert werden kann, wurde durch eine hiesige Arbeitsgruppe belegt. Leber-MF in fibrotischen veränderten Septen exprimieren im Gegensatz zu den MF der gesunden Leber vermehrt Desmin (Knittel et al. 1999). Der Entzündungsreiz scheint zu einer Hoch-Regulation der Desmin-Expression zu führen. Für glatte Muskelzellen konnte gezeigt werden, dass die Expression beider Intermediärfilamente auch in Abhängigkeit vom Differenzierungsgrad und mechanischem Stress unterschiedlich ist (Tang DD 2008). Die Übertragbarkeit dieser Ergebnisse könnte durch Langzeitkulturen und Stimulationsversuche geprüft werden.

Die In-vivo-Darstellung anhand von Organpräparaten erfolgte mit der Fragestelllung, ob die postulierte Lokalisation der MF mikroskopisch verifiziert werden kann. Die $\alpha-$ SMA- und Thy-1-Färbungen zeigten neben der Wandstruktur, in den subepithelialen Schichten zahlreiche Fluoreszenzsignale, die wir so nicht in der Desmin-Färbung finden konnten. Da die einzelnen Marker keine MF-Spezifität aufweisen, müssen die Ergebnisse für eine sichere Identifizierung der MF in der Summe analysiert werden. Die Anwendung einer Doppelfärbung ( $\alpha-S M A$ und Thy-1) hingegen könnte diesbezüglich weiteren Aufschluss bringen.

Die Anfertigung der Labteks sowie deren Färbung folgte den gleichen Protokollen. Verfahrensfehler wurden weiter minimiert durch zusätzliche Kontrollfärbungen. Die Präparate wurden vollständig gemustert und für die bildhafte Darstellung wurden exemplarisch einzelne Bezirke ausgewählt. Es wurden außerdem wiederholt Präparate angefertigt um die Ergebnisse zu verifizieren. Es spielt bei der Färbung 
sehr wahrscheinlich die absolute Zahl der Zellen sowie deren räumliche Anordnung eine Rolle. Im Gegensatz zur Lichtmikroskopie können die fluoreszenzmikroskopischen Präparate nicht im Verlauf beurteilt werden, da die Fixierung ein bis zwei Tage nach Passagierung erfolgte.

Schließlich unterliegt die Betrachtung der gefärbten Präparate auch immer subjektiven Eindrücken, so dass die gewonnenen Erkenntnisse nur im Zusammenhang mit weiteren Methoden gewertet werden sollten.

\subsection{Transmissionselektronenmikroskopie}

Die ultrastrukturelle Darstellung der MF diente der weiteren Objektivierung der bisherigen Erkenntnisse. Neben der Darstellung von Morphologie, Aktinfilamenten und Zellorganellen, war hier die Visualisierung von fokalen Adhäsionen und Fibronexus von Interesse. Die Letztgenannten stellen eine Verbindung der MF mit dem Extrazellularraum dar und haben Bedeutung bei der Diagnostik von myofibroblastischen Tumoren wie dem Myofibrosarkom (Qiu et al. 2008, Valentich et al. 1997). Die von uns isolierten Zellen zeigten alle das typische, spindelförmige Aussehen und einen prominenten Zellkern. Vereinzelt lagen die Zellen in enger räumlicher Beziehung und bildeten Zellkontakte aus. Darüber hinaus konnten in allen Zellreihen reichlich rER und intrazelluläre Filamente nachgewiesen werden. Des Weiteren sahen wir fokale Adhäsionen und Bündel extrazellulärer Filamente i. S. von Fibronexus, welche ein ungleichmäßiges Verteilungsmuster zeigten. Manche Autoren gehen davon aus, dass nur durch den Nachweis dieser Formationen eine sichere, ultrastrukturelle Identifizierung von MF möglich ist (Eyden 2005). Zusammenfassend ist zu sagen, dass durch den Einsatz der TEM die Erkenntnisse aus den optischen Verfahren untermauert werden konnten. Unterschiede zwischen den einzelnen Zellreihen konnten nicht gefunden werden bzw. sind mit diesem Verfahren nur schwer objektivierbar.

\subsection{Western-Blot}

Unsere mikroskopischen Untersuchungen identifizierten die Zellen aller Organe als MF. Um diese Ergebnisse auch durch eine molekularbiologische Untersuchung zu ergänzen, wurde ein Western-Blot zum qualitiativen Nachweis von a-SMA, Thy-1 und 
Desmin durchführt. Wir konnten die genannten Proteine in allen MF-Kulturen nachweisen. Unterschiede in den Blot-Intensitäten konnten beobachtet werden. Beispielsweise sahen wir bei den Darm-MF im a-SMA-Blot ein deutlicheres Signal als bei den Pankreas-MF. Auffällig war außerdem, dass die Blots von mehrfach aufgetragenen Proben des Ösophagus divergierten. Diese Ergebnissen könnten durch eine nicht ganz reine Zellkultur erklärt werden. Eine Vergleichbarkeit der Expressionsintensität der verschiedenen Marker ist aufgrund der unterschiedlichen Belichtungszeiten und Antikörper-Konzentrationen nicht gegeben. Grundsätzlich hätte eine photodensitometrische Auswertung der Blots zumindest eine quantitative Analyse für die einzelnen Marker möglich gemacht. Da hier jedoch der Eindruck bestand, dass aufgrund von Schwankungen eine größere Probenanzahl notwendig ist, wurde darauf verzichtet.

\section{$4.5 \underline{P C R}$}

Durch die vorangegangen Methoden konnten wir die isolierten Zellen unabhängig voneinander als MF identifizieren. Im Hinblick auf eine quantitative Auswertung sind die mikroskopischen Verfahren, insbesondere bezüglich der Vergleichbarkeit zwischen den verschiedenen Organpopulationen für unsere Marker, der PCR unterlegen. Durch die Anwendung der PCR wurde versucht die Ergebnisse weiter zu objektivieren und die Expression zusätzlicher Gene zu untersuchen und zu vergleichen.

Bei der Darstellung der Genprodukte der einzelnen Zellpopulationen fiel vor allem die ausgeprägte Expression des $\alpha$-SMA auf. Wie erwartet fanden wir ebenfalls eine Thy1- und Desmin-Expression in allen Zellreihen. Quantitativ unterscheidet sich diese jedoch deutlich von der Expression des SMA.

Beim Vergleich der a-SMA-Expression der verschiedenen Zellreihen untereinander, sahen wir deutliche Unterschiede. So fanden wir die stärkste Expression in den Leber-MF und die geringste Expression in den Ösophagus-MF. Manche Forschungsgruppen konnten an MF eine zunehmende $\alpha$-SMA-Expression unter bestimmten Umweltbindungen, beispielsweise unter dem Einfluss von TGF- $\beta$ beobachten (Border and Noble 1994, Muchaneta-Kubara and el Nahas 1997, Tomasek et al. 2002). Die von uns untersuchten Zellen waren nicht stimuliert und 
wurden unter gleichen Bedingungen kultiviert, um auszuschließen, dass Umweltfaktoren unsere Ergebnisse beeinflussen.

Der Vergleich der Thy-1-Expression zeigte ebenfalls eine heterogene Ausprägung in den verschiedenen Organen. Die stärkste Thy-1-Expression zeigten die Darm-MF, während die geringste Expression bei den Ösophagus-MF nachgewiesen werden konnte. Signifikanzen zeigten sich für die Expression des Thy-1 in den Darm-MF gegenüber den Leber- und Ösophagus-MF. Ebenso zeigte sich eine signifikante stärkere Expression der Pankreas- und Magen-MF gegenüber der Zellpopulation des Ösophagus. Während Thy-1 als spezifischer Marker für MF gilt (Dudas et al. 2007), konnte es daneben auf Leukozyten, Neuronen, Endothelien und Stammzellen nachgewiesen werden (Bradley et al. 2009). Die genaue Funktion des Membranproteins ist sehr vielfältig und weiterhin Gegenstand der Forschung (Avalos et al. 2009, Conrad et al. 2009, Goldberg et al. 2007).

Die geringste Genexpression sahen wir jeweils für das Desmin, was unsere Beobachtungen aus der Fluoreszenzmikroskopie und die bekannten Erkenntnisse untermauerte (Powell et al. 1999b). Im Vergleich der Zellreihen untereinander konnten wir die geringste Expression bei Leber- und Ösophagus-MF nachweisen.

Bei der Betrachtung der Strukturproteine bleibt festzuhalten, dass durch die PCR die Ergebnisse reproduziert werden konnten.

Wir fanden in jeder Zellreihe eine ausgeprägte Expression von Kollagen-1, vergleichbar der a-SMA-Expression. Ebenfalls nachweisbar, aber deutlich geringer ausgeprägt, war die Expression von Fibulin-1, Fibulin-2 und Fibrillin-2. Beim Vergleich der Zellreihen fanden wir nur geringe oder keine Unterschiede bei der Expression dieser EZM-Bestandteile. Dass hierbei keine größeren Unterschiede festzustellen waren, unterstreicht die Funktion der MF als Stroma- bzw. Bindegewebszelle in den verschiedenen Organen. Der Produktion von straffen Kollagenfasern scheint hier eine ebenso wichtige Funktion zuzukommen, wie der Produktion von elastischen Fasern. Auffällige Unterschiede zeigten sich interessanterweise bei der Kollagen-4-Expression. Nur bei den Leber-MF gelang hier ein deutlicher Nachweis. Demnach hätten besonders die Leber-MF am Aufbau einer spezifischen Basalmembran in den untersuchten Organen maßgeblichen Anteil.

Besondere pathophysiologische Bedeutung hat die Aktivität der MF bei der Produktion der EZM im Rahmen von chronischen Entzündungen und Fibrosen (Andoh et al. 2007, Neubauer et al. 2001). Bei diesen Vorgängen konnte eine 
Vermehrung bzw. ein vermehrtes Auftreten von MF beobachtet werden. Ob sich hierbei auch Veränderungen im Expressionsmuster der Zellen zeigen, könnte am Entzündungsmodell geklärt werden.

Die Untersuchung der Expression von Chemokinen sollte die exokrine und parakrine Funktion der Zellen charakterisieren. Auffällig zeigte sich hier die Ausprägung der IL6- und MCP-1-Expression im Organvergleich. Für die Leber konnten hier im Vergleich zum Darm signifikant höhere Messwerte erhoben werden. Geringe Unterschiede zeigten sich beim Nachweis in den anderen Organen. Die Ausprägung des MIP-1 war generell sehr gering. Unterschiede sahen wir bei Darm-MF und Leber-MF, jedoch bei großer Streuung der Werte. Die MIP-3-Expression zeigte sich bei den Magen-MF am stärksten. Auffällig gering ausgeprägt war die Expression in den Darm-MF. Bei der Betrachtung der Chemokine muss betont werden, dass die gemessenen Werte grundsätzlich die größte Streuung aufwiesen und hier die Kulturbedingungen sicherlich den stärksten Störfaktor ausmachen. Erhöhte Konzentrationen von IL-6 und MCP-1 sind im Rahmen von akuten Entzündungsprozessen nachweisbar (Deshmane et al. 2009, Donnelly et al. 1993). Wie eingangs bereits erwähnt, zeigten sich vor allem die Darm-Kulturen anfällig für mikrobielle Besiedlungen und mussten wiederholt vernichtet werden. Die gering ausgeprägte Expression der beiden Akute-Phase-Proteine und auch des MIP-3 könnte hiermit im Zusammenhang stehen. Es wäre denkbar, dass die IL-6Konzentrationen in den reinen Kulturen geringer ist Unsere Ergebnisse implizieren, dass die MF aller Organe an der Modulation der Immunantwort beteiligt sind. Diese Vorgänge könnten nach Stimulationsversuchen oder Untersuchung nach Zellschädigung weiter entschlüsselt werden .

\subsection{Zusammenfassung und Ausblick}

Unsere Arbeit hatte zum Ziel, MF aus den untersuchten Organen zu isolieren, zu identifizieren und eine Charakterisierung vorzunehmen. Die Kultivierung dieser Zellen zeigte Unterschiede in Wachstumsverhalten und Umweltresistenz. Durch die Fluoreszenzfärbung sowie die elektronenmikroskopische Untersuchung konnten die postulierten Zellbestandteile und -organellen nachgewiesen werden. Die 
angewandten molekularbiologischen Methoden stützten diese Beobachtungen und lieferten darüber hinaus ein Abbild der möglichen Funktion dieser Zellpopulationen. Wir konnten Korrelate für die Produktion von Bestandteilen der EZM sowie die Modulation der Immunantwort durch unsere Untersuchungen nachweisen. Obwohl wir zum Teil Unterschiede beim Färbeverhalten oder den Genprodukten feststellen konnten, ist die Bewertung dieser Ergebnisse schwierig. Größer angelegte Isolationversuche mit höheren Stückzahlen sind zur weiteren Verifizierung unserer Beobachtungen sicherlich nötig. Auch konnten wir im Rahmen unseres Experiments keine Stimulationeneffekte berücksichtigen. Ein vermehrtes Auftreten bzw. eine gesteigerte Aktivität von MF im Rahmen von chronischen Entzündungsprozessen konnte wiederholt beobachtet werden (Manetti et al. 2007, Omary et al. 2007, Ramadori et al. 2008). Die zugrunde liegenden pathophysiologischen Mechanismen im Sinne von Rekrutierung, Aktivierung und Differenzierungen sind hierbei von besonderem Interesse und werden intensiv beforscht. Die Effekte von Zellstimulation und Zellschädigung auf unsere Kulturen könnten weiteren Aufschluss bringen.

Die MF nehmen zwar unabhängig von ihrer Lokalisation, grundsätzliche ähnliche Aufgaben wahr (Powell et al. 1999a), aber die von uns erhobenen Daten zeigen z.T. deutliche Unterschiede. Im Hinblick auf den unterschiedlichen Organaufbau und die unterschiedlichen Organfunktionen gehen wir deshalb davon aus, dass die verschiedenen MF-Populationen auch organspezifische Aufgaben wahrnehmen.

Nicht zuletzt ist die Rolle der MF als Stromazelle beim Tumorwachstum von Interesse (Adegboyega et al. 2004, Kuroda et al. 2005, Mueller et al. 2007) und rechtfertigt die weitere Erforschung dieser speziellen Zellpopulation. 


\section{Zusammenfassung}

Myofibroblasten (MF) sind Bindegewebszellen mit Eigenschaften von glatten Muskelzellen und Fibroblasten. Charakteristischerweise besitzen sie kontraktile Filamente, welche sich in der Expression von alpha smooth muscle actin (a-SMA) widerspiegeln. Nachdem diese spezielle Zellpopulation zunächst nur in Granulationsgewebe beobachtet werden konnte, gilt ihr ubiquitäres Vorkommen als gesichert. Zudem konnte in der hiesigen Arbeitsgruppe das Oberflächenmolekül Thy-1 als spezifischer MF-Marker in der Leber nachgewiesen werden.

Während der Ursprung und die Vorgänge bei Differenzierung und Aktivierung von MF weiterhin kontrovers diskutiert werden, besteht hinsichtlich der Funktion weitgehend Konsens. MF nehmen Einfluss auf Wachstum und Differenzierung des Epithels sowie auf die Modulation der Immunantwort. Pathologische Bedeutung kommt innen vor allen Dingen bei chronisch entzündlichen Prozessen bzw. Fibrosen zu. Primär myofibroblastische Malignome sind selten, inre Rolle als Tumorstromazelle jedoch ein interessanter Aspekt aktueller wissenschaftlicher Forschung.

Diese Arbeit befasst sich mit den gastrointestinalen MF sowie den MF der Leber von gesunden Ratten. Mit Hilfe verschiedener Isolationsverfahren werden die MF zunächst kultiviert und im weiteren anhand von ultrastrukturellen und molekularbiologischen Markern identifiziert und charakterisiert.

Die lichtmikroskopischen Beobachtungen zeigen nur geringe Unterschiede in der Zellmorphologie. Hingegen zeigt sich bei der Proliferationsaktivität innerhalb der Zellkultur ein deutlicher Unterschied mit rascherem Erreichen einer Konfluenz insbesondere der Ösophagus-MF. Während die fluoreszenzmikroskopische in-vitroDarstellung eine sichere Identifikation der MF erlaubt, gibt die in-vivo-Darstellung Aufschluss über die Lokalisation der MF im gesunden Gewebe. Ergänzend kommen bei der elektronenmikroskopischen Betrachtung neben den kontraktilen Filamenten die Fibronexus als weitere MF-Charakteristika zur Abbildung.

Nachdem somit sichergestellt ist, dass die isolierten Zellen reine oder weitgehend reine MF-Kulturen sind, erfolgt in einem nächsten Schritt der molekularbiologische Nachweis der speziellen MF-Marker mit dem Ziel eines Vergleichs der unterschiedlichen MF. Mittels Western-Blot bestätigen sich die Beobachtungen der vorangegangenen Untersuchungen. Vergleichende Betrachtungen werden anhand 
der Genexpression durchgeführt. Hierzu werden die Marker in Strukturproteine ( $\alpha$ SMA, Thy-1, Desmin), Matrixproteine (Kollagen-1, Kollagen-4, Fibulin-1, Fibulin-2, Fibrillin-2) sowie Entzündungsmediatoren (IL-6, MCP-1, MIP-1, MIP-3) unterteilt. Es zeigen sich z. T. deutliche Unterschiede im Organvergleich. So wird die stärkste $\alpha$ SMA-Expression in den Leber-MF gemessen, während die Darm-MF die stärkste Thy-1-Expression aufweisen. Bei der Expression der Matrixproteine dominiert die Kollagen-1-Expression, die sich nicht signifikant unterschied. Die Kollagen-4Expression der Leber-MF ist im Vergleich zu den anderen MF deutlich erhöht. Geringfügigere Unterschiede sind auch für die Expression der übrigen Matrixproteine nachzuweisen. Die Entzündungsmediatoren zeigen große Unterschiede in der Expressionsintensität, mit einer signifikant erhöhten IL-6- sowie MCP-1-Expression in Leber-MF.

Neben den zahlreichen Gemeinsamkeiten hinsichtlich Morphologie, Färbeverhalten und Ultrastruktur legen die von uns gefundenen Unterschiede in der Genexpressionsanalyse eine dem Organ angepasste bzw. organspezifische Funktion der unterschiedlichen MF nahe. Um diese Unterschiede weiter herauszuarbeiten und $\mathrm{zu}$ analysieren, sollten weitere Versuche z.B. im Entzündungsmodell folgen. 


\section{Literaturverzeichnis}

Adegboyega PA, Ololade O, Saada J, Mifflin R, Di Mari JF, Powell DW (2004): Subepithelial myofibroblasts express cyclooxygenase-2 in colorectal tubular adenomas. Clin Cancer Res 10, 5870-9.

Ahmed A (1990): The myofibroblast in breast disease. Pathol Annu 2드, 237-86.

Aigner T, Neureiter D, Muller S, Kuspert G, Belke J, Kirchner T (1997): Extracellular matrix composition and gene expression in collagenous colitis. Gastroenterology $113,136-43$.

Andoh A, Bamba S, Brittan M, Fujiyama Y, Wright NA (2007): Role of intestinal subepithelial myofibroblasts in inflammation and regenerative response in the gut. Pharmacol Ther 114, 94-106.

Anjos-Afonso F, Siapati EK, Bonnet D (2004): In vivo contribution of murine mesenchymal stem cells into multiple cell-types under minimal damage conditions. J Cell Sci 117, 5655-64.

Avalos AM, Valdivia AD, Munoz N, Herrera-Molina R, Tapia JC, Lavandero S et al. (2009): Neuronal Thy- 1 induces astrocyte adhesion by engaging syndecan-4 in a cooperative interaction with alphavbeta3 integrin that activates PKCalpha and RhoA. J Cell Sci 122, 3462-71.

Baba M, Imai T, Nishimura M, Kakizaki M, Takagi S, Hieshima K, Nomiyama H, Yoshie O (1997): Identification of CCR6, the specific receptor for a novel lymphocytedirected CC chemokine LARC. J Biol Chem 272, 14893-8.

Bachem MG, Schneider E, Gross H, Weidenbach H, Schmid RM, Menke A et al. (1998): Identification, culture, and characterization of pancreatic stellate cells in rats and humans. Gastroenterology 115, 421-32.

Beaussier M, Wendum D, Schiffer E, Dumont S, Rey C, Lienhart A, Housset C (2007): Prominent contribution of portal mesenchymal cells to liver fibrosis in ischemic and obstructive cholestatic injuries. Lab Invest 87, 292-303. 
Beon M, Harley RA, Wessels A, Silver RM, Ludwicka-Bradley A (2004): Myofibroblast induction and microvascular alteration in scleroderma lung fibrosis. Clin Exp Rheumatol $\underline{22}$, 733-42.

Berschneider HM, Powell DW (1992): Fibroblasts modulate intestinal secretory responses to inflammatory mediators. J Clin Invest $\underline{89}$, 484-9.

Bhowmick NA, Neilson EG, Moses HL (2004): Stromal fibroblasts in cancer initiation and progression. Nature $\underline{432}, 332-7$.

Border WA, Noble NA (1994): Transforming growth factor beta in tissue fibrosis. N Engl J Med 331, 1286-92.

Bostrom H, Willetts K, Pekny M, Leveen P, Lindahl P, Hedstrand $\mathrm{H}$ et al. (1996): PDGF-A signaling is a critical event in lung alveolar myofibroblast development and alveogenesis. Cell $\underline{85}, 863-73$.

Bradley JE, Ramirez G, Hagood JS (2009): Roles and regulation of Thy-1, a contextdependent modulator of cell phenotype. Biofactors $\underline{35}$, 258-65.

Brittan M, Wright NA (2004): Stem cell in gastrointestinal structure and neoplastic development. Gut $\underline{53}, 899-910$.

Cassiman D, Libbrecht L, Desmet V, Denef C, Roskams T (2002): Hepatic stellate cell/myofibroblast subpopulations in fibrotic human and rat livers. J Hepatol $\underline{36}, 200-$ 9.

Chai J, Norng M, Tarnawski AS, Chow J (2007): A critical role of serum response factor in myofibroblast differentiation during experimental oesophageal ulcer healing in rats. Gut $\underline{56}, 621-30$.

Conrad DM, Furlong SJ, Doucette CD, Boudreau RT, Hoskin DW (2009): Role of mitogen-activated protein kinases in Thy-1-induced T-lymphocyte activation. Cell Signal 21, 1298-307.

Crowston JG, Salmon M, Khaw PT, Akbar AN (1997): T-lymphocyte-fibroblast interactions. Biochem Soc Trans $\underline{25}$, 529-31. 
Deshmane SL, Kremlev S, Amini S, Sawaya BE (2009): Monocyte chemoattractant protein-1 (MCP-1): an overview. J Interferon Cytokine Res $\underline{29}$, 313-26.

Desmoulière A, Geinoz A, Gabbiani F, Gabbiani G (1993): Transforming growth factor-beta 1 induces alpha-smooth muscle actin expression in granulation tissue myofibroblasts and in quiescent and growing cultured fibroblasts. J Cell Biol $\underline{122}$, 103-11.

Desmoulière A, Tuchweber B, Gabbiani G (1995): Role of the myofibroblast differentiation during liver fibrosis. J Hepatol $\underline{22}, 61-4$.

Desmoulière A, Chaponnier C, Gabbiani G (2004): Tissue repair, contraction, and the myofibroblast. Wound repair and regeneration $\underline{13}, 7-12$.

Desmoulière A, Guyot C, Gabbiani G (2004): The stroma reaction myofibroblast: a key player in the control of tumor cell behavior. Int J Dev Biol $\underline{48}, 509-17$.

Direkze NC, Forbes SJ, Brittan M, Hunt T, Jeffery R, Preston SL et al. (2003):

Multiple organ engraftment by bone-marrow-derived myofibroblasts and fibroblasts in bone-marrow-transplanted mice. Stem Cells 21, 514-20.

Direkze NC, Hodivala-Dilke K, Jeffery R, Hunt T, Poulsom R, Oukrif D, Alison MR, Wright NA (2004): Bone marrow contribution to tumor-associated myofibroblasts and fibroblasts. Cancer Res $\underline{64}, 8492-5$.

Donnelly RP, Crofford LJ, Freeman SL, Buras J, Remmers E, Wilder RL, Fenton MJ (1993): Tissue-specific regulation of IL-6 production by IL-4. Differential effects of IL4 on nuclear factor-kappa B activity in monocytes and fibroblasts. J Immunol $\underline{151}$, 5603-12.

Dubois RN (2001): Nonsteroidal antiinflammatory drugs, cyclooxygenase-2, and colorectal cancer prevention. Curr Opin Gastroenterol 17, 65-71.

Dudas J, Mansuroglu T, Batusic D, Saile B, Ramadori G (2007): Thy-1 is an in vivo and vitro marker of liver myofibroblast. Cell Tissue Res $\underline{329}, 503-14$. 
Dudas J, Mansuroglu T, Batusic D, Ramadori G (2009): Thy-1 is expressed in myofibroblasts but not found in hepatic stellate cells following liver injury. Histochem Cell Biol $\underline{131}$, 115-27.

Elenbaas B, Weinberg RA (2001): Heterotypic signaling between epithelial tumor cells and fibroblasts in carcinoma formation. Exp Cell Res $\underline{264}, 169-84$.

Eyden B (2005): The myofibroblast: a study of normal, reactive and neoplastic tissues, with an emphasis on ultrastructure. part 2 - tumours and tumour-like lesions. J Submicrosc Cytol Pathol $\underline{37}$, 231-96.

Fiocchi C (1997): Intestinal inflammation: a complex interplay of immune and nonimmune cell interactions. Am J Physiol 273, 769-75.

Forstermann U, Boissel JP, Kleinert H (1998): Expressional control of the 'constitutive' isoforms of nitric oxide synthase (NOS I and NOS III). FASEB J $\underline{12}, 773$ 90 .

Fritsch C, Simon-Assmann P, Kedinger M, Evans GS (1997): Cytokines modulate fibroblast phenotype and epithelial-stroma interactions in rat intestine.

Gastroenterology 112, 826-38.

Furuya S, Furuya K (2007): Subepithelial fibroblasts in intestinal villi: roles in intercellular communication. Int Rev Cytol 264, 165-223.

Gabbiani G (1996): The cellular derivation and the life span of the myofibroblast. Pathol Res Pract 192, 708-11.

Gabbiani G, Ryan GB, Majne G (1971): Presence of modified fibroblasts in granulation tissue and their possible role in wound contraction. Experientia 27, 54950 .

Giardiello FM, Hamilton SR, Krush AJ, Piantadosi S, Hylind LM, Celano P, Booker SV, Robinson CR, Offerhaus GJ (1993): Treatment of colonic and rectal adenomas with sulindac in familial adenomatous polyposis. N Engl J Med $\underline{328}, 1313-6$. 
Giovannucci E, Egan KM, Hunter DJ, Stampfer MJ, Colditz GA, Willett WC, Speizer FE (1995): Aspirin and the risk of colorectal cancer in women. N Engl J Med $\underline{333}$, 609-14.

Gockel I, Bohl JR, Eckardt VF, Junginger T (2008): Reduction of interstitial cells of Cajal (ICC) associated with neuronal nitric oxide synthase (n-NOS) in patients with achalasia. Am J Gastroenterol $\underline{103}$, 856-64.

Goldberg ED, Dygai AM, Zyuz'kov GN (2007): Role of Thy-1,2+ cells in the regulation of hemopoiesis during severe hypoxia. Bull Exp Biol Med 143, 18-21

Haffen K, Kedinger M, Simon-Assmann P (1987): Mesenchyme-dependent differentiation of epithelial progenitor cells in the gut. J Pediatr Gastroenterol Nutr $\underline{6}$, 14-23.

Hall PA, Coates PJ, Ansari B, Hopwood D (1994): Regulation of cell number in the mammalian gastrointestinal tract: the importance of apoptosis. J Cell Sci 107, 356977.

Halttunen T, Marttinen A, Rantala I, Kainulainen H, Maki M (1996): Fibroblasts and transforming growth factor beta induce organization and differentiation of T84 human epithelial cells. Gastroenterology 111, 1252-62.

Hao H, Gabbiani G, Camenzind E, Bacchetta M, Virmani R, Bochaton-Piallat ML (2006): Phenotypic modulation of intima and media smooth muscle cells in fatal cases of coronary artery lesion. Arterioscler Thromb Vasc Biol 26, 326-32.

Hautmann MB, Madsen CS, Owens GK (1997): A transforming growth factor beta (TGFbeta) control element drives TGFbeta-induced stimulation of smooth muscle alpha-actin gene expression in concert with two CArG elements. J Biol Chem $\underline{272}$, 10948-56.

Hinterleitner TA, Saada JI, Berschneider HM, Powell DW, Valentich JD (1996): IL-1 stimulates intestinal myofibroblast COX gene expression and augments activation of $\mathrm{Cl}$ - secretion in T84 cells. Am J Physiol 271, 1262-8. 
Hinz B, Phan SH, Thannickal VJ, Galli A, Bochaton-Piallat ML, Gabbiani G (2007): The myofibroblast: one function, multiple origins. Am J Pathol 170, 1807-16.

Hirota S, Isozaki K, Moriyama Y, Hashimoto K, Nishida T, Ishiguro S et al. (1998): Gain-of-function mutations of c-kit in human gastrointestinal stromal tumors. Science $\underline{279}, 577-80$.

Inatomi O, Andoh A, Yagi Y, Ogawa A, Hata K, Shiomi H et al. (2007): Matrix metalloproteinase-3 secretion from human pancreatic periacinar myofibroblasts in response to inflammatory mediators. Pancreas $\underline{34}, 126-32$.

Isozaki K, Hirota S, Nakama A, Miyagawa J, Shinomura Y, Xu Z, Nomura S, Kitamura $Y$ (1995): Disturbed intestinal movement, bile reflux to the stomach, and deficiency of c-kit-expressing cells in Ws/Ws mutant rats. Gastroenterology $\underline{109}$, 456-64.

Izumi M, Suda K, Torii A, Inadama E (2001): Pancreatic ductal myofibroblasts. Proliferative patterns in various pathologic situations. Virchows Arch $\underline{438}, 442-50$.

Johnson SJ, Hines JE, Burt AD (1992): Phenotypic modulation of perisinusoidal cells following acute liver injury: a quantitative analysis. Int $\mathrm{J}$ Exp Pathol $\underline{73}, 765-72$.

Joyce NC, Haire MF, Palade GE (1987): Morphologic and biochemical evidence for a contractile cell network within the rat intestinal mucosa. Gastroenterology $\underline{92}, 68-81$.

Junqueira L, Kaneiro J, Kelley R: Histologie. Springer-Verlag, Berlin 2001.

Kassen A, Sutkowski DM, Ahn H, Sensibar JA, Kozlowski JM, Lee C (1996): Stromal cells of the human prostate: initial isolation and characterization. Prostate $\underline{28}, 89-97$.

Kedinger M, Simon-Assmann P, Bouziges F, Haffen K (1988): Epithelialmesenchymal interactions in intestinal epithelial differentiation. Scand $J$ Gastroenterol Suppl 151, 62-9.

Kim KK, Kugler MC, Wolters PJ, Robillard L, Galvez MG, Brumwell AN, Sheppard D, Chapman HA (2006): Alveolar epithelial cell mesenchymal transition develops in vivo during pulmonary fibrosis and is regulated by the extracellular matrix. Proc Natl Acad Sci U S A $\underline{103}, 13180-5$. 
Knittel T, Kobold D, Piscaglia F, Saile B, Neubauer K, Mehde M, Timpl R, Ramadori G (1999): Localization of liver myofibroblasts and hepatic stellate cells in normal and diseased rat livers: distinct roles of (myo-)fibroblast subpopulations in hepatic tissue repair. Histochem Cell Biol 112, 387-401.

Knittel T, Mehde M, Grundmann A, Saile B, Scharf JG, Ramadori G (2000):

Expression of matrix metalloproteinases and their inhibitors during hepatic tissue repair in the rat. Histochem Cell Biol 113, 443-53.

Kohnen G, Kertschanska S, Demir R, Kaufmann P (1996): Placental villous stroma as a model system for myofibroblast differentiation. Histochem Cell Biol 105, 415-29.

Komuro T (1989): Three-dimensional observation of the fibroblast-like cells associated with the rat myenteric plexus, with special reference to the interstitial cells of Cajal. Cell Tissue Res 255, 343-51.

Komuro T, Hashimoto Y (1990): Three-dimensional structure of the rat intestinal wall (mucosa and submucosa). Arch Histol Cytol $\underline{53}, 1-21$.

Kuroda N, Toi M, Nakayama H, Miyazaki E, Yamamoto M, Hayashi Y, Hiroi M, Enzan $H$ (2004): The distribution and role of myofibroblasts and CD34-positive stromal cells in normal pancreas and various pancreatic lesions. Histol Histopathol $\underline{19}, 59-67$.

Kuroda N, Nakayama H, Miyazaki E, Toi M, Hiroi M, Enzan H (2005): The distribution of CD34-positive stromal cells and myofibroblasts in colorectal carcinoid tumors. Histol Histopathol 20, 27-33.

Mahida YR, Beltinger J, Makh S, Goke M, Gray T, Podolsky DK, Hawkey CJ (1997a): Adult human colonic subepithelial myofibroblasts express extracellular matrix proteins and cyclooxygenase-1 and -2. Am J Physiol 273, 1341-8.

Mahida YR, Galvin AM, Gray T, Makh S, McAlindon ME, Sewell HF, Podolsky DK (1997b): Migration of human intestinal lamina propria lymphocytes, macrophages and eosinophils following the loss of surface epithelial cells. Clin Exp Immunol 109, 377-86. 
Manetti M, Neumann E, Milia AF, Tarner IH, Bechi P, Matucci-Cerinic M, IbbaManneschi L, Muller-Ladner U (2007): Severe fibrosis and increased expression of fibrogenic cytokines in the gastric wall of systemic sclerosis patients. Arthritis Rheum 56, 3442-7.

McKaig BC, Hughes K, Tighe PJ, Mahida YR (2002): Differential expression of TGFbeta isoforms by normal and inflammatory bowel disease intestinal myofibroblasts. Am J Physiol Cell Physiol 282, C172-82.

Mecham RP: The Extracellular Matrix An Overview. Springer-Verlag, Berlin 2010.

Menten P, Wuyts A, Van Damme J (2002): Macrophage inflammatory protein-1. Cytokine Growth Factor Rev $\underline{13}$, 455-81.

Mermall V, Post PL, Mooseker MS (1998): Unconventional myosins in cell movement, membrane traffic, and signal transduction. Science 279, 527-33.

Mews P, Phillips P, Fahmy R, Korsten M, Pirola R, Wilson J, Apte M (2002): Pancreatic stellate cells respond to inflammatory cytokines: potential role in chronic pancreatitis. Gut $\underline{50}, 535-41$.

Minin AA, Moldaver MV (2008): Intermediate vimentin filaments and their role in intracellular organelle distribution. Biochemistry (Mosc) $\underline{73}, 1453-66$.

Moore R, Carlson S, Madara JL (1989): Villus contraction aids repair of intestinal epithelium after injury. Am J Physiol 257, 274-83.

Muchaneta-Kubara EC, el Nahas AM (1997): Myofibroblast phenotypes expression in experimental renal scarring. Nephrol Dial Transplant $\underline{12}$, 904-15.

Mueller L, Goumas FA, Affeldt M, Sandtner S, Gehling UM, Brilloff S et al. (2007): Stromal fibroblasts in colorectal liver metastases originate from resident fibroblasts and generate an inflammatory microenvironment. Am J Pathol 171, 1608-18.

Nakamura M, Oda M, Inoue J, Ito T, Akiba Y, Kitajima M, Tsuchiya M, Ishii H (1995): Plasticity of myofibroblasts appearing in granulation tissues after acetic acid treatment. Effect of bFGF. Dig Dis Sci $\underline{40}, 2477-80$. 
Nakayama H, Enzan H, Miyazaki E, Toi M (2002): Alpha smooth muscle actin positive stromal cells in gastric carcinoma. J Clin Pathol $\underline{55}, 741-4$.

Neubauer K, Saile B, Ramadori G (2001): Liver fibrosis and altered matrix synthesis. Can J Gastroenterol 15, 187-93.

Nishida A, Andoh A, Shioya M, Kim-Mitsuyama S, Takayanagi A, Fujiyama Y (2008): Phosphatidylinositol 3-kinase/Akt signaling mediates interleukin-32alpha induction in human pancreatic periacinar myofibroblasts. Am J Physiol Gastrointest Liver Physiol 294, 831-8.

Novosyadlyy R, Tron K, Dudas J, Ramadori G, Scharf JG (2004): Expression and regulation of the insulin-like growth factor axis components in rat liver myofibroblasts. J Cell Physiol 199, 388-98.

Ogawa T, Tateno C, Asahina K, Fujii H, Kawada N, Obara M, Yoshizato K (2007): Identification of vitamin A-free cells in a stellate cell-enriched fraction of normal rat liver as myofibroblasts. Histochem Cell Biol 127, 161-74.

Omary MB, Lugea A, Lowe AW, Pandol SJ (2007): The pancreatic stellate cell: a star on the rise in pancreatic diseases. $\mathrm{J}$ Clin Invest 117, 50-9.

Ota S, Bamba H, Kato A, Kawamoto C, Yoshida Y, Fujiwara K (2002): Review article: COX-2, prostanoids and colon cancer. Aliment Pharmacol Ther 16, 102-6.

Pan TC, Kostka G, Zhang RZ, Timpl R, Chu ML (1999): Complete exon-intron organization of the mouse fibulin-1 gene and its comparison with the human fibulin-1 gene. FEBS Lett $\underline{444}$, 38-42.

Pang G, Couch L, Batey R, Clancy R, Cripps A (1994): GM-CSF, IL-1 alpha, IL-1 beta, IL-6, IL-8, IL-10, ICAM-1 and VCAM-1 gene expression and cytokine production in human duodenal fibroblasts stimulated with lipopolysaccharide, IL-1 alpha and TNF-alpha. Clin Exp Immunol 96, 437-43.

Paramio JM: Intermediate Filaments. Springer-Verlag, Berlin 2006

Peehl DM, Sellers RG (1997): Induction of smooth muscle cell phenotype in cultured human prostatic stromal cells. Exp Cell Res 232, 208-15. 
Pinchuk IV, Saada JI, Beswick EJ, Boya G, Qiu SM, Mifflin RC, Raju GS, Reyes VE, Powell DW (2008): PD-1 ligand expression by human colonic myofibroblasts/fibroblasts regulates CD4+ T-cell activity. Gastroenterology $\underline{135}$, 1228-37

Piotrowska AP, Solari V, Puri P (2003): Distribution of interstitial cells of Cajal in the internal anal sphincter of patients with internal anal sphincter achalasia and Hirschsprung disease. Arch Pathol Lab Med 127, 1192-5.

Piscaglia F, Dudas J, Knittel T, Di Rocco P, Kobold D, Saile B, Zocco MA, Timpl R, Ramadori $G$ (2009): Expression of ECM proteins fibulin-1 and -2 in acute and chronic liver disease and in cultured rat liver cells. Cell Tissue Res $\underline{337}$, 449-62.

Plateroti M, Rubin DC, Duluc I, Singh R, Foltzer-Jourdainne C, Freund JN, Kedinger M (1998): Subepithelial fibroblast cell lines from different levels of gut axis display regional characteristics. Am J Physiol 274, 945-54.

Powell DW, Mifflin RC, Valentich JD, Crowe SE, Saada JI, West AB (1999a):

Myofibroblasts. I. Paracrine cells important in health and disease. Am J Physiol $\underline{277}$, $1-9$.

Powell DW, Mifflin RC, Valentich JD, Crowe SE, Saada JI, West AB (1999b):

Myofibroblasts. II. Intestinal subepithelial myofibroblasts. Am J Physiol ㅍ7, 183-201.

Powell DW, Adegboyega PA, Di Mari JF, Mifflin RC (2005): Epithelial cells and their neighbors I. Role of intestinal myofibroblasts in development, repair, and cancer. Am J Physiol Gastrointest Liver Physiol 289, 2-7.

Qiu X, Montgomery E, Sun B (2008): Inflammatory myofibroblastic tumor and lowgrade myofibroblastic sarcoma: a comparative study of clinicopathologic features and further observations on the immunohistochemical profile of myofibroblasts. Hum Pathol $\underline{39}$, 846-56.

Racine-Samson L, Rockey DC, Bissell DM (1997): The role of alpha1beta1 integrin in wound contraction. A quantitative analysis of liver myofibroblasts in vivo and in primary culture. J Biol Chem $\underline{272}, 30911-7$. 
Ramadori G, Moriconi F, Malik I, Dudas J (2008): Physiology and pathophysiology of liver inflammation, damage and repair. J Physiol Pharmacol $\underline{59}$, 107-17.

Ramadori G, Saile B (2002): Mesenchymal cells in the liver--one cell type or two? Liver 22, 283-94.

Regan MC, Flavin BM, Fitzpatrick JM, O'Connell PR (2000): Stricture formation in Crohn's disease: the role of intestinal fibroblasts. Ann Surg 231, 46-50.

Roberts Al, Nadler SC, Ebert EC (1997): Mesenchymal cells stimulate human intestinal intraepithelial lymphocytes. Gastroenterology $\underline{113}, 144-50$.

Saada JI, Barrera CA, Reyes VE, Adegboyega PA, Suarez G, Tamerisa RA et al. (2004): Intestinal myofibroblasts and immune tolerance. Ann N Y Acad Sci $\underline{1029}$, 379-81.

Saada JI, Pinchuk IV, Barrera CA, Adegboyega PA, Suarez G, Mifflin RC, Di Mari JF, Reyes VE, Powell DW (2006): Subepithelial myofibroblasts are novel nonprofessional APCs in the human colonic mucosa. J Immunol 177, 5968-79.

Saiki, R., Scharf, S., Faloona, F., Mullis, K., Horn, G., and Erlich, H (1985):

Enzymatic amplification of beta-globin genomic sequences and restriction site analysis for diagnosis of sickle cell anemia. Science $\underline{230}, 1350-54$

Saile B, Matthes N, Neubauer K, Eisenbach C, El-Armouche H, Dudas J, Ramadori $G$ (2002): Rat liver myofibroblasts and hepatic stellate cells differ in CD95-mediated apoptosis and response to TNF-alpha. Am J Physiol Gastrointest Liver Physiol $\underline{283}$, 435-44.

Sanders KM (1996): A case for interstitial cells of Cajal as pacemakers and mediators of neurotransmission in the gastrointestinal tract. Gastroenterology 111 , 492-515.

Saotome T, Inoue H, Fujimiya M, Fujiyama Y, Bamba T (1997): Morphological and immunocytochemical identification of periacinar fibroblast-like cells derived from human pancreatic acini. Pancreas $\underline{14}$, 373-82. 
Sasaki T, Mann K, Murphy G, Chu ML, Timpl R (1996): Different susceptibilities of fibulin-1 and fibulin-2 to cleavage by matrix metalloproteinases and other tissue proteases. Eur J Biochem 240, 427-34.

Schmitt-Graff A, Desmoulière A, Gabbiani G (1994): Heterogeneity of myofibroblast phenotypic features: an example of fibroblastic cell plasticity. Virchows Arch $\underline{425}$, 324.

Simo P, Bouziges F, Lissitzky JC, Sorokin L, Kedinger M, Simon-Assmann P (1992): Dual and asynchronous deposition of laminin chains at the epithelial-mesenchymal interface in the gut. Gastroenterology $\underline{102}, 1835-45$.

Simon-Assmann P, Kedinger M, De Arcangelis A, Rousseau V, Simo P (1995):

Extracellular matrix components in intestinal development. Experientia 51, 883-900.

Smith MA, Court EL, Smith JG (2001): Stem cell factor: laboratory and clinical aspects. Blood Rev 15, 191-7.

Sprenger H, Kaufmann A, Garn H, Lahme B, Gemsa D, Gressner AM (1997):

Induction of neutrophil-attracting chemokines in transforming rat hepatic stellate cells. Gastroenterology $\underline{113}$, 277-85.

Stallmach A, Hahn U, Merker HJ, Hahn EG, Riecken EO (1989): Differentiation of rat intestinal epithelial cells is induced by organotypic mesenchymal cells in vitro. Gut 30, 959-70.

Streutker CJ, Huizinga JD, Driman DK, Riddell RH (2007): Interstitial cells of Cajal in health and disease. Part I: normal ICC structure and function with associated motility disorders. Histopathology $\underline{50}, 176-89$.

Tang DD (2008): Intermediate filaments in smooth muscle. Am J Physiol Cell Physiol 294, 869-78.

Tang WW, Ulich TR, Lacey DL, Hill DC, Qi M, Kaufman SA, Van GY, Tarpley JE, Yee JS. (1996): Platelet-derived growth factor-BB induces renal tubulointerstitial myofibroblast formation and tubulointerstitial fibrosis. Am J Pathol 148, 1169-80. 
Tomasek JJ, Gabbiani G, Hinz B, Chaponnier C, Brown RA (2002): Myofibroblasts and mechano-regulation of connective tissue remodelling. Nat Rev Mol Cell Biol $\underline{3}$, 349-63.

Torihashi S, Gerthoffer WT, Kobayashi S, Sanders KM (1994): Identification and classification of interstitial cells in the canine proximal colon by ultrastructure and immunocytochemistry. Histochemistry 101, 169-83.

Toyoda H, Ina K, Kitamura H, Tsuda T, Shimada T (1997): Organization of the lamina propria mucosae of rat intestinal mucosa, with special reference to the subepithelial connective tissue. Acta Anat (Basel) $\underline{158}, 172-84$.

Valentich JD, Popov V, Saada JI, Powell DW (1997): Phenotypic characterization of an intestinal subepithelial myofibroblast cell line. Am J Physiol $\underline{272}, 1513-24$.

Vanderwinden JM, Liu H, De Laet MH, Vanderhaeghen JJ (1996): Study of the interstitial cells of Cajal in infantile hypertrophic pyloric stenosis. Gastroenterology 111, 279-88.

Watari N, Hotta Y, Mabuchi Y (1982): Morphological studies on a vitamin A-storing cell and its complex with macrophage observed in mouse pancreatic tissues following excess vitamin A administration. Okajimas Folia Anat Jpn $\underline{58}$, 837-58.

Weber KT, Sun Y, Katwa LC (1997): Myofibroblasts and local angiotensin II in rat cardiac tissue repair. Int J Biochem Cell Biol $\underline{29}$, 31-42.

Wester T, Eriksson L, Olsson Y, Olsen L (1999): Interstitial cells of Cajal in the human fetal small bowel as shown by c-kit immunohistochemistry. Gut $44,65-71$.

Won JH, Zhang Y, Ji B, Logsdon CD, Yule DI (2011): Phenotypic changes in mouse pancreatic stellate cell $\mathrm{Ca} 2+$ signaling events following activation in culture and in a disease model of pancreatitis. Mol Biol Cell 22, 421-36.

Wu KC, Jackson LM, Galvin AM, Gray T, Hawkey CJ, Mahida YR (1999): Phenotypic and functional characterisation of myofibroblasts, macrophages, and lymphocytes migrating out of the human gastric lamina propria following the loss of epithelial cells. Gut $\underline{44}, 323-30$. 
Youngman KR, Simon PL, West GA, Cominelli F, Rachmilewitz D, Klein JS, Fiocchi C (1993): Localization of intestinal interleukin 1 activity and protein and gene expression to lamina propria cells. Gastroenterology 104, 749-58.

Zeisberg M, Kalluri R (2004): The role of epithelial-to-mesenchymal transition in renal fibrosis. J Mol Med $\underline{82}, 175-81$.

Zeroogian JM, Chopra S (1994): Collagenous colitis and lymphocytic colitis. Annu Rev Med $\underline{45}$, 105-18.

Zhang H, Apfelroth SD, Hu W, Davis EC, Sanguineti C, Bonadio J, Mecham RP, Ramirez F (1994): Structure and expression of fibrillin-2, a novel microfibrillar component preferentially located in elastic matrices. J Cell Biol $\underline{124}, 855-63$.

Zhang K, Rekhter MD, Gordon D, Phan SH (1994): Myofibroblasts and their role in lung collagen gene expression during pulmonary fibrosis. A combined immunohistochemical and in situ hybridization study. Am J Pathol 145, 114-25. 


\section{Danksagung}

Ich möchte mich bei allen bedanken, die mich beim Abfassen meiner Dissertation unterstützt haben.

Allen voran bedanke ich mich bei Herrn Prof. Dr. med. Jörg Wilting, von der Abteilung Anatomie und Zellbiologie der Medizinischen Fakultät der Universität Göttingen für die freundliche Übernahme der Funktion des Doktorvaters und die kompetente Führung und Unterstützung. Daneben bedanke ich mich besonders bei Frau Dr. med. Silke Cameron, M.A., von der Abteilung für Gastroenterologie und Endokrinologie im Zentrum Innere Medizin der Medizinischen Fakultät der Universität Göttingen für ihre Betreuung bzw. das unermüdliche Engagement, die intensive Zusammenarbeit und die hilfreichen Gespräche, mit denen sie mich in jeder Phase der Arbeit begleitet hat.

Des weiteren möchte ich mich bei Herrn Dr. József Dudás, Ph. D. von der Abteilung für Hals-Nasen- und Ohrenkrankheiten der Medizinischen Universität Innsbruck bedanken für die geduldige Anleitung der Methodik und das Einbringen seiner großen Fachkompetenz bei der Auswertung der Ergebnisse.

Mein Dank gilt darüber hinaus Herrn Prof. Dr. med. Nicolai Miosge, Leiter der AG orale Biologie und Gewebsregeneration der Abteilung Prothetik der Medizinischen Fakultät der Universität Göttingen für die großzügige Unterstützung und kompetente Beratung bei der Umsetzung der elektronenmikroskopischen Darstellung der Myofibroblasten.

Ich bedanke mich außerdem bei allen Mitarbeiterinnen und Mitarbeitern in den Laboren für die außerordentlich gute Zusammenarbeit. 